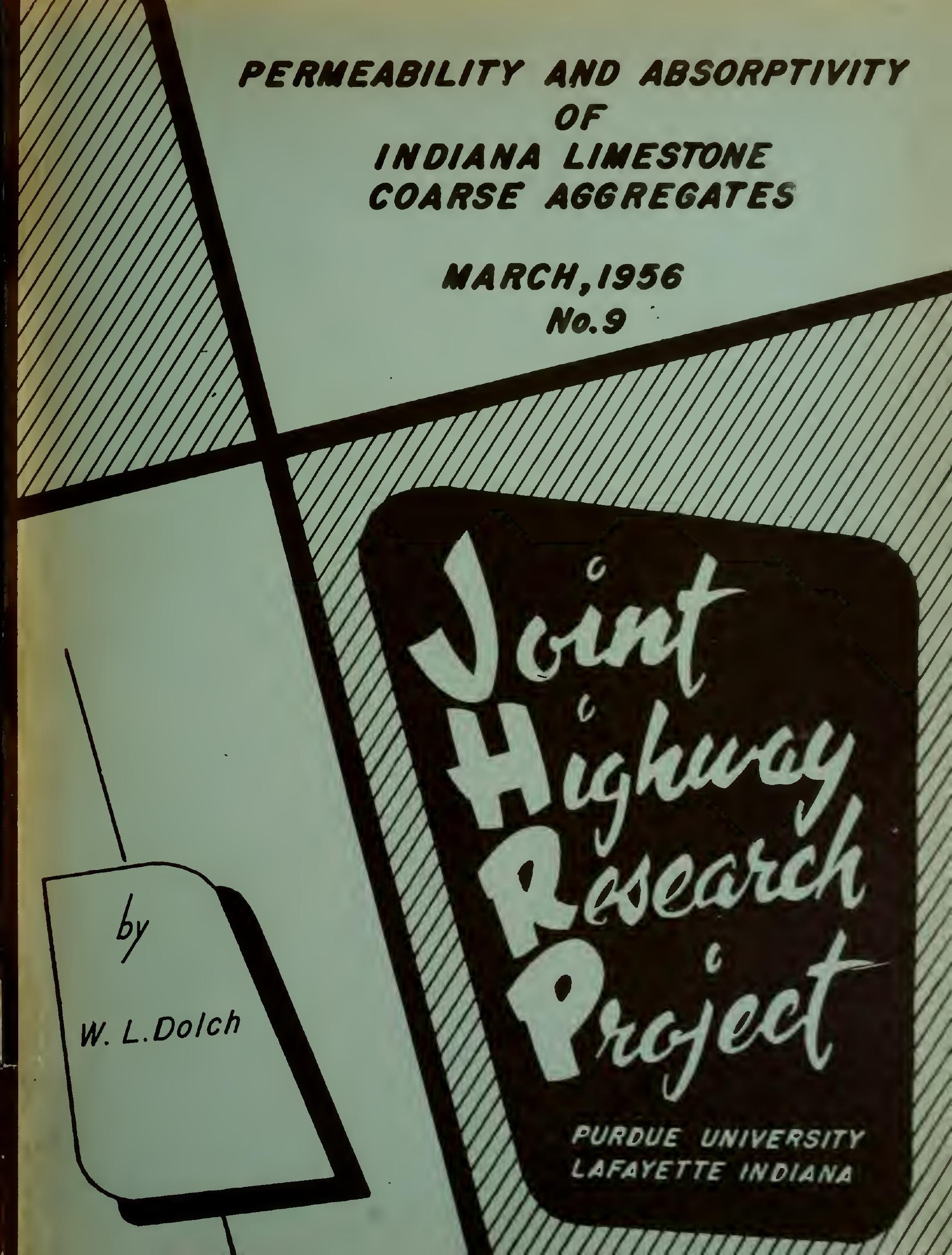





\section{PERMEABILITY AND ABSORPTIVITY}

OF

INDIANA LINESTONE COARSE AGGEEGATES

TO: K. B. Woods, Director

Jolnt HIghway Research Projoct

FRol: Harcld L. Michael, Asslgtant Director
Larch 13, 1956

Fule: $5-7-7$

C-36- $47 F$

Attached is a copy of a report, "Pormeablilty and Absorptivity of Indiana Limestone Coarse Aggregates," by W. L. Dolch of our staff. The report cover's work done in the chemlstry laboratory of the jolnt HLghway Research Project on tho pore structure of certain coarse aggregates and its relation to thelr durability historles in concrete.

Respectrulis subalttod,

$$
\text { HL Michael /wCD }
$$

Harold L. Ulchael, Assistant Director Jolnt, HIghway Research Project

HEM/NLD:Cjg

Attachment

ce: J. R, Cooper

J. T. Hallett

F. F. Havey

G. A. Hawkins

G. A. Leonards

B. B. Lenls
R. E. KU113

B. H. Petty

Lloyd Poindexter

C. E. Vogelgerang

J. L. Wallng 
Digitized by the Internet Archive in 2011 with funding from

LYRASIS members and Sloan Foundation; Indiana Department of Transportation 


\section{PEPAEABRITY AND ABSORPTIVITY \\ OF \\ INDIANA LIMESTONE COARSE AGGREGATES}

by

W. L. Dolch, Research Ass1stant

Jolnt HIghway Research Project

Fule: $5-\hat{i}-7$

$C-36-47 F$

Purdue Univers1ty

Lafayette, Indiana

March 13, 1956 


\section{A CKNOW LEDGMENTS}

The friendly advice and counsel of Prof. K.E. Woods, Head of the School of Civil Engineering, Purdue University, are acknorledged with many thanks. The encouragement and academic sponsorship of Dr. M.G. Mellon, Professor of Chemistry, Purdue Universtty, have been greatly appreciated.

Dr. G.A. Leonards, Professor of Soil Mechanics, Purdue University, has been generously helpful in every way. His techniczl advice and assistance and his review of the manuscript are gratefully acknowledged.

Wr. L.S. Gifford, Jr. finished most of the sample prisms and built the air bath and bir. B. Bradley traced the data curves.

This work was $f$ inanced by the state Hignway Comission of Indiana through the Advisory Board of the Joint Highway Research Project. This support is gratefully acknowledged. 
CONTENTS

Page

LIST OF TABLES . . . . . . . . . . . . . . . . V v

LIST UF FIGURES . . . . . . . . . . . . . . . . vI

ABSTRACT ....................... vil

INTRODUCT ION . . . . . . . . . . . . . . . 1

Statement of the Problem................ I

Statement of Purpose .... . . . . . . . . . 2

Literiture Review ................... . . . . 3

Approach Used in this irork........... 15

EXPER IMENTAL WORK. . . . . . . . . . . . . . . 16

luaterials. . . . . . . . . . . . . . 16

Sample Preparation ................ 19

Apparatus and Procedure.............. . . 21

Absorption ................. . . . 21

Densities .................. 22

Porosity ..................... 20 26

Specific jurface . . . . . . . . . . . . 30

Tortuosity . . . . . . . . . . . . . 35

Permeability . . . . . . . . . . . . . 38

Absorptivity...................... 46

Calculations .................. 48

Data................................ 49

Density, Porosity, Absorption, and Saturation. .... 49

Tortuosity ................. . . . . 49

Specific Surface . . . . . . . . . . . 52

Permeability . . . . . . . . . . . . 52

Absorptivity ................. 63

DISCUSSION . . . . . . . . . . . . . . 72

Theoretical Backiground.............. 72

Permeability and Pore Stmicture.......... . . 72

Absorptivity and Pore Structure........... 78

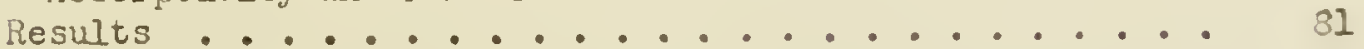

Discussion of Data and Results ........... \$3

Densities and Porosity................. 85

Tortuosity ................... 87

Sorption l.easurements............. 38

Permeability . . . . . . . . . . . . 9

Absorptivity .................. 92

Saturation .................... 95

Absorptivity-Permeability.Relationsnip . . . . . . 97

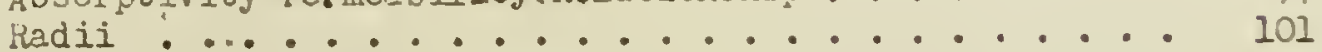

specific surfaces. . . . . . . . . . . . 102 
Interpretation of Data and Results......... 106 SULMARY OF RESULTS . . . . . . . . . . 12.5 CONCLUSIONS . . . . . . . . . . . . . . . 208, RECOLIENDATIONS .................................... 130 BIBLIOGRAPHY . . . . . . . . . . . . . . . 132 APPENDIX A. INFLUENCE OF $n$ ON TORTUOSITY .......... 139 A PPENDIX B. DEIRIVATION OF PELEADETE E.UATION . . . . . . $U_{1} I$ APPENDIX C. DERIVATION OF PERIEABILITY RELATIONSHIPS . . . 145 A PPENDIX D. LERIVATION OF SLIP FACTOR RELATIORSHIP . . . 14Z APPENDIX E. DEIIVATIUN CF ABSCRPTIVITY RELATIONSHIPS • . . 152 APPEMDIX F. REEF ROCK DATA . . . . . . . . . 155

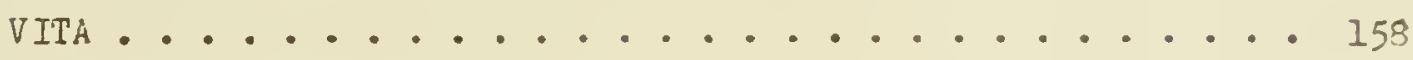




\section{LIST OF TABLAS}

Page

1. Gencral Description of Test liaterials . . . . . 17

2. Chemical and lineralofical Coraposition of Test Materials ................ . . 18

3. Densities, Porosity, Absorption, and Saturation . . 50

4. Tortuosities and Associated Factors ....... . 51

5. Specific Surfaces . . . . . . . . . 54

6. Permeability and Slip Factor .......... 62

7. Absorptivity Results ............. 63

8. Calculated Average Pore Radii of the Rocks .... 82

9. Calculated Specific Surfaces of the Rocks . . . . 84

10. Unit Saturations ............. 121

11. Absorptivity-Perneability Ratios . . . . . . 122 


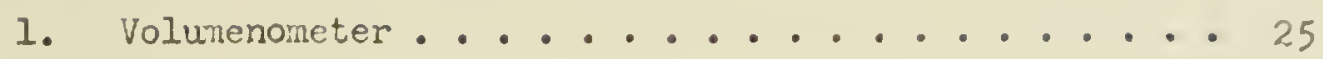

2. Porosinteter................... 28

3. Sorption Apparatus ............. 33

4. Permeameter .................. 43

5. Sorvtion Isotizerns .......... 53

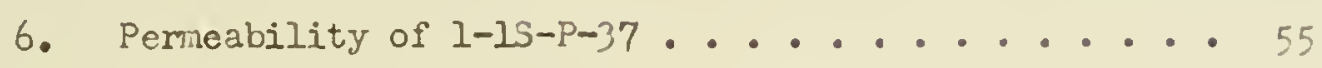

7. Permeability of $3-15-4-P-30$ p .......... 56

8. Permeability of $9-15-P-73 \ldots . . . . .47$

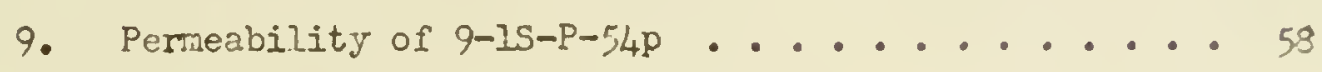

10. Permeability of 9-15-P-73, Low Pressure Runs ... 59

11. Perneability of 47-25-P-98 ............ 60

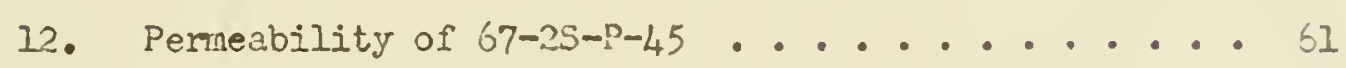

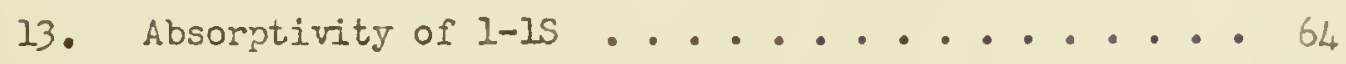

14. Absorptivity of $3-15-11-\mathrm{P}-30 \mathrm{p} \ldots \ldots . . . . .65$

15. Absorptivity of $9-15-p \ldots 66$

16. Absorptivity of 9-15, Effect of Flov: Direction . . 67

17. Absorptivity of 9-15-p-199, Effect of Various

Exposures .................. 68

18. Absorptivity of $47-25 . \ldots 69$

19. Absorptivity of $67-25 \ldots . . . . . . .70$

20. $\mathrm{pK}_{2}$ vs. $\mathrm{pK}_{1} \ldots \ldots \ldots \ldots$

21. Absorptivity of Reef Rock ......... 156 


\section{ABSTRACT}

Nany studles have shown the importance of the coarye aggregate component in the detemination of the resistance to freezing and thawling as a durabllity factor in the performance of pavenent conzrete. Fleld and laboratorg studles have been used in Indianz to ideatify certain Ilmestone coarse aggregates as outstandingly good or poor with respect to the resistance to frast action of the concrete made with them. Data from standard tests of aggregates are only part1ally successful in the prodiction of the field performanct of pavenents. Infomation is Inadequate concerning the mechandsas by which these materlals exert such great influence.

Slnce the presonce of water is fundamental to frost danage, the detalls of the acquisition and retention o: water by these materials and of its movement thoreln bucome important. The pore structure has been shown to be one of the nost Lmportant properties of coarse aggregates when they are used in portland-cement concrete. The nature of this structure is not completelg evaluated by tests now belng performed on these materials. More infornation is needed concerning this property.

Th1s study mas deslgned to lavestigate the usefullness of sloplo fluld-now measurements and of the data derlved therefron with respect to the elucidation of the pore structure of limestone coarse aggregates and to a possible correlation with the durability histories of pavements made with 1 imestone aggregatos. 
Five linestones with well-established durability histories

were chosen. The quarries were samiled. Snall prisus were cut from the larger samples and were firishod by hand grinding. Their dimensions were measured. The specific surfaces were determined on pulverized samples by the use of water-vapor sorption rith a gravimetric technique and the Bmnauer, Emmett, Teller theory. Values of the absorption for both the innersed and the vacuur-gaturated conditions were deternined by conventional methods on the prists. Porosities and tme and bulk densities were detemined using a fascompression volumenometer and a McLeod gage porosimeter. Permeabilities were determined at various mean pressures with a pressuredecay perneameter and an equation derived for this apparatus. The Klinkenberg slip factors and tine pressure-independent per..ezbilities were deternined from the plots of the permeability data. Tortuosities of the rocks were measured by the electrical-analog resistivity method. Absorptivities were determined with a simple gravimetric technique.

The specific surfaces and average pore radii were calculated from these data on the basis of a tortuous capillary-tube model. These calculations were made using the Kozeny equation for the permeabilities, a modified Klinkenberg equation for the slip factors, and $a$ derived equation for the absorptivities.

The absorptivity method was found to be superior to the permeability or slip methods as an interpreter of specific surface. An empirical relation was show by means of which a fairly-goot value of the permeability could be derived from the easily-ineasured absorptivity value. 
The tortuosities, slip factors, and average pore radil had no relation to the durability histories of the materials. The poorquality materials had higher porosities, perneabilities, specif1c surfaces, and absorptivities than did the good-quality naterials. The differences were especially noticible in the case of tne absorptivity values. The materials could also be separated accordin to their durability histories on a basis of tne rate of capillary saturation which was calculated from the absorptivities and the porosities and on a basis of the ratio of absorptivity to permeability; the poor-quality materials in every case had higner rates of saturation and higher absorptivity to permeability ratios. "he usefullness of the methods and principles involved and the desirability of their further application to evaluating the guality of coarse aggregates for use in portland-cement concrete are indicated. 


\section{Statement of the Problem}

During 1943-4 a comprehensive performance survey was made of Indiana's rigid pavements. The results were reported by Woods, Sweot, and Shelburno (95) and constituted the starting point for subsequent work on Indiana's coarse aggregate materials. Deterloration of concrete pavements, especially the frequency of blomups and map cracking, was studied in its relation to influential factors. The significant results of the study, as stated in the synopsis, were:

(1) An outstanding correlation existed between certain coarse aggregates used in the concrete mix and the blomp performance of the pavements.

(2) No correlation existed between the cement, fine aggregate, traffic, or subgrade solls used and blomp performance.

(3) Extensive laboratory resesrch is indicated as necessary to determine the basic reason for the variation in performance.... and to develop new and better methods of tests....

These data [1.e., results] were considered important, since it was observed generally that nap cracking, serious disintegration, and a relatively short pavement life accompanied the blown failures.

A research prozran was therefore started at the Joint Highway Research Project. This program is a part of the general research studies on the durability of concrete. Significant results have coxe from these studies. Non-durable materials have been identified. Tests for perfomance prediction have been set up and improved. Accurate information on the properties of some of the components of concrete has been obtained. Hypotheses concerning the influences of 
various agents on concrete have been derived and, in some cases, verified. Considerable insight into the nature of concrete durability has been obtalned, but the picture is far from conplete. In the studies at the Joint Highway Research Project principle exphasis has been placed on the influence exerted over the durability of concrete by the coarse aggregate component. This component seems to be determinative in Indiana experience. The study reported here is part of that continuing program and was designed to give information on what are considered to be important properties of aggregates.

\section{Statement of Purpose}

The pore stmucture of coarse aggregates has been shown to have an important influence on the durability of concrete. This structure is of particular importance in freezing-and-tharing durability and probably exerts considerable influence on blomp frequency, cement-aggregate reaction, and bond of aggregate with the paste. Past investigations of porosity have been limited to determinations of the totel porosity and of the degree of microporosity of the aggregate. Additional inforisation is needed on the pore structures of these materials.

The purpose of this study was to investigate the pore structure of certain Indiana Iimestone coarse aggregate materials by means of fluid-flow experiments and to relate the data obtained to properties of the material, to field performance, and to hypotheses conceming the movernent and freezing of water in concrete. 


\section{Literature Review}

In this reviev the problem of the durability of concrete is outlined. Special attention is placed on the influence of the coarse aggregate under freezing and thawing conditions. Hypotheses of frost action are summarized and the importance of the pore structure is emphasized. Work which has been done to elucidate the pore structure of aggregates and concrete is outlined.

The problem of the durabllity of concrete is complex. Concrete is a heterogeneous material and this, in itself, introduces complications. There are several choices of aggrezate materials and gradations. Cements differ in chemical and physical properties. The possibility of a number of additives exists. Mix designs differ as do methots of handling, placement, and curing. Environmental canditions for tive finished concrete are widely variable. All these factors can influence durability, by which is meant permanence when overlazding, in the stmctural sense, is not primarily involved.

The general problem of the durability of concrete has been reviewed recently by Scholer (75) and by Jones (36). These reviewers stressed the complex nature of the problem and cited the large number of possible influences and interactions. They give the impression that in hardly any of its aspects can the question of concrete durability be consideret satisfactorily solved.

Two methods of approsch are possible. One is to study the properties of the mixture and the other is to study the properties of the individusl components. From such individual properties deductions are 
then made conceming the behavior and properties of the combined material. This is a valid approach if it is realized that the interactions may modify the behavior of the components once they are combined.

The properties of cement paste have been investigated with great thoroughness. Illustrative of this work is the series of papers by Powers and Bromyand (60). Experlence in Indiana is, horever, that the component exerting the greatest influence on pavement durability is the coarse aggregate. Most of what follows will, therefore, be confined to the influence of the coarse aggregate while realizing that it can be considered separately only to a degree.

Lack of durability due to coarse aggregate can take a variety of forns. First in importance, for the purposes here, is failure due to instability in freezing and thawing. The aggregate may be responsible for frequent blowups of the pavement concrete. The thermal properties of coefficient of expansion and diffusivity of the aggregate may be so incompatible with those of the paste that failure is caused by heating and cooling. The aggregate may contain material which undergoes chemical reactions with the paste. This can, in turn, result in excessive expansion of the concrete. The best-known of such reactions is the alkali-aggregate reaction in which certain silicious materials in the aggregate react with alkalis from the cement. There may be, however, other harmful reactions. The aggregate may contain substances, such as certain clays, that swell and contract to a large extent on wetting and drying and thereby contribute to expansion of the concrete mass. The differential swelling and contracting between the aggregate itself and 
the paste as the degree of saturation changes can also cause stress. All these influences can cause distress of the concrete.

The properties of aggregate materials and their influence on concrete are discussed in the above-mentioned reviews by Scholer (75) and by Jones (36). The reviews by Blanks (II) and by Rhoades and Lielenz (66, 67) deal specifically with aggregates. Sweet (82) gave a revlew of the influence of aggregates on parement durab1lity. He also reviered methods of testing aggregates and the meaning of the results of such tests (80). Aggregates were discussed, with specific reference to the influence and measurement of porosity, by Lewis, Dolch, and iloods (45). Powers (59) recently reviewed the properties of paste and aggregates, alone and in combination, from the point of view of the relationship between physical structure and the movement of water on freezing and thawing.

The early conclusions of woods, Sweet, and Shelbume (95) were expanded as a result of a subsequent peper by Sweet and iroods (83) which showed the importance of the subgrade soil and its moistureretention properties. Lack of durability was most prevalent and deterioration most rapid on poorly-drained soils. Chert was identified as a particularly deleterious constituent of Indiana aggregates (79). Then in 1948 sweet (81) reported a comprehensive study of Indiana aggregates with well- or partly-established performance records. His tests included unconfined freezing and thawing, freezing and thawing of concrete, microscopic determination of micropores, and sodium-sulfate soundness, as well as the more ordinary determinations such as absorption and specific gravity. He found the same aggregates which had been 
identified by Woods, Sweet, and Shelbume as causing severe blomp distress and cracking to be non-durable in freezing and thawing. Unconfined freezing and thawing and sodium-sulfate soundness results did not confirm field experience of durability. Absorption and degree of saturation of the aggregates were fairly good indexes of freezing and thawing performance but a range was found which was internediate between the clearly good and the clearly poor materials. One of the most interesting findings was that all the harnful materials had voids ratios greater than 0.1 for voids smaller in diameter than five microns (micro pores) while the good materials had corresponding ratios of less than 0.06 . Fears (28) confirmed this finding in his investigation of the microscopic method of determining microporosity.

Chemical tests of most of the state's stones and some of its gravels were reported by Slate (77) and showed no consistent relationship between chemical composition and field performance. Nore of the poor-performing stones were dolomites than linestones and this trend was attributed to porosity characteristics. These materials were also tested for alkali reactivity and only one material, a chert, was found to have borderline reactivity. Blackburn (9) has since reported positive results for the "quick chenical test" for alkali reactivity of several Indiana gravels but the stones seem to be immune.

Sweet (81) mentioned the possibility of thermal incompatibility being a factor in the deterioration he observed. A Iinited amount of work on the thermal properties of the state's stanes was dane by Lu (49), who measured the expansion coefficient, and by Fox and Dolch (30) who determined the thermal diffusivity. The latter study shored the 
poor perfoming stanes to have slightly higher diffusivities than the good. Both kinds had values considerably higher than that of cerent paste. The presence of small amounts of water changed the measured diffusivities considerably. Lu's tosts showed a reversal of the expected trend. One of the best materials in the state had a lower coefficient of thermal expansion than did one of the poorest, and this latter almost matched the accepted coefficient for paste. These tests seem to show that themal incompatibility, if present as a harmful infuence, is only of minor importance for Indiana materials.

Work has been done by Bugg (16) and by Blackburn (8) on the ferformance, in freezing and thawing tests, of concrete containing these same Indiana aggregates and various amounts of entrained air. Their results showed that just enough air to protect the paste did not beneIit a bad aggregate but that benefit was obtained as the air content was increased to higher values. The benefit was considerably greater for stones than for gravels. This difference is thought to be due to the localized nature, e.g., chert pebbles, of the harmful elements in gravels. Recent work on gravels by Levis and Venters (46) shored the deleterious constituents to be highly absorptive particles of low specific gravity. Wuch of the foregoing work has been sumarized by Low is and Woods (47).

Some of the work at the Joint Higray Research Project has paralleled and complimented work of a similar nature in other organizations. Problems of aggregate durability in freezing and thawing are widespread. (In a paper by Walker and Bloem (85) is a good list of refer- 
ences on the general subject.) The Indlana studies have been reviered in detail because the materlals were the same as those used in this work.

The results of the studies point to field performance, with respect to a widespread type of distress (characterized by D-line cracking, followed by slab fallure), being reasonably reproducible in laboratory freezing and thawing tests. Assuming favorable conditions with respect to the paste component, the deterioration of the concrete seems traceable to the aggregate component and, in Indiana at least, to the coarse aggregate component.

The research work on the freezing and thawing durability of concrete has had two aspects. By far the greater amount of work has been done on test methods in an effort to reproduce field performance and to predict such performance for new materials. Several variations of test methods have been devised. A trend toward automation and acceleration of testing has taken place. The other aspect of the rork has been the attempts toward an understanding of the phenomena involved, i.e., toward the postulation of a mechanism and toward its verification. A full understanding of the problem waits on such results, hovever perfect the diagnostic tests may become.

The work on test methods has also given useful fundamental information. An example is the work of sweet (81) which showed the importance of absorption, saturation, and microporosity.

Much fundamental information on these matters has core from workers in the fields of brick, building stane, ceramics, soils, and cement paste. 
An early paper on bricks was written by Jones (37) in 1907 in which he discussed the freezing of water in a porous system and pointed out the importance of the permability of the material. His discussion was a foremnner of the modern hydraulic pressure theory.

In the early 1920's Washbum and his comorkers presented a series of papers $(87,89,90,91,92)$ on the pore structure, absorption, capillarity, and saturation of ceramics that included an analysis of methods for measuring these properties.

Work on building stone has been of particular importance. With the modification of inclusion of the cement paste. component, the freezing problems for building stone are analagous to those of aggregate materials and much of the results has bearing on the aggregate problem.

Howe (34) in 1910 noted the importance of the type of porosity and the degree of saturation. Seipp (76) stated the critical degree of saturation to be about 0.91 for freedom from frost action but Kreuger (4l) found lower critical degrees of saturation-of the order of 0.85 -and postulated inhomogeneous water distribution.

Comprehensive reports on building gtones are those bJ Schaffer (7I) and by Thomas (84). Schaffer was concerned with all aspects of building stone durability. His report seems to be the first to announce a pore diameter of five microns as critical, with respect to freezing durability. This value was obtained from microscopic measurements. It was substantiated for aggregates by Sweet (81) and by Fears (28) who used the microscopic method and by Blanks (II) who used capillary pressure messurements. 
Thomas (84) dealt specifically with the mechanism of freezing in building stones. He showed the importance of the degree of saturation, freezing temperature, freezing rate, and specimen size. He also presented a few curves on rate of saturation by simple imersion.

Madgwick measured porosity and permeability (to air) of bullding stones $(50,51)$. He derived theoretical relationships for capillary movement of water and for its transmission in terms of the experimental variables and various constants (52). These constants were evaluated in a fourth paper (53) for stones, brick, and plaster but were not related to the structure of the materials.

The work by Powers and his associates on the nature of cement paste has a two-fold bearing on the question at hand--both from the point of view of a freezing mechanism and of the fact that pastes are a constituent of concrete. What happens to the concrete and to the aggregate is influenced by what happens to the paste. Powers and Brownyard (60) reported investigations of the physical nature of cement paste and its water component. Briefly stated, the paste was found to consist of small spheres of hydrated cement gel about 100 Angstrom units in diameter and separated by gel pores with a hydraulic radius of about 10 Angstrom units. At a water-cement ratio of around 0.4 the paste is made up entirely of such a gel structure. At larger watercement ratios another kind of pore space is present. These are called capillary pores. They are usually considerably larger than the gel pores. Powers (58) presented evidence leading to the conclusion that "throughout the practical range of water-cement ratios the capillary 
pores are discrete pockets..." and that at higher ratios they gradually become an interconnected network.

Four mechanisms have been postulated to be operative when the water in the capillary pores freezes. (The water in the gel pores does not freeze at any temperatures normally found in the field.) The most obvious point is that if the saturation is greater than about 0.9 and no escape from the body is possible, then the increase in volume of the water on freezing must cause dilation and stress which will mpture the body unless its strength is sufficient to withstand the action. This might be termed the hydrostatic or degree-of-saturation mechanise. Powers (57) originated a second postulate which has become lnown as the hydraulic pressure hypothesis. In this mechanism escape is possible for the water and the growing ice volume forces it through the porous medium. Such escape can be to an outside surface or to voids in the interior of the body which are not saturated. Yut this movement must take place through a comparatively inpermeable porous solid and, therefore, hydraulic pressure will be generated which, depending on the magnitude of such variables as freezing rate, length of flow path, permeability, and strength, may rupture the body. A princinle function of entrained air is to Innit the distance such water must traverse and so keep the pressures within safe limits. The thind mechanism was presented by Powers and Helnuth (62) and involves the surface diffusion of the (unfrozen) gel water to ice in the capillary pores along a free energy gradient crested by the temperature decline below $\mathrm{O}$. This process causes swelling prossure in the capillaries and conseguent dilation of tie specimen. The action is comparatively slon and depends 
upon the temperature being maintained for an appreciable time. Entrained air also helps minimize this difficulty by enabling gel water to diffuse to air voids rather than to capillary pores. The fourth mechanisu involves osmotic pressure between the gel water and the water, in a capillary, whose salt concentration has been increased by partial freezing of the solvent water. Powers (59) discussed these matters in a recent review.

He also used the results on paste and those of others on aggregates and building stone to postulate mechanisms for the action under freezing of the aggregate component and of the concrete as a whole.

The argument goes as follows. In concrete the aggregate piece is sezled in a paste of low permeability whose pore system is generally smaller than that of the aggregate. When freezing begins, if the paste contains air bubbles of the proper number and spacing it should be immune to distress from the hydrostatic, hydraulic, and to a certain extent, the capillary accretion sources of stress. The osmotic pressure source is thought to be of comparatively minor importance. So entrained air should protect the paste under all ordinary conditions. Water in the aggregate pieces should start freezing sooner and at a higher temperature than that in paste capillaries because the aggregate water is in larger pores and has a lorver salt concentration. (Also, the aggregate piece ousht to change temperature more rapidy than the paste because of its higher thermal diffusivity.) If the piece of rock has an overall saturation higher than about 0.9 some water must be expelled into the paste. The paste is comparatively impermesble and this process will result in dilation. But saturations 
less than 0.9 do not necessarily render inmunity. If, due to inhorogeneous distribution of the water, any part of the aggregate 13 unable to accommodate the volume increase on freezine, the water mat travel to less-saturated places in the rock or to the surrounding paste. In either case excessive pressures can develop.

The pore system of the aggregate is generally larger than that of the paste so, for conditions of partial saturation, the water will migrate to the paste by virtue of the higher capillary pressure and lower vapor pressure in the more finely-porous system. For the aggregate to reach a high degree of saturation by capillarity the paste rust flrst have its capillary system virtually saturated. Water preceding by capillarity in concrete will prefer to stay in the paste, so to speak, rather than enter an aggregate particle.

This, of course, assumes simplifying ideal conditions. In a practical concrete there are pores other than the aggregate pores and the various void spaces of a perfect paste. Bleeding channels, imperfect-consolidation spaces, shrinkage cracks, and settlement spaces under aggregate particles exist. Jones (36) states "This [ideal system] will hardly be true in some actual mortars and cancretes because of imperfect packing of aggregate particles combined with lack of sufficient cement to fill all interstices, because of porosity arising by imperfect adhesion between aggregate and paste surfaces, and because of porosity of the aggregate itself."

Some of these spaces might provide entrance channels ior capillary or percolating water. 
The above points to the importance of the presence or absence of water in the aggregate in situations where the aggregate is one of the harmful components of the concrete. The acquisition of rater by capillarity and its movements vithin the piece are involved in the properties of absorptivity and permeability. Jones (36) stated with respect to aggregates "It is necessary to study chiefly porosity, absorption and permeability; surface texture; and shape," and "OnIy if full dat? are available can a proper assessment be made of relative importance of various factors as regards durability." Blarks (II) and Rhoades and Wielenz (66) gave first importance to the pore structure of the aggregate and its relationship to water.

Little work has been done on the pore structure of aggregates or on the movement of water through this structure. Lost correlations with durability heve been made with the absorption, total porosity, specific gravity, or various absorption ratios. Nuch of this work was reviewed by Lewis and Dolch $(44)$. The measurements on microporosity by Sweet (8I), Blanks (11), Fears (28) and Schaffer (71) heve given further insight into the structures of these materials. In their paper on the permeability of pastes (6I) Porrers et al. gave some data on the permeability of various rocks as a comparison to show the average pore size of the rocks to be larger than that of the paste. iiray and Lichtfeld (96) measured the rate of saturation of gravels and found that the stream-wet conition was difficult to reproduce by simple inmersion. Vacuum saturation was considerably more effective than immersion and the material that saturated most readily ras the poorest in freezing and thawing. Blaine, Hunt, and Tomes (10) measured the 
specific surfaces of various materials by sorption teciniquea and found comparatively high specific surfaces for materials poor in freezing and thawing and for limestone aggregates with bad serrice reconds in concrete.

There has been a large amount of work on the permeability of concreto. Slate's bibliography (78) gives a list of references up to 1947. The subject is of practical importance where concrete is used as $z$ barrier to liquid. Most of the studies have been made to determine the transmission properties of the material under various heads, and have not been concerned with pore structure. One of the most comprehensive of these studies was that of Ruettgers, Vidal, and Wing (70). Their paper and the more recent one by Cook (21) show the apparatus and conditions for the test with water.

\section{Approach Used in This Work}

Aggregates with both good and poor field performance were chosen. The quarries were sampled. Small rectangular prisms were shaped from the rock and their dimensions were measured. True density, porosity, and bulk density were determined. Permeability to air was measured in a pressure-decay apparatus at various pressures and the slip correction was determined. The absorptivity coefficient was measured by capillary absorption on a free-water surface. Tortuosity was determined by the electrical analog method. Specific surface was deterwined by the sorption method using water vapor. These data were then used to calculate characteristics of the pore systern on the basis of a siraple model. 


\section{EXPER IIENTAL WORK}

\section{Waterials}

The materials studied in this work were five linestanes or dola mitic Iimestones which are being, or have been, used as concrete coarse aggregates in Indjana rigid pavement construction. These materials have well-established field-perfornance records. They have been studied repeatedly.

The geologic origin, appearance, and field periomance of the materials are listed in Table 1. The chemicel compositions and calculated mineralogical compositions, both for major constituents only, are listed in Table 2.

The quarrios from which these samples were obtained were described by Sweet (82). Care was taken to secure material from the appropriate ledge in those cases in which different materials are present in the same quarry. The samples taken were reasonably homogeneous, i.e., inclusions, seams, fractures, and weathered surfaces were avoided. Nio effort was made to assure representative sampling on a statistical basis. The simples were merely selectod at randon and with an eye towards similarity to the general mass. For an exploratory study such as the one reported here, this sampling procedure was considered adequate.

A corollary of this sampling technique is the assumption that the material obtained is reasonably representative of that used in the pavements for which the field performance ratings were obtained. Explicitly, it is assumed that if material exactly like these samplos 


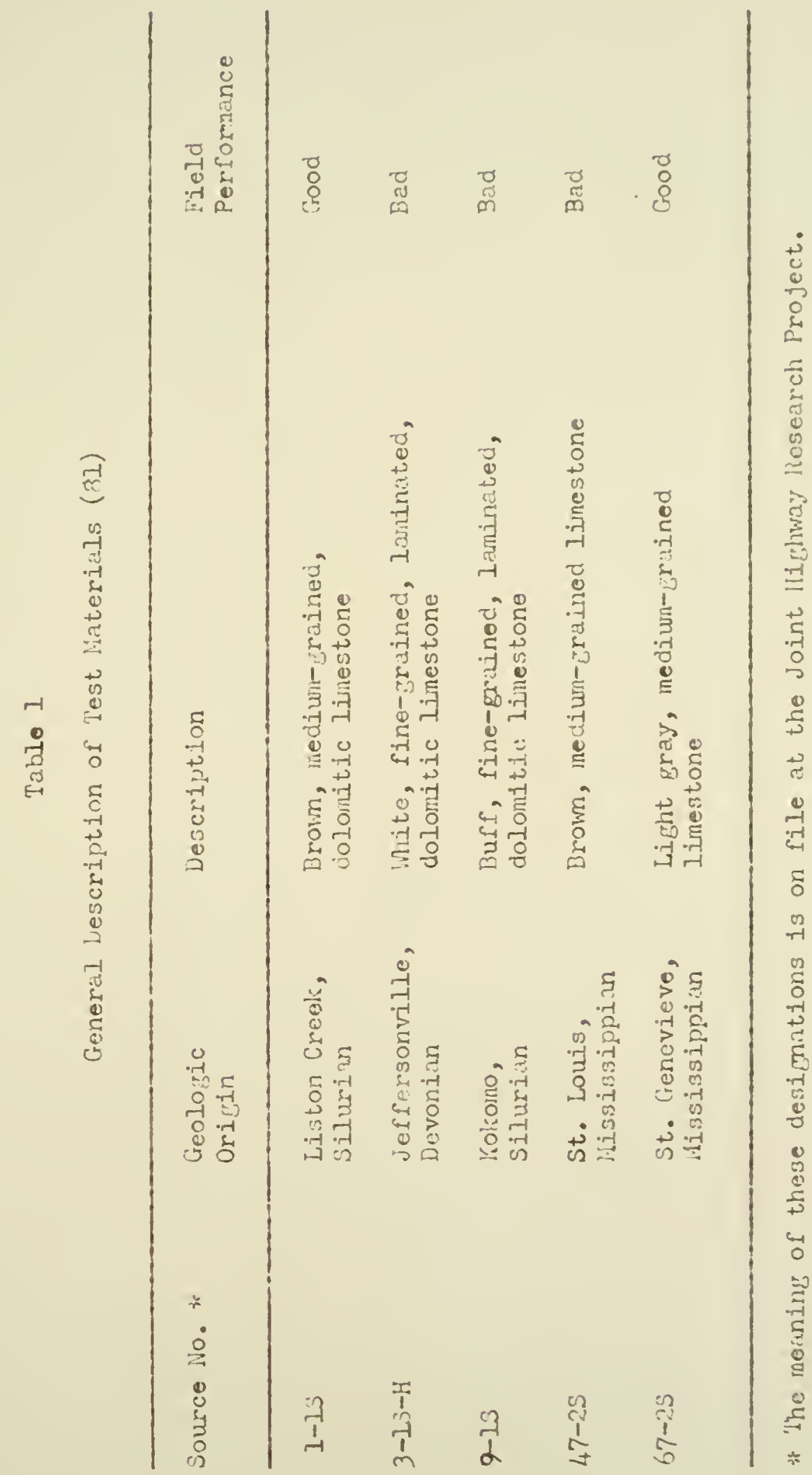


Table 2

Chemical and bineralogical Composition of Test laterials (23)*

\begin{tabular}{|c|c|c|c|c|c|}
\hline Source & $1-1 S$ & $3-15-H$ & $9-15$ & $47-25$ & $607-25$ \\
\hline CaO & 30.08 & 32.1 & 29.9 & 42.3 & 54.64 \\
\hline bigo & 20,24 & 18.07 & 19.4 & 3.78 & 0.34 \\
\hline $\mathrm{CO}_{2}$ & 44.61 & 46.10 & 44.53 & 38.9 & 41.53 \\
\hline $\mathrm{SiO}_{2}$ & 1.95 & 0.56 & 3.00 & 3.95 & 1.12 \\
\hline $\mathrm{Al}_{2} \cdot \mathrm{O}_{3}$ & 2.72 & 2.90 & 1.3 & 4.14 & 1.80 \\
\hline Calcite & 3 & 12 & 5 & 77 & 97 \\
\hline Dolonite & 93 & 83 & 89 & 17 & 2 \\
\hline
\end{tabular}

*All values are percentages of oven-dry sample. 
had been made into pavements, those pavements would have durihility historles similar to those of the pavements that were actually made with material from the corresponding sources.

One exception to the above may exist. This is the material labeled 3-1S-H. The samples from this source, although thought to be taten from the proper ledge, exhibited absorptions and saturations that are lover than those of samples taken some years ago. This material therefore may not be truly representative of that used in the pavements. In fact, all tests imply that if pavements had been made from this sample they would not have particularly bad durability ratings. This source was not included in the first plans and was tested when an additional source was thought desirable. Only small pieces were available; hence only small prisms (about $3 \mathrm{~cm}$. Iong) could be made. This materlal seems on appearance the least homogeneous of the rochs tested and the samples may be less representative than those from the other sources.

\section{Sample Preparation}

Wost of the runs were made on small rectangular prisms of rock. It was necessary to have regular geometrical shapes and prisms seened the simplest to prepare.

Slabs about one inch in thiclmess were cut from the large pieces using a "Clipper" masonry saw" with a dianond blade. Fron these slabs rough blanks for the prisms were then cut. The final finishing was done by hand grinding on a glass plate using (generally) 100 mesh 
alundum or comundum powder. The grinding was done wet so that porder would not be carried into the pores by capillary water. Rectangularity of the cross section was checked with a small square. The finished prisms were scrubbed under the faucet with a test-tube brush. They were then rinsed, dried over-night in a $105 \mathrm{C}$ oven and stored over anhydrous magnesium perchlorate in a dessicator. Considerable attention was paid to the selection of homogeneous material, free from defects, for the final prisms.

The individual prisms were given a designation that shored the source and the weight to the next lowest decigram and so permitted identification without marking in any way, e.g., 47-25-P-116. The 47-25 is the source designation. P means shaped prism (some of the early work was done with small chips). 116 means a weight of $11.6 \mathrm{~g}$. All weights throughout this work were measured on an analytical chainomatic balance and were read to the nearest $0.0001 \mathrm{~g}$. All units are c.g.s. unless stated to be otherwise.

The dimensions of each prism were measured vith a Brom and Sharpe precision caliper. Measurements were made to the nearest $0.002 \mathrm{~cm}$. In those instances where the prisms were several centimeters long a width measurement was made about every centimeter along the length and the average was taken as the dimension in question.

The assumption is made that prisms, from the same source, cut from adjacent material, and selected to appear homogeneous are alike in their physical properties. This assumption is necessitated by the use of properties that were measured on one particular prism for calculations involving another and is obviously not strictly true but 
is probably true enough for the purposes involved here. A variety of duplicated measurements have led to no sorlous discrepancies in this respect. The prisms are further assumed to be representative of the samples taken and therefore, on the b.isis previousiy discussed, of the source.

One series of experiments, the sorption runs, was done on granular material. The rock was processed by crusing some of the rough prisms and sieving the material to obtain the fraction passing the No. 10 (Tyler) and ret三ined on the No. 30 (U.S. Standard). The sieving was done dry and the material was then washed with distilled water on the No. 30 sieve, dried in an oven, and resieved.

\section{Apparatus and Procedure}

\section{Absorption}

Absorption is defined as the amount of water (or other liquid) contained in a porous substance undor specified conditions and is expressed here as a fraction of the oven-dry weight of the sample. Many workers have investigated this property, trying various liquids and methods for saturating the sample. Usually the attempt izas been to obtain higher, preferably complete, saturation. Typical of these experiments is the work of Washbum and Footitt (92). Types of imersion have been simple imnersion, evacuation and immersion, boiling in the fluid, and evacuation, immersion, and application of pressure. Various ratios of the absorption under different conditions have been advocated as characteristic of the naterial (66). Frequently, the assumption is made that liquids completely saturate a porous material 
but repeated demonutrations are to the contrary.

In this work the absorptions were measured after $24 \mathrm{hr}$. imersion and after evacuation for $1 \mathrm{hr}$. followed by $23 \mathrm{hr}$. immergior.

The apparatus used for the vacuun absorption mis was a oneliter filtration flask. The prisms were placed therein, 3 stopper carrying a separatory funnel was placed in the neck, and the funnel was filled with water. An aspirator was attached to the side $3 m$ and the flask and its contents were evacuated. Sweet (82) has shom that there is no point in using a vacuum pump for this operation and that an aspirator is sufficient. After one hour of evacuation, the rater in the funnel was admitted to cover the samples, atmospheric pressure was restored to the system, and the samples ivere allowed to rema in imnersed for $23 \mathrm{hr}$. At the end of this time they were removed, blotted surface-dry on a damp cloth, and weighed rapidly. The balance was preset to approximately the correct weight and was magnetically damped. The weighings, therefore, took only about $20 \mathrm{sec}$. and evaporation was minimized. For the $24 \mathrm{hr}$. immersion runs the samples were simply immersed in distilled water for the requisite tine and timen treated sirilarly. This technique for surface drying gave reproducible results for suecessive trials. With these polished surfaces it was possible to see free moisture as a reflecting glisten. The surface dry point was a uniform dullness.

\section{Densities}

True density is defined as

$$
\rho_{\mathrm{T}}=\frac{W_{s}}{v_{s}}
$$




$$
\text { where } \begin{aligned}
P_{T} & =\text { true density } \\
W_{S} & =\text { mass of solids } \\
V_{S} & =\text { volume of solids. }
\end{aligned}
$$

Bult: density is defined as

$$
p_{B}=\frac{W_{s}}{V_{B}}
$$

where $P_{B}=$ bulk density

$V_{B}=$ bulk volune, i.e., volume of solids and volds.

Methods for determining the density of solids are given in standand texts on experimental methods $(65,93)$. The mothods used on porous solids in general and concrete aggregates in particular were reviewed by Lewis, Dolch, and Woods (45).

The true density of a porous solid is determined by displacement methods using either a liquid or a gas. If a liquid is used tne solid should be powdered so that as complete a penetration of the pores as possible is obtained (4). Since it was desired to have a non-destructive test, a gas-displacement method was chosen for this study. The apparatus was essentially that proposed by Washburn and Bunting (90). In any such test the question of which gas to use arises. Frequently helium is chosen because it is so little adsorbed and errors due to this factor are thereby avoided. These rocks, however, have comparatively low spocific surfaces and sorption should not be a problem in the density measurements. Air was therefore chosen as the gas because of obvious simplicity. 
The apparatus is shown in Fig. 1. All Blassivare used in apparatus in this work was Pyrex. All stopcociss and ground joints were handfinished with No. 220 alundum porder.

The use of the apparatus depends on compressing the syster by a certain known volume. This volume was that of the bulb in the center of the figure. Scratch marks for calibration vere mate on the wubes leading to the bulb. The volume between tnese maks was deterrined by affixing a stopcock onto the botton end and drawing mercury into this assembly to the upper scratin mark. The mercury was then run into 3 tared weighing bottle until the bottom mark was reached. The weifit of this mercury then permitted calculation of the corresponding rolume.

In operation the mercury level ras raised exactly to the bottom mark with the leveling bulb and a screw adjustment (not shom). At this time the stopcock at the left was closed, thus closing the syster above the mercury in the left leg. The mercury level was then raised exactly to the upper scratch nark by means of the leveling bulb. This process compressed the air in the system by the known volume. The correspondine pressure was read on the meter-stick-manometer assembly. The barometer was read and room temperature was detemined. The barometric reading and the manometer reading were both fully corrected.

These data then permitted calculation of the volune of the sjsten, assuming Boyle's law to hold. The final equation, resulting from simple algebra is

$$
V_{2}=\frac{P_{a} \Delta V}{\Delta P}
$$




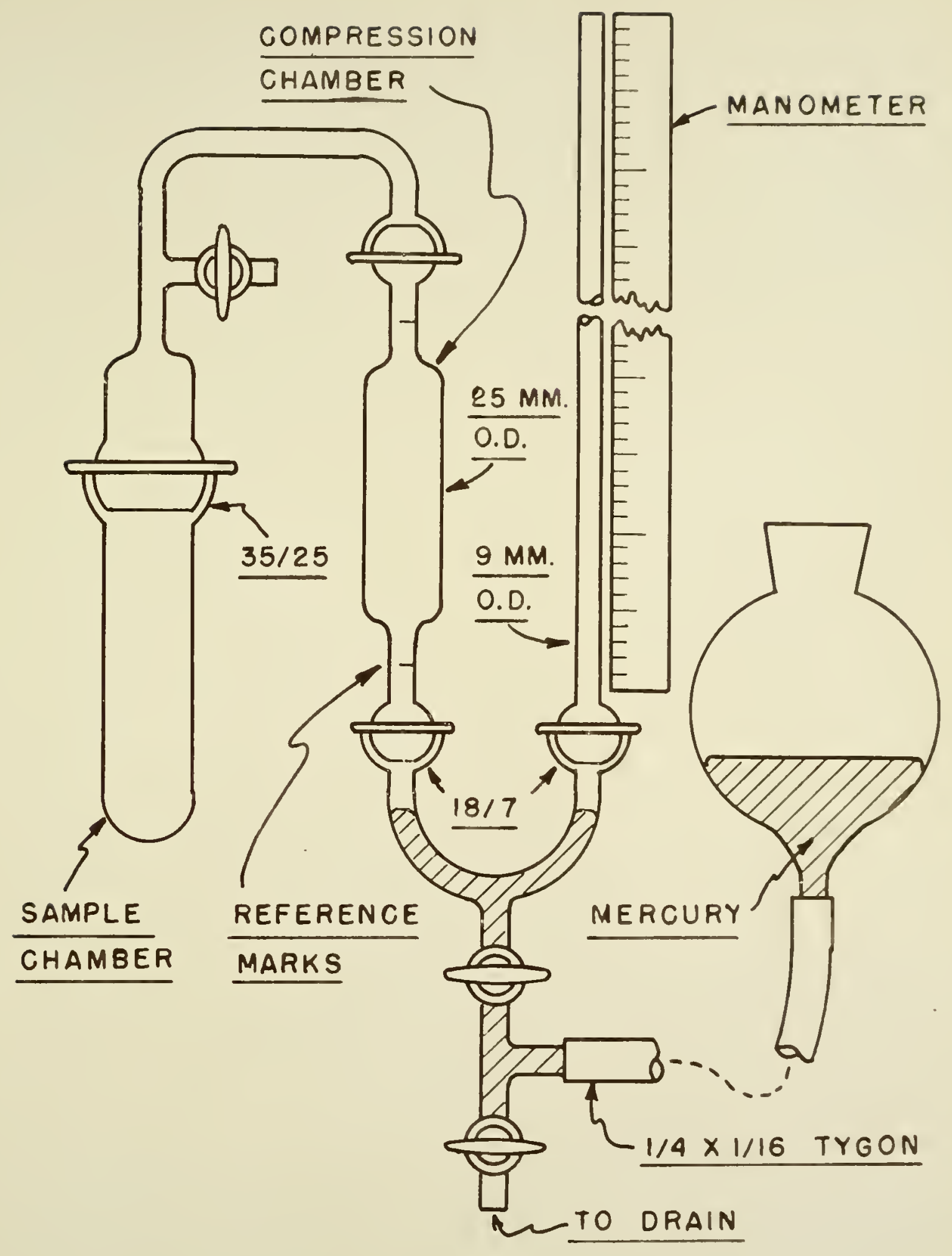

FIG. I VOLUMENOMETER 


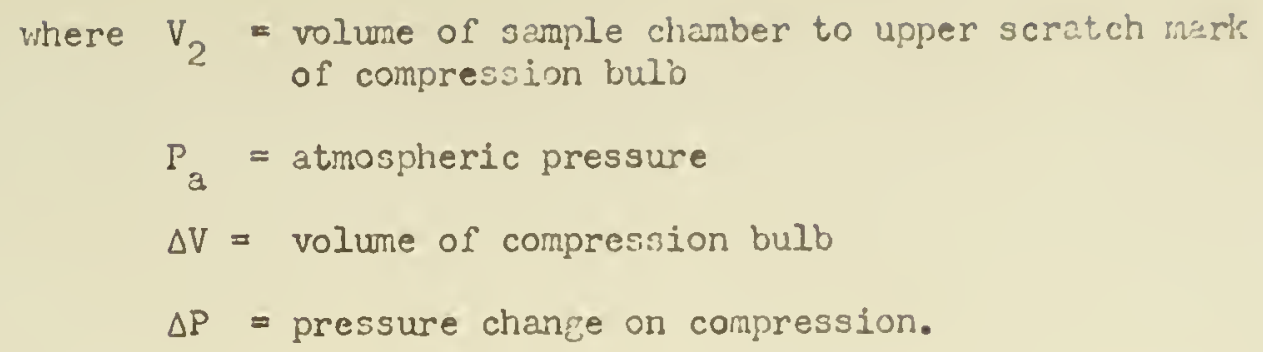

Constant tempersture during the mun was assumed. Since the mas took only a few minutes this assumption seemed justified. If the measurement is done on the empty chamber and repeated with a sasple in the chamber the difference in volume gives the volume of the solids of the sample. From this value and the sample weight the true density was calculated. The assumption is that the gas in the pores attains the equilibrium pressure rapidly. This was checked by the fact that no pressure change with time was observed after the compression.

When the densitios of known substances (mercury and calcite) were measured there were pergistent small errors in the final values which were attributed to gas law deviations and unknow sources. To correct for these errors a run was made on a lonown volume of mercury and the empty volume of the sample chamber was determinod empirically. Subsequent checks on calcite gave good results (2.72 compared with 2.71 (88 p. 143)). This empirically-determined value for the volume of the sample chamber was used in all lator runs.

\section{Porosity}

Two ratios that express the volume of pore space in a porvus material are in common use. One is called the porosity, and the other the voids ratio. Porosity is defined as 
$\varepsilon=\frac{V_{V}}{V_{B}}$

and the voids ratio is defined as

$$
R_{V}=\frac{V_{V}}{V_{3}}
$$

These are related by

$$
\varepsilon=\frac{R_{v}}{1+R_{v}} .
$$

Methods of measuring porosity were reviewed by Lewis, Dolch, and Woods (45) and by Fancher, Lewis, and Barnes (26). Two frequentlyused methods are by calculation from the true and bulk densities according to

$$
\varepsilon=I-\frac{\rho_{B}}{\rho_{T}}
$$

or by saturation with a liquid and weighing. The objection to the latter method is the assumption of complete saturation.

Since a direct measurement was preferred, an adaptation of the McLead gauge porosineter of ivashburn and Bunting (91) vas used. The apparatus is show in Figure 2. The upper section was a $5 \mathrm{ml}$. micro buret graduated in $0.02 \mathrm{ml}$.

The operation of the apparatus follows. The sample was placed in the container and the apparatus was assembled. The ball and socket joint was carefully greased and clamped with a No. 35 clamp. The mercury level was then raised by means of the levelling bulb. The sample floated and soon contactod the small intrusions in the glass just above the ground joint. As the levelling bulb continued to be raised the 


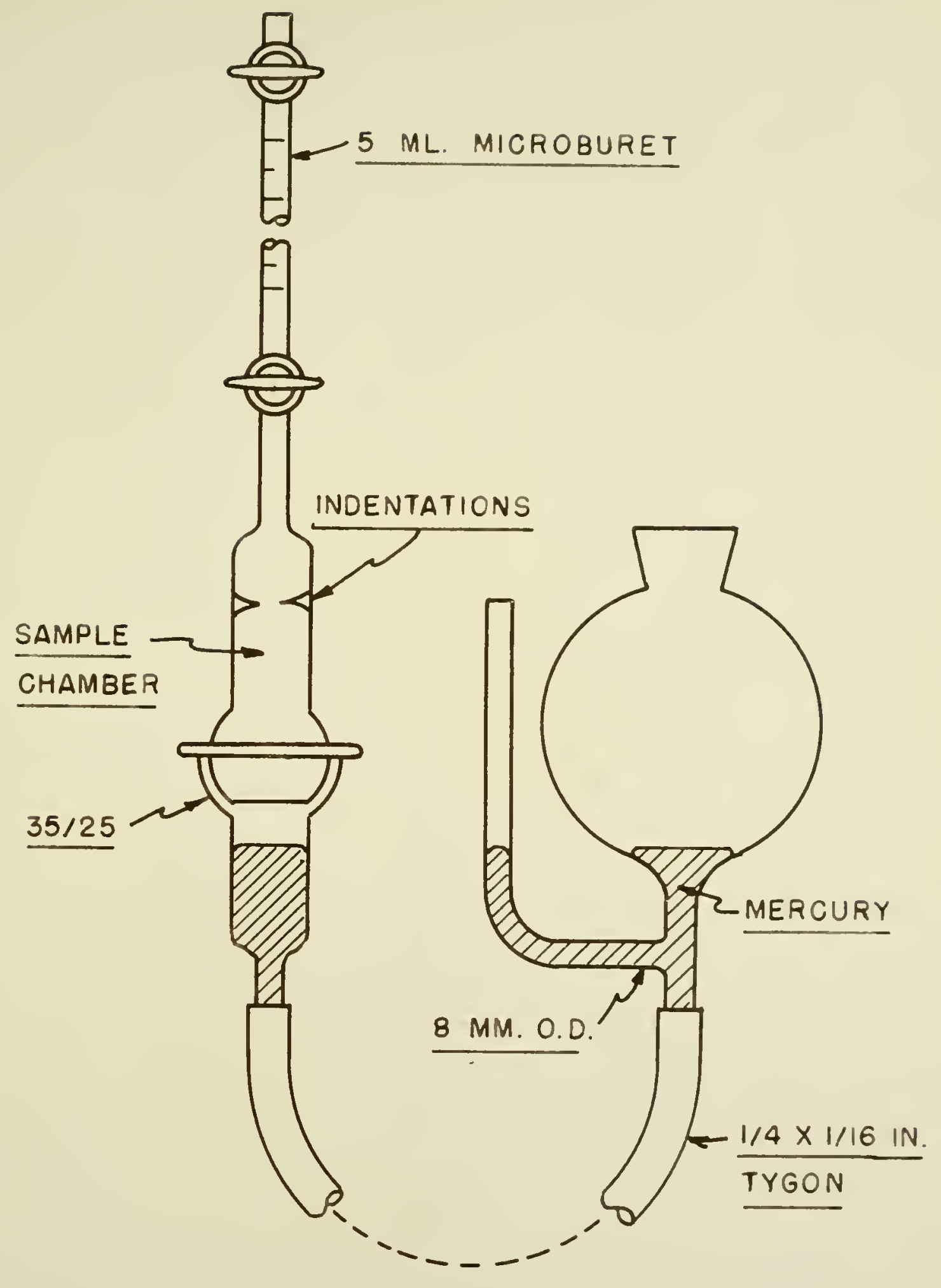

FIG.2 POROSIMETER 
mercury covered the saraple and trapped the air in the volds at atmospheric pressure. The level was raised to the top mark of the buret and both stopcocks were closed. The levelling bulb was then lowered. As the pressure on the sample fell the air in the volds expanded and bubbled up through the mercury. This lowering was continued unt1l the sample was entirely exposed. The level was then raised again and the air which had been emitted from the voids was trapped above the mercury at the lower stopcock. This stopcock was then opened and the air was allowed to rise into the buret. Since the rising mercury had trapped a certain amount of air in the voids at the comparatively low "evacuation" pressure, the lower stopcock was then closed and the pro cedure was repeated. The increments of air from the pores were combined in the buret. Finally the levelling bulb was raised and adjusted to the level in the buret and the volume of air in the pores, i.e., the pore volume, was read directly from the buret. The number of evacuations needed before no significant change was noticed in the cumulative volume was around four.

The question was raised concerming the length of tine the sample needed to be exposed to the low pressure on the evacuation. Considerable tine might be necessary for the air to come out of inpermeable rocks. Accordingly, arrangements were made to have the level remain lowered for about fifteen minutes rather than for the customary one minute or so. When exposed for the longer time no noticesble difierence was observed in results on the same sample. It is probable that at the low pressures involved the permeability becomes high due to slip flow. 
The above procedure gave the volume of volds. The previouslydescribed procedure gave the volume of solids. Their ratio is the voids ratio. Porosity was calculatad by means of equation (6) and the bulk density by means of equation (7). An altemative to this procedure is to calculate $P_{B}$ directly from the weight and the measured dimensions according to equation (2) and $\epsilon$ directly fror $V_{\mathrm{v}}$ and the measured dimensions according to equation (4). This method of determining bulk volume is, however, influenced by errors in the measurements of the sample dimensions and was used, except as a check, only for 3-lS-H for which only small prisms were available. On these stall prisms the error in the determination of the volume of solids in the volumenometer would have been large.

\section{Specific Surface}

The specific surface of a porous material is the surface area, including that of the pores, per unit of material. Two expressions of that area have been used in this work. These are the surface area per unit bulk volume, $S$, and the aroa per unit weight, $S_{g}$. These are related by

$$
S=S_{g} P_{B}
$$

A number of methods exist for measuring this property of a porous material. Many were listed by Ergun (25) and were discussed more canpletely by Brunauer (14).

Two independent methods have been used in this work. These are the fluid flow method, in connection with the major purpose of this study, and the gaseous sorption method. Investigators have found dis- 
crepancies between the results of these two rethods (13) and havo attributed the differences to different areas being contacted by the sorbed vapor and by the flowing fluid. In an effort to inrestigate this discrepancy for these rocks, the sorption test was parforced.

The sorption method involves the calculation, from the data of the low-pressure part of the isotherm, of the amount of gas refuired to form a sorbed layer one molecule in thickness on the solid. This value, combined with a knowledge of the surface area occupled by one molecule, permits calculation of the total surface ares.

The equation most widely used for this calculation is probably that derived by Brunauer, Eunnett, and Teller (BET) (14, 15) to represent their multimolecular condensation theory of the sorption process. The BET equation can be written

$$
\frac{I}{w}\left(\frac{x}{I \tau x}\right)=\frac{1}{V_{m} c}+\frac{c-1(x)}{V_{m} C}
$$

where $w$ = weight of sorbate per unit weight of sorbent

$$
\begin{aligned}
V_{m}= & \text { weight of sorbate in a monolayer per unit weight of } \\
& \text { sorbent }
\end{aligned}
$$

This is the equation of a straight $I$ ine in $(1 / w)(x / 1-x)$ and $x$ with an intercept of $I / \mathrm{V}_{\mathrm{m}} \mathrm{C}$ and a slope of $(\mathrm{C}-1) \mathrm{V}_{\mathrm{m}} \mathrm{C}$. The value of $\mathrm{V}_{\mathrm{m}} \mathrm{can}$ therefore be obtained and from this value the total surface area is calculated. Katz (39) and Gleysteen and Kalousek (31) simplified equation (9) by noting that $\mathrm{C}$ is frequently large compared to unity and that $1 / N_{m} C$ is then a small number. These authors, therefore, assumed that a plot of the isotherm using only the origin and one 
point constituted a close approximation to the curve obtalned by taking several data polnts. Some carly runs were aade using this simplified procedure. The results of these experiments were checied by repeating the deternination using several data points. The results showed the value of $C$ to be so small for these systemis (rock and water vapor) that the assumptions of the simplified theory were unwarranted. Accordingly, all muns were made using several data points and the original BET oquation.

The apparatus used to obtain the data of the amount of vapor sorbed on the solid as a function of the sorbate pressure was a rodification of that used by Gleysteen and Kalousek (31) and is shown in Figure 3. The sample-flask assemblies were connected to the manifold by short lengths of Tygon tubing. The tubing was merely slipped on with the aid of a little moisture and was found to hold well, with no leaks at all. The dibutyl phthalate minometer was used to measure the lower vapor pressures involved and the mercury manometer was used for higher pressures. The apparatus was housed in an air bath made from $3 / 4$ in. plywood. The bath was cooled by tap water running through a coil of copper tubing and was heated by a light bulb which was controlled with a Themocap relay activated by a themometer graduated in 0.2 Centigrade degrees. The temperature maintained in this bath and used for all the sorption runs was $25.0 \pm 0.1 \mathrm{C}$. 


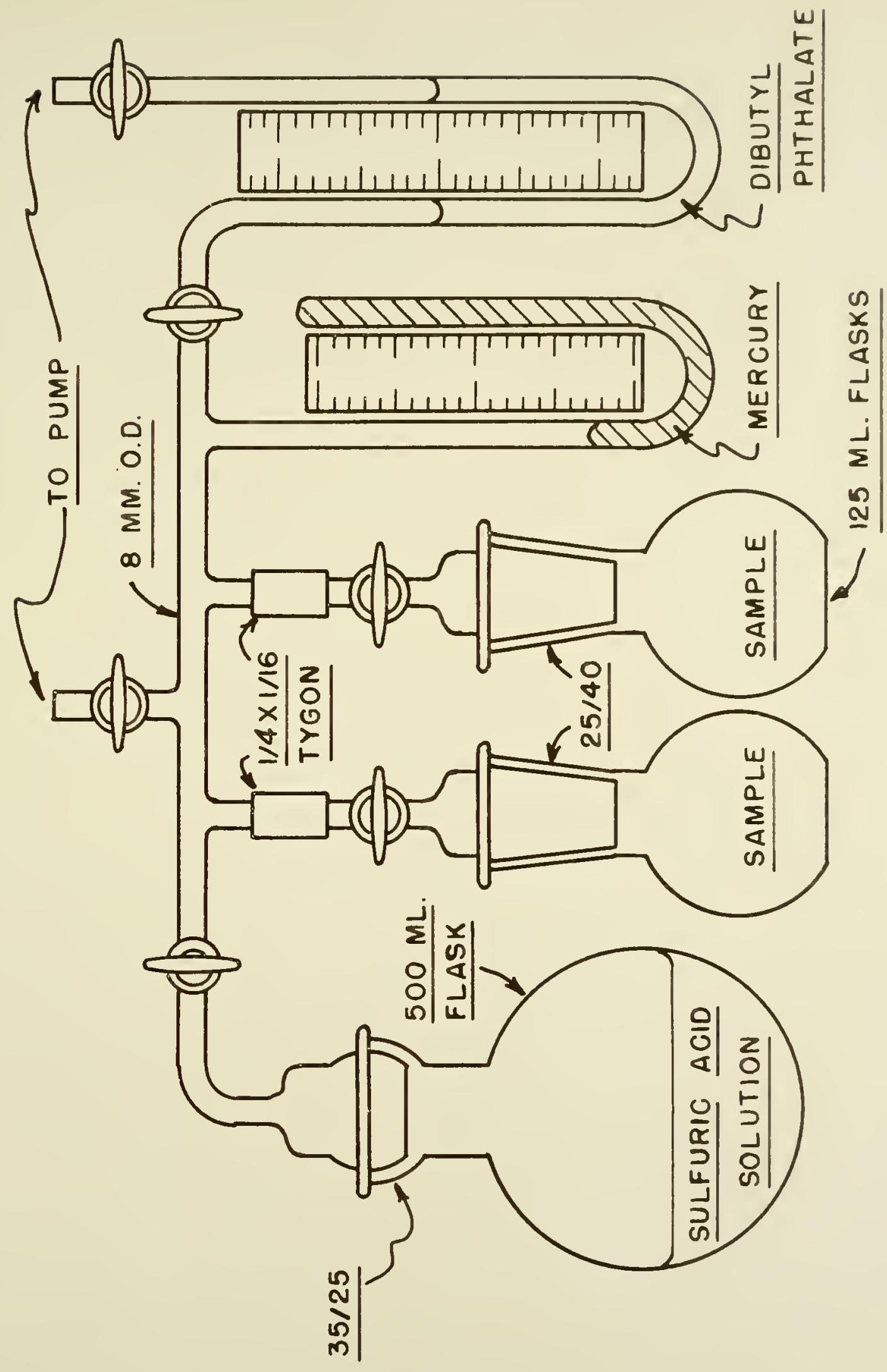

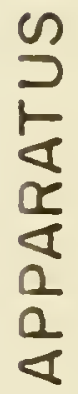

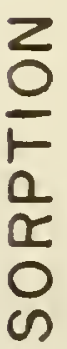

$m$

$\frac{0}{4}$ 
Sulfuric acid solutions were used in ti!n Lare flask as sources of water vapor, which was the sorbate. The solutions riers made up to approximately the correct strength, as stated in handbook tablas (33 p. 1926), and the actual pressures involved in the determinations vere measured with the appropriate manometer.

The procedure for the measurement was as follows. The oven-dry rock, No. 10 (Tyler) to No. 30 (U.S. Std.), was reighed into the $125 \mathrm{ml}$. flasks by difference. Charges of around $60-70 \mathrm{~g}$. were used. The apparatus was then assembled and, with all stopcocks open except that leading to the larger flask, the system was evacuated on the Hegavac. The samples were warmed slightly to assist outgassing and the pumping was continued for $\mathrm{l} \mathrm{hr}$. This evacuation was needed not only to outgas the rocks but also to remove possible volatile matter from the dibutyl phthalate. The stopcocks to the sample flasks and to the ofl manoneter were then closed. The Tygon connections were cut off and the semplerlask assemblies were veighed. The apparatus was reassembled and the manifold and the solution flask were pumped out. When the solution began to boil the stopcock leading from the ranifold to the pump ras closed and the water vapor was admitted to the samples. From tine to time the amount of sorbed vapor was detemined by removing the flasis and weighing. Sorption was continued until constant reight ras obtained. About one hour was sufficient time. At this point the vapor pressure of the water in the evacuated system was measured with the dibutyl phthalate manometer. The data for other points or the curve were obtained by repeating the above procedures using other con- 
centrations of sulfuric acid solution. The neight-of-sorbate values obtained by this method wiere corrected for the weight of unsorbed vater vapor in the sample-flask assemblies.

\section{Tortuosity}

The tortuosity of a pore system is defined as the square of the ratio of the average actual length of flow path to the exterior length of the flow path, i.e.,

$$
k_{t}\left[\begin{array}{ll}
\text { or } & \tau
\end{array}\right]=\left(\frac{I_{t}}{I}\right)^{2}
$$

$$
\begin{aligned}
\text { where } k_{t}\left[\begin{array}{ll}
\text { or } & ]
\end{array}\right] & =\text { tortuosity } \\
L_{t} & =\text { average tortuous length of flow path } \\
L & =\text { macro length of flow path. }
\end{aligned}
$$

The tortuosity of the pore system of a consolideted porous medius is presently measured in one of two general ways. One method involves the determination of the curve of capillary pressure as a function of saturation, and the other is an electrical anslog method. The electrical analog mothod, as discussed in papers by Willie and Rose (98) and Wyllie and Spangler (99), was used in this work because of its simplicity and proved applicability.

The method is based on the premise that electric current flowine through a conducting liquid in the pores of a porous body will follaw the same path as will a fluid flowing through these pores in a fluidflow experiment. The ratio of the resistance of the porous medium cor-taining the conducting liquid to the resistance of an ancunt of the liquid alone equal in size to the bulk dimensions of the sample is called the formation factor, F. F car be related to the structural 
properties of the material. A difference of opinion exists as to the form this relation should take. Wyllie and Rose (98) and wyllie and Spangler (99) considered that the effective cross-sectional area of current flow is $\varepsilon \mathrm{A}$ where $\mathrm{A}$ is the macro cross section. Accordingly

$$
k_{t}=F^{2} \varepsilon^{2}
$$

Cornell and Katz (22), on the other hand, assumed an effective crosssectional area of $\leq \mathrm{A} / \mathrm{k}_{\mathrm{t}}^{\frac{1}{2}}$. In this case

$$
\tau=F \varepsilon
$$

Wyllie and Gregory (97), who investigated this discrepancy for unconsolidated aggregates, stated "Arguments in favor of both approaches may be adduced." The details of these arguments, however, seer, to be lacking in the aforementioned papers. It may be mentioned that empirical relations between the variables involved have been advanced (27, 94) which are different from those of either of the above two equations. The matter is referred to again in the Discussion section.

Assuming the correctness of equation (11), if the solid is inconpletely saturated with the conducting fluid the formation factor, Fe, will be larger than $F$ and given by

$$
F_{e}=\frac{k_{t e}^{1 / 2}}{\varepsilon S_{W}}
$$

where $k_{t_{\theta}}=$ tortuosity of conducting phase

$S_{W}=$ fractional saturation

by analogy with equation (II). The ratio of these formation factors is called the resistivity index I,

$$
I=\frac{F_{e}}{F}
$$


The resistivity index has been experimentally determined to be a simple function of the degree of saturation,

$$
I=s_{W}^{-n}
$$

The exponent $n$ seems to be independent of the value of saturation for values high enough so that the conducting phase is reasonably continuous (99), and has a magnitude which varies for different rock textures but is approximately 2. This is the value used here. By the use of these equations the tortuosity of a porous medium at any saturation can be calculated if the formation factor at a known saturation is measured and the porosity is known.

The determination of the formation factor was as follows. The ends of the prisms were painted (two coats) with a colloidal silver, conducting paint used in the electronic industry for printed circuits. When the paint was dry the prisms were vacuum saturated with an exactly five percent sodium chloride solution (i.e., $50 \mathrm{~g}$. per liter). The apparatus used was that described under the section on the determination of absorption. The samples were allowed to stay innersed for only about an hour, however, rather than for the $23 \mathrm{hr}$. used in the regular vacuum saturation procedure. Each prism was then removed from the solution, was blotted dry on a cloth moist with the solution, and its resistance was measured rapidly. After the resistance was measured the sample was weighed rapidly on a preset balance. The instrument used for the resistance measurements was a Bouyoucos portable bridge operating at 2000 cycles with an auditory indication of the balance point.

* Wood and Metal Products Co., Bloomfield Hills, Lichigan. 
The resistance of an equal-sized volume of the pure solution ras calculated from the measured dimensions and the specific conductance at the appropriate temperature which was obtained from tables (33 p. 1967).

The ratio of these resistances was the formation factor at the measured saturation. Using an exponent of 2 in equation (15) the resistivity index was calculated and the formation factor for complete saturation was obtained using equation (14). The tortuosity was then calculated from equations (II) or (12). A reversal of these calculations gives the tortuosity applicable at any other saturation.

The errors most likely to be influential in affecting this determination (assuming the equality of flow path with current path) are involved in the choice of the value for the exponent $n$. An analysis of the error involved in this choice is given in Appendix $\dot{A}$.

\section{Permeability}

Permeability refers to the ability of a solid to permit passage of a fluid.

By far the greatest anount of work on the methods of measurement of permeability, its theoretical interpretation, and its use has been done in the two fields of soil mechanics and petroleum technology. For rocks, the publications in the latter field are especially valuable and were the starting point for the present work on the question.

The quantitative relationship between the factors involved in permeation under viscous flow conditions is known as Darcy's law, and was found empirically to be 


$$
u_{a}=K_{i} 1
$$

where $u_{a}=$ approach (or discharge) velocity

$$
\begin{aligned}
& \mathrm{K}_{1} \quad=\text { permeability or transmission coefficient } \\
& i \quad \text { a hydraulic gradient. }
\end{aligned}
$$

I'he approach velocity 1 s the ratio of the volume rate of flor to the total approach area and the hydraulic gradient is the loss in total head per unit macro length of flow path. $K_{j}$ in this expression depends on the properties of both the solid and the fluid. in altemate and more frequently-used expression defines a quantity called the specific permeability, but herein called simply the permeability, which is independent of the properties of the fluid. This altermate form of Darcy's law is

$$
u_{a}=\frac{K \nabla P}{\eta}
$$

where $K=\operatorname{spec} 1 f$ ic permeability

$$
\begin{aligned}
\nabla P & =\text { hydraulic gradient in pressure units } \\
\eta & =\text { viscosity of fluid. }
\end{aligned}
$$

Darcy's law is discussed in detail in Nuskat's book (55).

Various units are possible for the permeability and transmittion coefficient. $K_{i}$ in equation (16) has the dimensions of a velocity and the units in most common use arz crn./sec. and $\mathrm{ft} . / \mathrm{sec}$. $K$ in equation (17) has, if c.g.s. units are used, the dimensions of an area, and the square centineter is the unit of specific permesbility. It 1s, however, such a large unit that a smaller one is frequently used. This is the millidarcy (md.) which is one thousandth of a darcy which is, in turn, the unit for $K$ if the pressure gradient is expressed in 
atmospheres/cm., the viscosicy in certipoises, and the relocity in crn./sec. Most soil permeability work has been done in terns of ch./ sec., most on concrete in $\mathrm{ft.} / \mathrm{sec}$, and most on petroleum-bearing rocks in terns of $\mathrm{md}$. If one assumes water at $25 \mathrm{C}$ to be the permeating fluid (viscosity $=0.394 \mathrm{cp}$. ) ther the various unlis have the following relationship:

$1 \mathrm{~cm}^{2}=(1.013)\left(10^{11}\right) \mathrm{mo} .=(1.097)\left(10^{5}\right) \mathrm{cm} . / \mathrm{sec} .=(3.50)\left(10^{3}\right) \mathrm{ft} . / \mathrm{sec}$.

The determination of permeability invoives a inouledge of the various quantities in equation (1\%), i.e., the flow rate, the dinensions of the sample, the viscosity of the fluid, and the pressure differential causing the mow. The measurement of permeability is discussed in Muskat's boo' (55) and apparatus that his been used on concrote is shown in papers by Kuettgers, Vidal, and Wing (70) and by Cook (2I), that used on cement paste by Powers et al. (6I), and 0.1 soil by Larnbe (4?).

With cement paste, concrete, and soil it is necessary to use water as the permeant because for the use of gases the solid rust be dry and such a drying operation would so seriously change the properties of the materials that the permeability value obtalned would be meaningless. For material not harmed by dryins, however, the lise of gases is to be preferred for permeability measurements on dense samples because of the shorter time and the lower pressure gradients involvod in the test. In such experiments the volume flow rate of the gas far use in equation (17) mast be that at the mean pressure acyoss the sample $(55$ p. 77$)$. 
On samples of comparatively high permeability (e.g•, open bandstones) the results from gas and lizuid measurements are in clos? agreement. With samples of lower permeabili.ty, however, the values obtained with gases are generally higher than thase oltalned using li.quids (26). The reason for this discrepancy was first given by Klinkenberg (40). The permeability coefficient in equation (17) is constent only if one assumes viscous flow of the gas. When the mean Free path of the gas becomes appreciable with respect to the size of the channels through which it is flowing the viscous-flow assumption of zero gas velocity at the tube wall no longer holds and the gas begins to "slip" past the tube walls. This has been know for some time and is discussed in texts on the kinetic theory of gases (48). The slip contributes an additional component to the velocity beyond that of viscous flow and this component becones appreciable at low pressures and/or when the channels are extremely small. The result of this slip component is a higher value for permeability yhich is no longer pressure independent. Based on the laws of slip flow, Klinkenbers derived the erpation

$$
K=K_{I}\left(1+\frac{b}{P_{m}}\right)
$$

where $K_{1}=$ a constant

$$
\begin{aligned}
& K \quad=\text { measured permeability } \\
& P_{m}=\text { mean pressure across sample } \\
& b \quad=\text { slip factor. }
\end{aligned}
$$

This is the equation of a straight $l$ ine of $K$ as a function of $\frac{1}{P_{m}}$ whose slope is $K_{1} b$ and whose intercept is $K_{1}$. Klinkenbers showed that $b$ is 
related to the properties of the solid and tre fluid and that, theoretically, $K_{I}$ should be the permeability value that rould be obtaired if slip were not present, i.e., the permeability to liquids. His experiments confirmed this hypothesis and it will be assumed henceforth here that $K_{I}$ is the jrossure-independent, liquid jermeability of tne solid. The liquid permeability reported for the rocks in this study was determined by measuring the apparent permesbility, $k$, 39 a function of the reciprocal mean pressure and detemining the intercept of the plot.

In making gas permeability messurements the floiv rate can be measured by collecting the outlet gas, by using a capillary-tube or orifice flowmeter, or, for lower flow rates, some device such as the soap-bubble flometer described by Bonillas (12), all of winch leave something to be desired for dense samples.

The apparatus used in making the permeability measurements in this wor's is shom in Figure 4. It is $\mathrm{sn}$ adaptation of that of Amezl (3). Rigden (69) and Kamack (38) also used the same principle for their experiments. The principle of the apparatus is that tine flow rate is measured by following the decay of a pressure difierential imposed across the sample. A knowledge of this decay riste, the sample dimensions, and certain apparatus constants permits the calculation of the permeability.

The operistion of the apparatus was as follows. The oven-dry prism of rock was first coated on its sides (spejising in teras of the flow experiment) with a hard asphalt cement (penetration of about 10). The asphalt was melted and then buttered on the sides of the pris= witir a small spatula. A thin, evan, coat was applied and smoothed with 


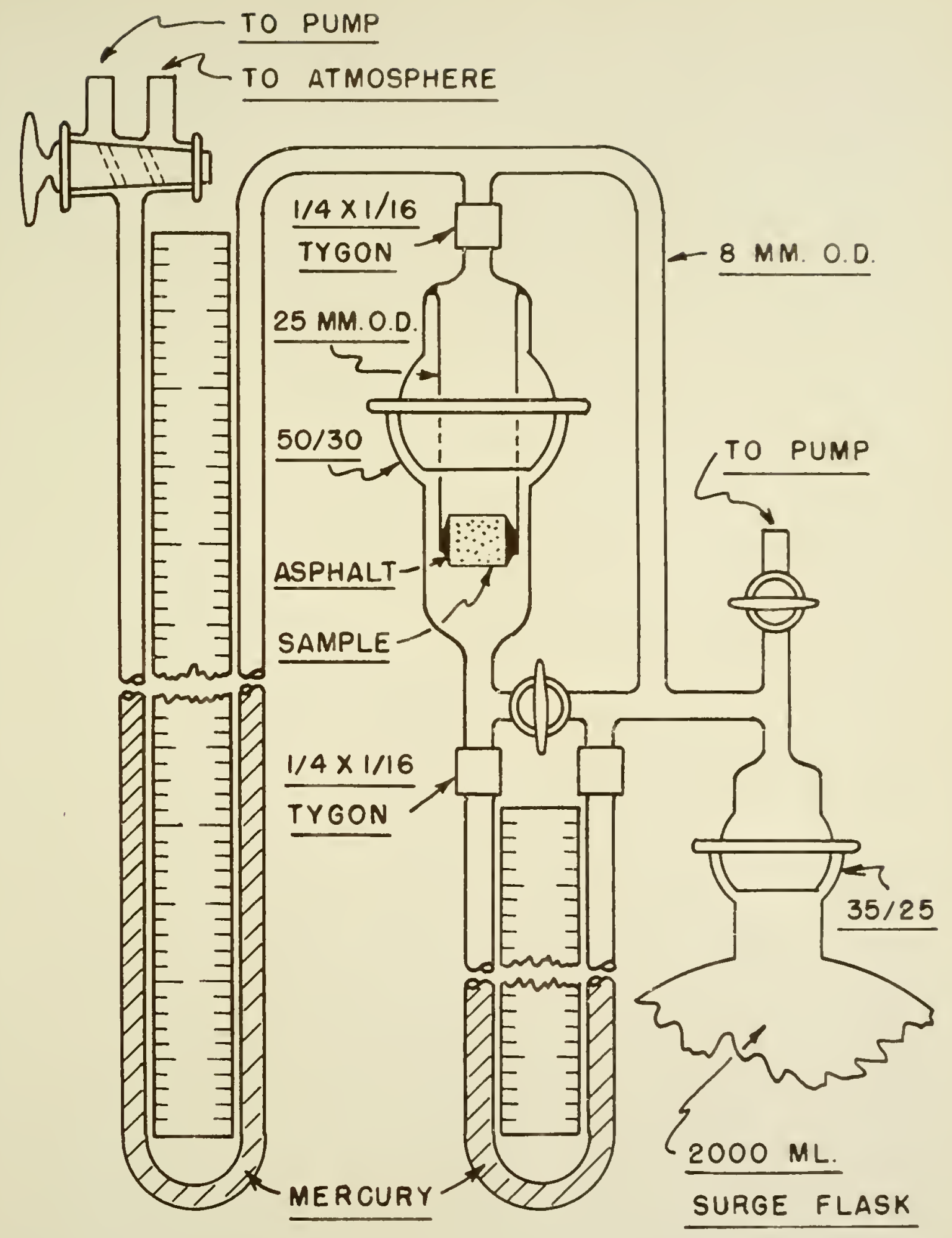

FIG. 4 PERMEAMETER 
the hot spatula. Final smoothing was done by brushing with a bumer flame. The sample was then placed in position in the holder and sealed in place with a ring of the same asphalt cement. The ring was made as thick as possible to achieve considerable strength. Final smoothing of the outside (the part protmiding from the tube) of the ring was done by brushing with a flame. The asphalt was allored to harden for several hours. The sample holder was then placed in position, the $50 / 30$ ball and socket joint was clamped, and the unit ras connected by means of the Tygon joint. The left leg of the large manometer was evacuated to give a direct reading of the pressure. With tho bypass stopcock open, the stopcock at the surge tank was opened to pump and the system was pumped dom to the high pressure desired. This pressure was, obviously, atmospheric or anything less. At this point the bypass stopcock was closed and the pumping was continued until the desired pressure differential was attained as shown by the differential manometer across the sample. The stopcock at the surge flask was then closed and the pressure differential was allowed to decay as the air flowed through the sample. The differential manometer was read with a magnifier and the rate of decay was followed with the aid of an electric stopwatch reading in hundredths of a minute. The time for the run varied approximately from one minute to half an hour depending on the permeability. Measurement of the pressure on the larpressure side of the sample was made by reading the long manometer, and measurement of the temperature of the system with an adjacent thermom eter completed the data needed. The decay curve is not, of course, 3 straight line but it was possible to take readings over an interval of 
head loss of about one centimeter of $\mathrm{Hg}$ and thus to avold drawing the curve for each run. The curve, in othor words, was considered to be straight between points whose difference in magnitude was of the given order.

The equation used to calculate the permeability was

$$
\begin{aligned}
& K=\frac{\eta L(1.013)\left(10^{11}\right)}{\Delta P A P_{m}(1.333)\left(10^{4}\right)(60)}\left(\frac{d h}{d t}\right)\left(V_{h}+\frac{A_{t} h}{2}+\frac{A_{t} P_{h}}{2}\right) \\
& \text { where } K=\text { permeability, md. } \\
& \eta \quad=\text { viscosity of gas, poise } \\
& \text { L = specimen length, } \mathrm{cm} \text {. } \\
& \mathrm{A} \quad=\text { specimen approach area, } \mathrm{cm}^{2} \\
& A_{t}=\text { area of iifferential menometer tube, cr. } 2 \\
& \begin{aligned}
V_{h}= & \text { volume of the high pressure side of the syster } \\
& \text { down to the equilibrium position in the differ }
\end{aligned}
\end{aligned}
$$

and, with respect to a certain small (in terms of head change) interval in the decay process and to the midpoint of this interval,

$$
\begin{aligned}
& P_{h}=\text { high pressure on sample, cm. Hg } \\
& P_{n} \quad=\text { mean pressure on sample, cm. } \mathrm{Hg} \\
& h \quad=\text { height difference on differential manometer, cm. } \\
& \Delta P \quad=\text { pressure differential across sample, } \mathrm{cm} . \mathrm{Hg} \\
& \mathrm{dh} / \mathrm{dt}=\text { time rate of change of } \mathrm{h}, \mathrm{cm} . / \mathrm{min} .
\end{aligned}
$$

$\Delta P$ and $h$ are numerically equal if mercury is used and the rate of change of head can be taken, as mentioned above, to be the head loss divided by the tine interval, i.e., $d h / d t=\Delta h / \Delta t$.

The derivation of equation (19) and an explanation of the deter mination of the values of $V_{h}$ and $A_{t}$ are given in Appendix $B$. 


\section{Absorptivity}

A special type of permeation is that in which the drivine pressure is the capillary pressure at the meniscus as the liquid proceeds through the solid. Capillary pressure exists by virtue of the curvature of the meniscus and the presence of surface free energy and is Lnversely proportional to the size of the channel in question.

Much vrork has been done on the question of capillary absorption with reference to soils because of the connection of these matters with agriculture and with soil mechanics. Comparatively little has been done on the capillary dynamics of stone in general and aggregates in particular.

The coefficient of absorptivity, or the absorptivity for short, is defined here after Powers and Brownyard (60 p. 865) by

$$
\frac{V^{2}}{A^{2}}=K_{a} t
$$

where $V=$ volume of liquid absorbed

$$
\begin{aligned}
& A=\text { macro or approach area } \\
& t=\text { time elapsed from start of absorption } \\
& K_{a}=\text { absorptivity coefficient. }
\end{aligned}
$$

The absorptivity of the samples was measured in the following ray. The prism was taped on the sides with "Scotch" brand* plastic electrical tape. This operation was done carefully. The tape was placed so that the sides were completely covered and the covering was pressed firmly into place to form the best-possible seal. Special care was 
taken to seal the places where the tape overlappod. Sevoral layers of filter paper were then placed on the desk top and wettsd thoroughly with distilled water. A water supply was arranged through a cloth wick into an adjacent beaker filled with water. The surface of the paper under these circumstances was quite wet but not sloppy and, it is assumed, was essentially a free-water surface. The taped prism ras then placed firmly on this wet surface and an electric stopratch was started simultaneously. At certain arbitrary tine intervals the stopwatch was intermpted and the prism was removed from the filter paper, blotted surface-dry on a damp cloth, and weighed. The balance was pre-set and magnetically damped so the weighing took only around twenty seconds: The sample was then replaced on the wet filter paper and the stopwatch started again. The first weighing was usually made two minutes after the start of the run and subsequent ones were made every few minutes up to around twenty minutes. After this the intervals became progressively longer as the rate of absorption decreased. The test was continued until capillary absorption had sensibly stopped. Some small weight gain continued, even at this point, to be recorded but it is assumed that this gain was due to diffusion and not to capillarity.

The data were plotted on $\log -\log$ paper, $V / A$ as ordinate against $t$ as abcissa. From this plot the absorptivity and capillary saturation were determined.

This technique for the determination of absorptivity is extremely simple. There are, however, possible objections. First of these is the surface-drying method. This is discussed in the section on absorp- 
tion. Secondly, there is the possibility of moisture moverent durinz the weighing operation. Lioisture will be dram to the more inelyporous part of a body both by capillarity because of the larger capillary pressure in the smaller pores and by vapor diffusion due to the lower vapor pressure in the smaller pores. The latter procoss is slon at the small vapor pressure differentials (a few ma. of $\mathrm{Hg}$ ) involved. The caplllary redistribution is also thought to be slav under tine small capillary pressure differentials invalved when no free water source is present. At any rate, no discontinuities were observed in the curves at the data points. The third possible source of error involves temperature control. Both the surface tension and the riscosity of the liquid enter into the calculations. These properties are functions of temperature and even though the ratio of the two is used in the calculations the coefficients are not compensating and the ratio is also a function of temperature. Therinostating seened to promise small help because the free-water surface was cooled by evaporation. The resultant compronise was that the measurements were made when the room temperature was such as to make the water temperature on the free surface about $25 \mathrm{C}$ and this value was assumed for 311 muns.

\section{Calculations}

All calculations in this work were performed on a slide rule with the exception of those for which it was necessary to have more tinan three significant figures. The latter were perforwed on a calculator. 
Density, Porosity, Absorption, and Saturation

In Table 3 are presented the results of the calculations for true and bulk density, porosity, absorption, and the corresponding saturations. The porosity was calculated fron the voids ratio by means of equation (6). The voids ratio was calculated using equation (5), the value of $V_{V}$ obtained with the McLeod gauze porosimeter, and the value of $V_{s}$ obtained with the volumenometer. The bulk densities were calculated by means of equation (7). In other words, the values for bulk and true density, porosity, and voids ratio all vere derived basically from values for solid and void volumes. The one exception to the above are the values for the source 3-IS-H. As mentioned previously, only small prisms of this rock were available so the bulk volume ras calculated from the dimensions, the vold volume was obtained from the porosimeter experiment, and the porosity was calculated from equation (4) and the true density from equation (7).

\section{Tortuosity}

In Table 4 are given the measured and calculated formation factors and tortuosities. $F_{e}$ is the formation factor obtained from the resistance data and $S_{w r e}$ is the corresponding saturation. F is the formation factor calculated therefrom. The tortuosities rarked $k_{t}$ and $k_{t \alpha}$ are the calculated tortuosities, according to iiyllie and Rose (i.e., $F^{2} \epsilon^{2}$ ), at complete saturation and at the saturation obtained in the absorptivity experiments respectively. Those marked $\tau$ and $\tau_{\alpha}$ are the 


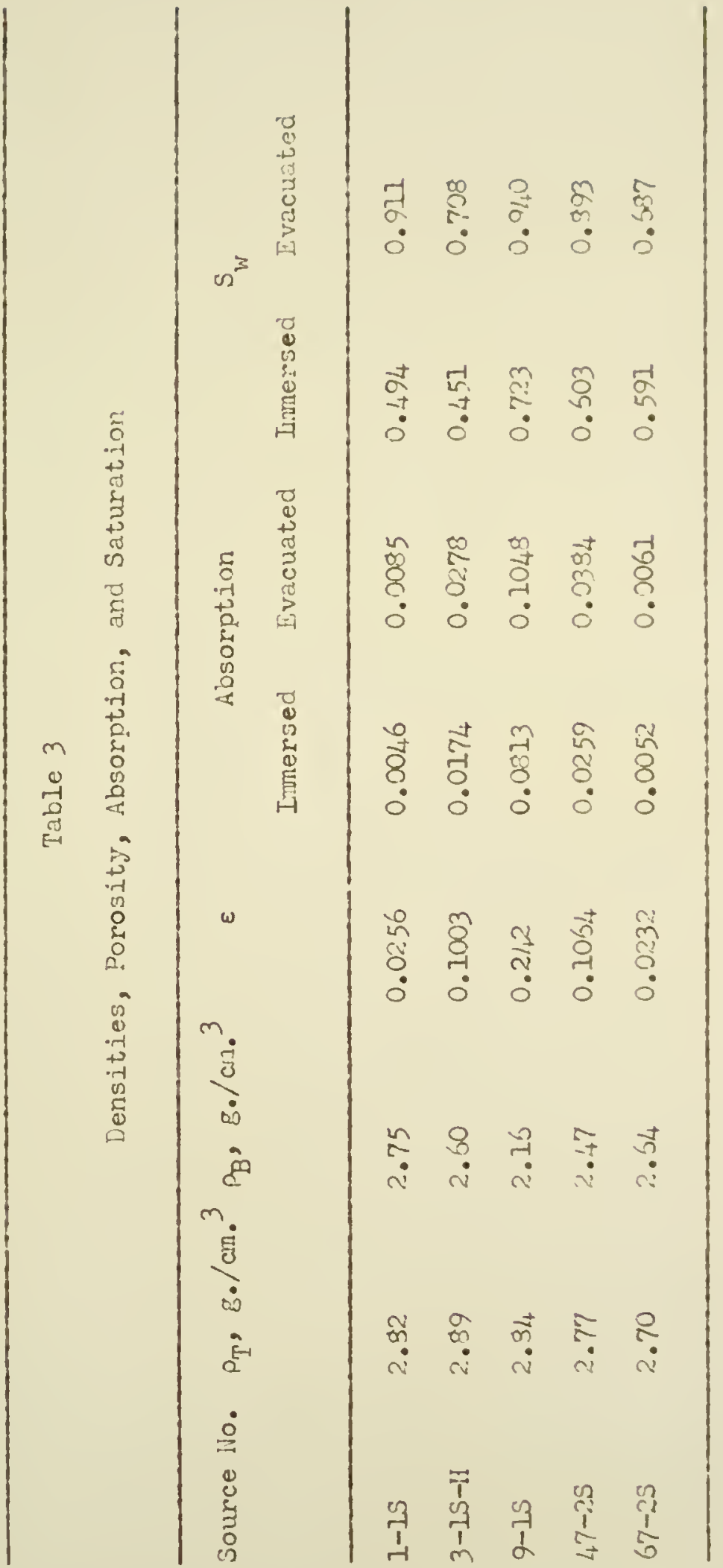


correspondine Cornell and Katz tortuosities (i.e., F $€$ ). The equations used in calculating the formation factors and tortuosities at other than the measured saturations are equations (11) through (15) w1th the exponent $\mathrm{n}$ taken to equal 2.

Table 4

Tortuosities and Associated Factors

\begin{tabular}{lcccccccc}
\hline Source No. & $F_{e}$ & $S_{\text {we }}$ & $F$ & $k_{t}$ & $k_{t_{\alpha}}$ & $\tau$ & $\tau_{\alpha}$ \\
\hline $1-1 S$ & 7070. & 0.329 & 765. & 384. & 2245. & 19.6 & 47.3 \\
3-1S-H-p & 158. & 0.708 & 79.1 & 63.1 & 174. & 7.95 & 13.2 \\
9-1S & 15.8 & 0.910 & 13.1 & 10.0 & 18.7 & 3.16 & 4.32 \\
$9-1 S-p$ & 16.6 & 0.945 & 14.8 & 11.3 & 28.4 & 3.36 & 5.33 \\
47-2S & 107. & 0.841 & 76.0 & 65.5 & 176. & 8.09 & 13.3 \\
$67-2 S$ & 1704. & 0.427 & 317. & 54.1 & 176. & 7.35 & 13.3 \\
\hline
\end{tabular}

The notation "p" after a source number indicates that the direction of the flow (of electricity or fluid) was parallel to the laminations of the specimen. The laminated rocks were 3-15-H and 9-1S. The former was tested only in the parallel direction and the latter was tested both parallel and perpendicular to the laminations in order to indicate the effects of this variable.

The values for the source $1-1 \mathrm{~s}$ should be regarded as the rost uncertain in the group. Difficulty was experienced in measuring the resistance values of this sample. The other rocks had resistances which checked well in repeated measurements. But the resistance values 
on the 1-1S sample had a large scatter (extremes of $80-120 \%$ of the average). This performance was puzzling in vievi of the close checks with the other rocks and the only explanation that can be offered is that, with this very high tortuosity, any slight reorientation of the conducting fluid from mun to mun would have a large effect on the measured resistance.

\section{Specific Surface}

Figure 5 shows the data obtained in the sorption tests in the form of conventional isotherms. These data were then plotted linearly, according to equation (9). The equation vias solved graphically for $V_{m}$ and $C$ and the $V_{m}$ values were converted to specific surface by means of

$$
s_{g}=\frac{a_{1} V_{m} N}{M}
$$

$$
\begin{aligned}
& \text { where } \begin{aligned}
a_{1} & =\begin{array}{l}
\text { area of surface occupied by one molecule of } \\
\text { sorbate }
\end{array} \\
\mathrm{N} & =\text { Avogadro's number } \\
\mathrm{H} & =\text { molecular weight of sorbate. }
\end{aligned}
\end{aligned}
$$

The value used for $a_{1}$ was $(10.6)\left(10^{-16}\right) \mathrm{cm}^{2}(60$ p. 489). The values so obtained for the specific surfaces of the various rocks are given in Table 5. The values for the individual runs are given together with their average. Although the information does not apply directly to this study, it may be noted that the values for $C$ ranged about fram four to eight.

\section{Permeability}

The permeability was calculated from the decay flow data by means of equation (19). The values obtained for the rocks are plotted against 


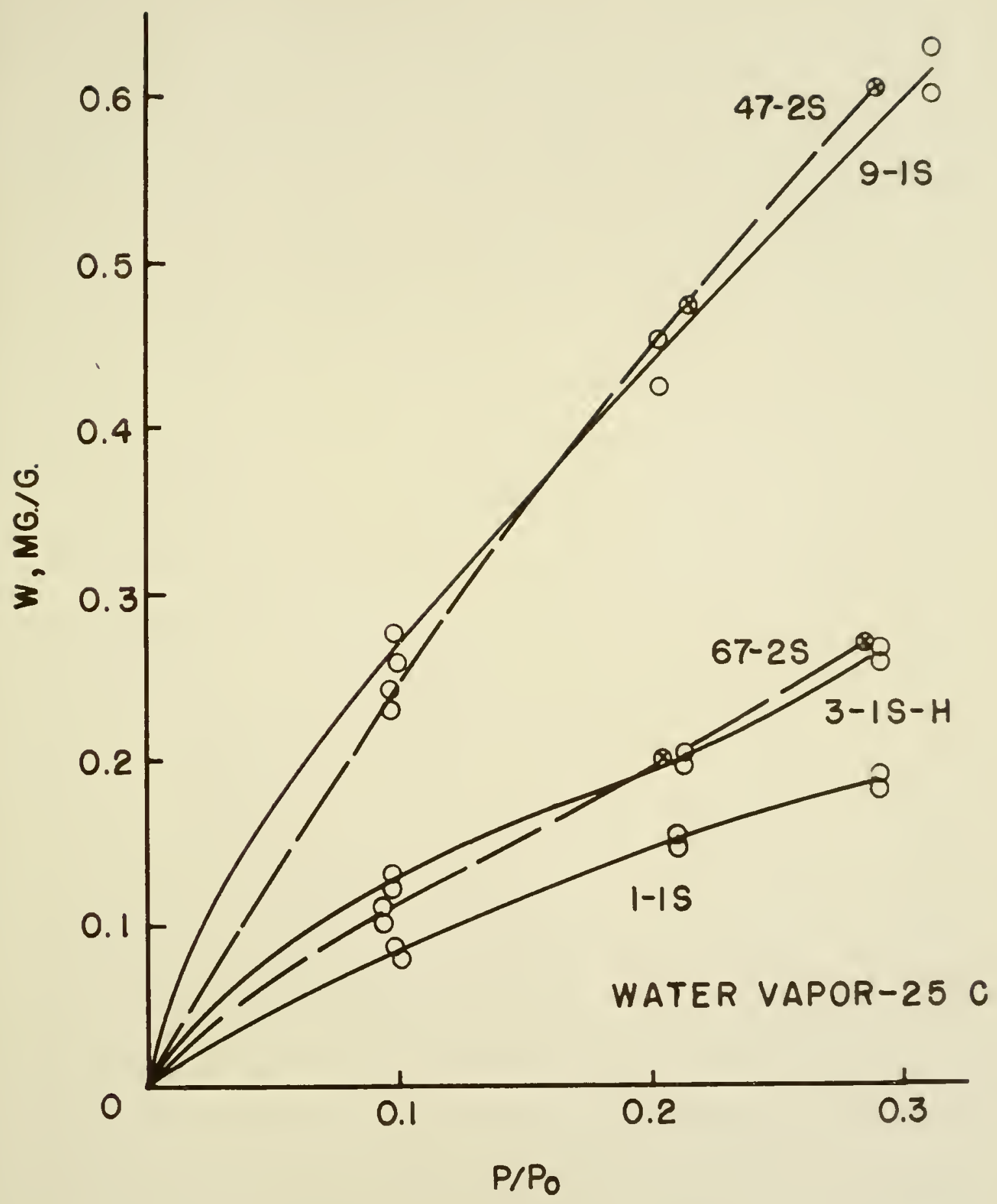

FIG. 5 
the reciprocal mean pressures in Figures $6-12$.

Table 5

Specific Surfaces

Source No.

$s_{g}, m \cdot 2 / g$.

Avg.

$\begin{array}{lll}1-1 S & 0.68,0.66 & 0.67 \\ 3-1 S-4 & 0.88,0.86 & 0.87 \\ 9-15 & 2.02,2.06 & 2.04 \\ 47-2 S & 2.44,2.65 & 2.54 \\ 67-2 S & 1.06,1.11 & 1.09\end{array}$

Straight lines were drawn through the data. This was done by least squares in the case of 1-1S but for all others the lines vere drawn by eye. The latter procedure was used because the data, vith the exception noted, fit a straight line very closely.

The slopes and intercepts were then obtained from the curves and put in the form of a Klinkenberg equation (equation 18). The inter cept permeability to liquid, $K_{I}$, and the $b$ factor of the Klinkenberg equation are tabulated in Table 6. Also given is a value labelled $\mathrm{pK}_{1}$ which is the logarithn of the reciprocal of the permeability expressed in $\mathrm{cm}^{2}$. This notation is introduced as a convenient way to indicate permeability when wide variations are encountered and it will be used later when comparisons are made.

It will be noted that Figures 6 and 12 show one data point each which is farther from the curve than is accountable to experimental 


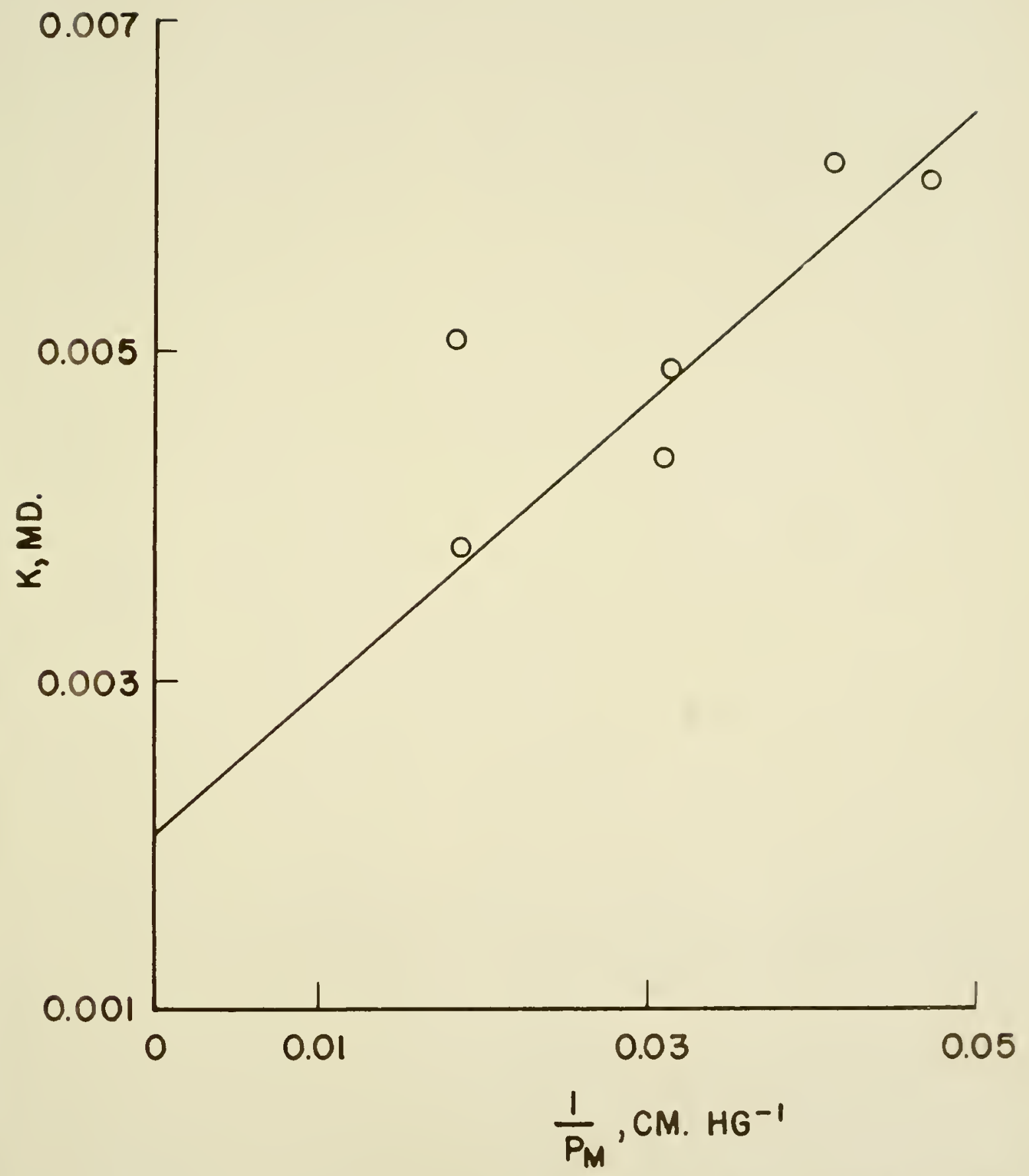

FIG. 6 PERMEABILITY OF 1-IS-P-37 


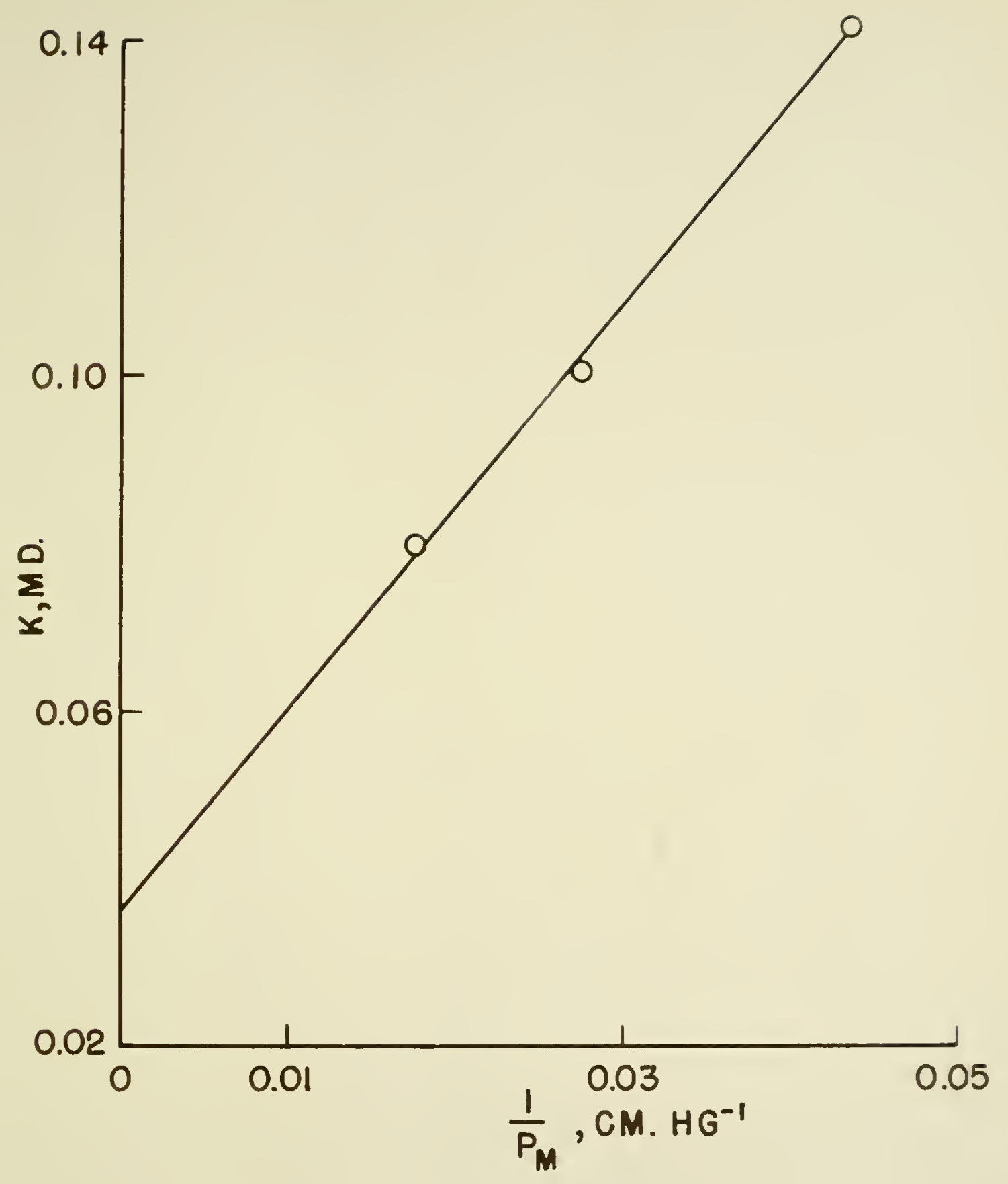

FIG. 7 PERMEABILITY OF $3-1 S-H \cdot P \cdot 80_{P}$ 


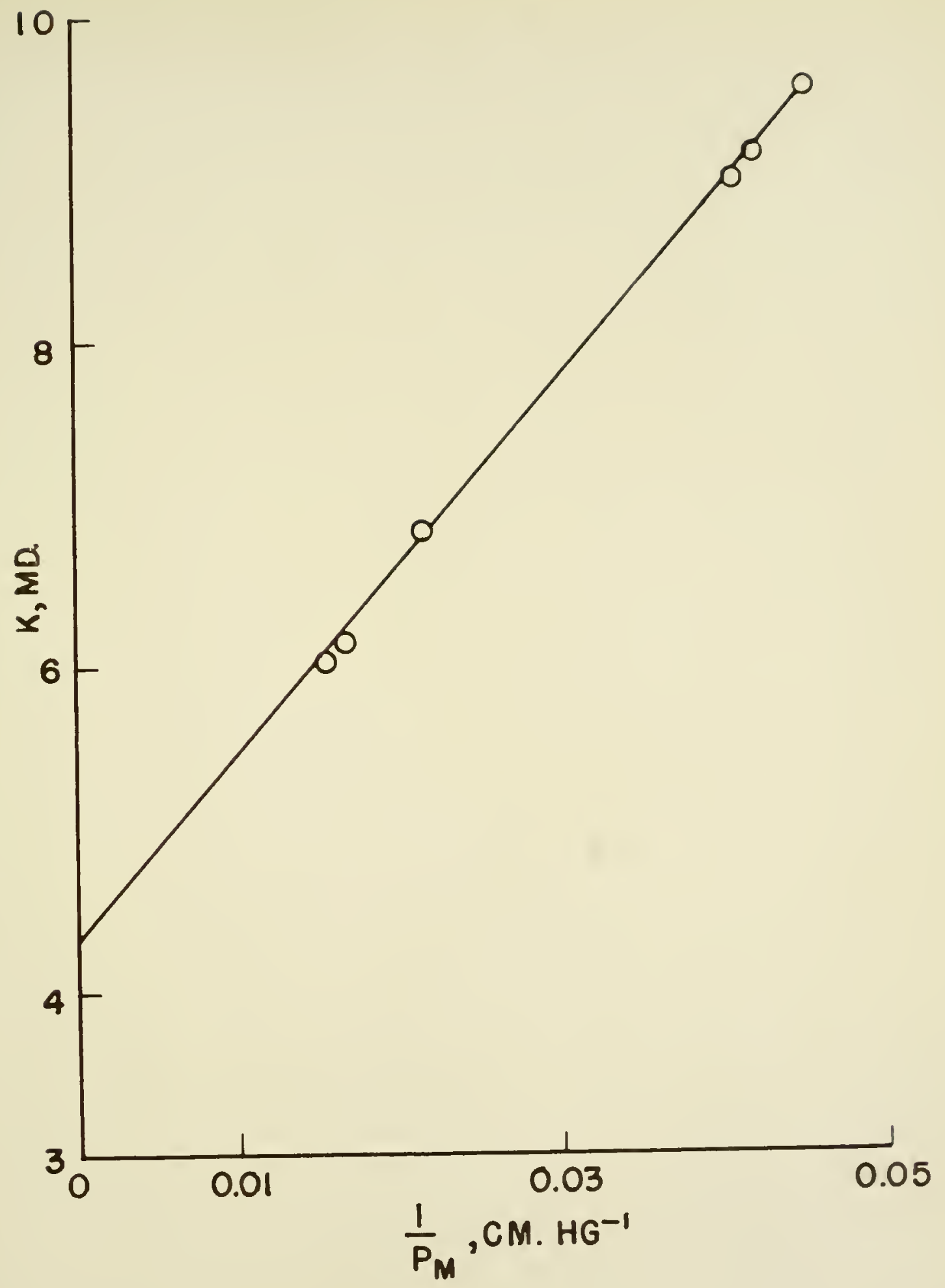

FIG. 8 PERMABILITY OF $9-1 S-P-78$ 


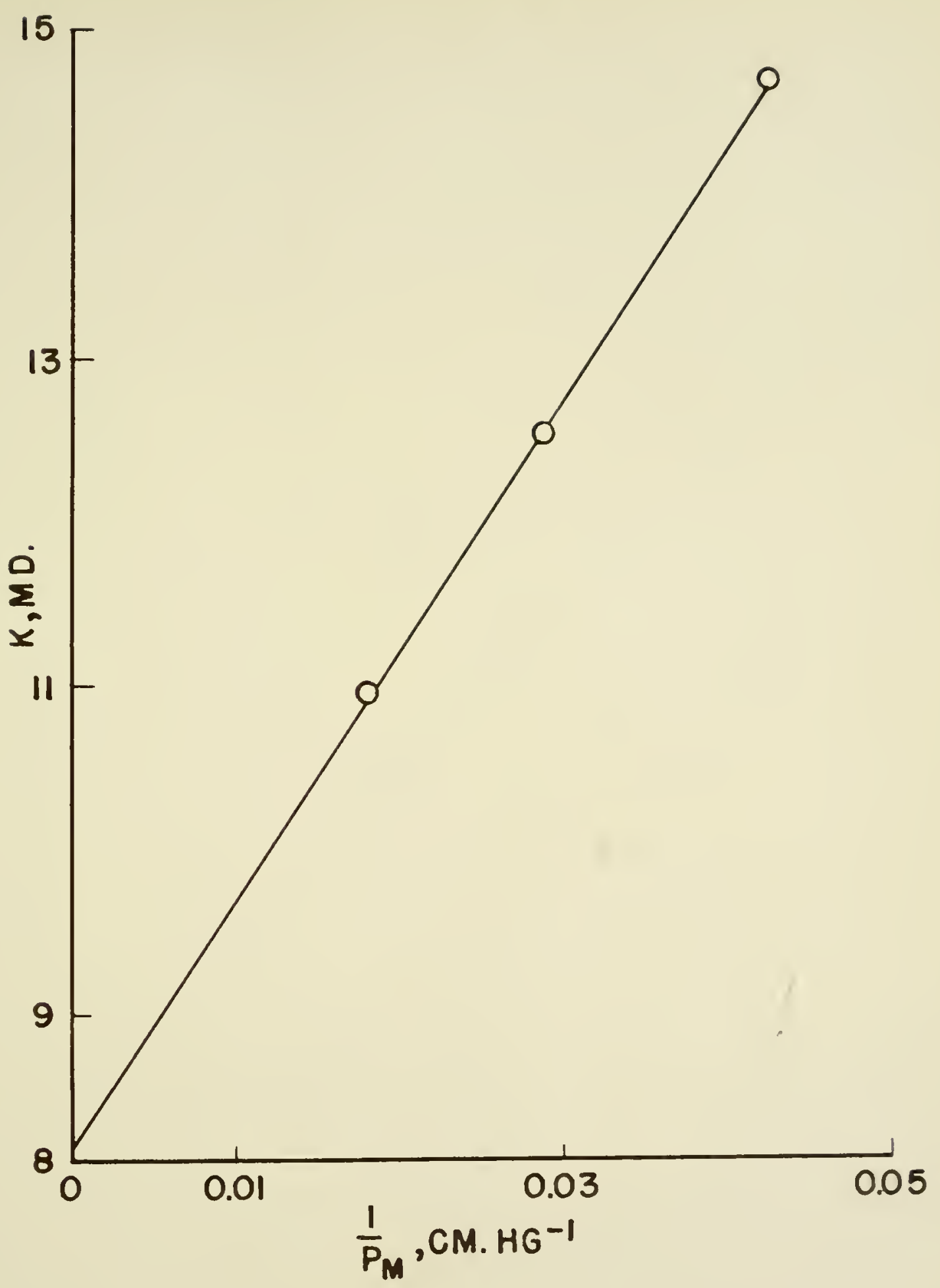

FIG. 9 PERMEABILITY OF 9-IS-P-54p 


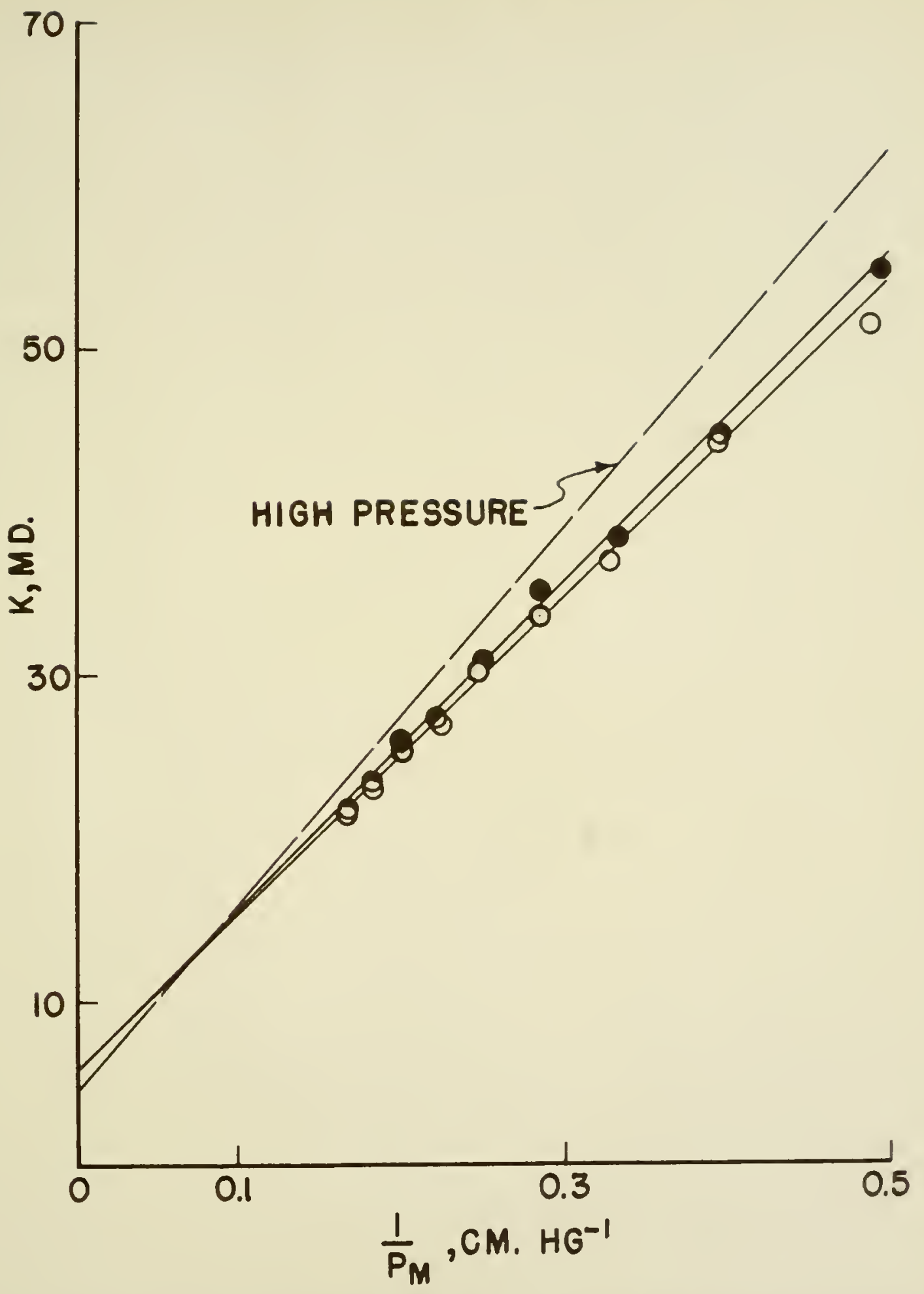

FIG. 10 PERMEABILITY OF 9-1S.P.78 LOW PRESSURE RUNS 


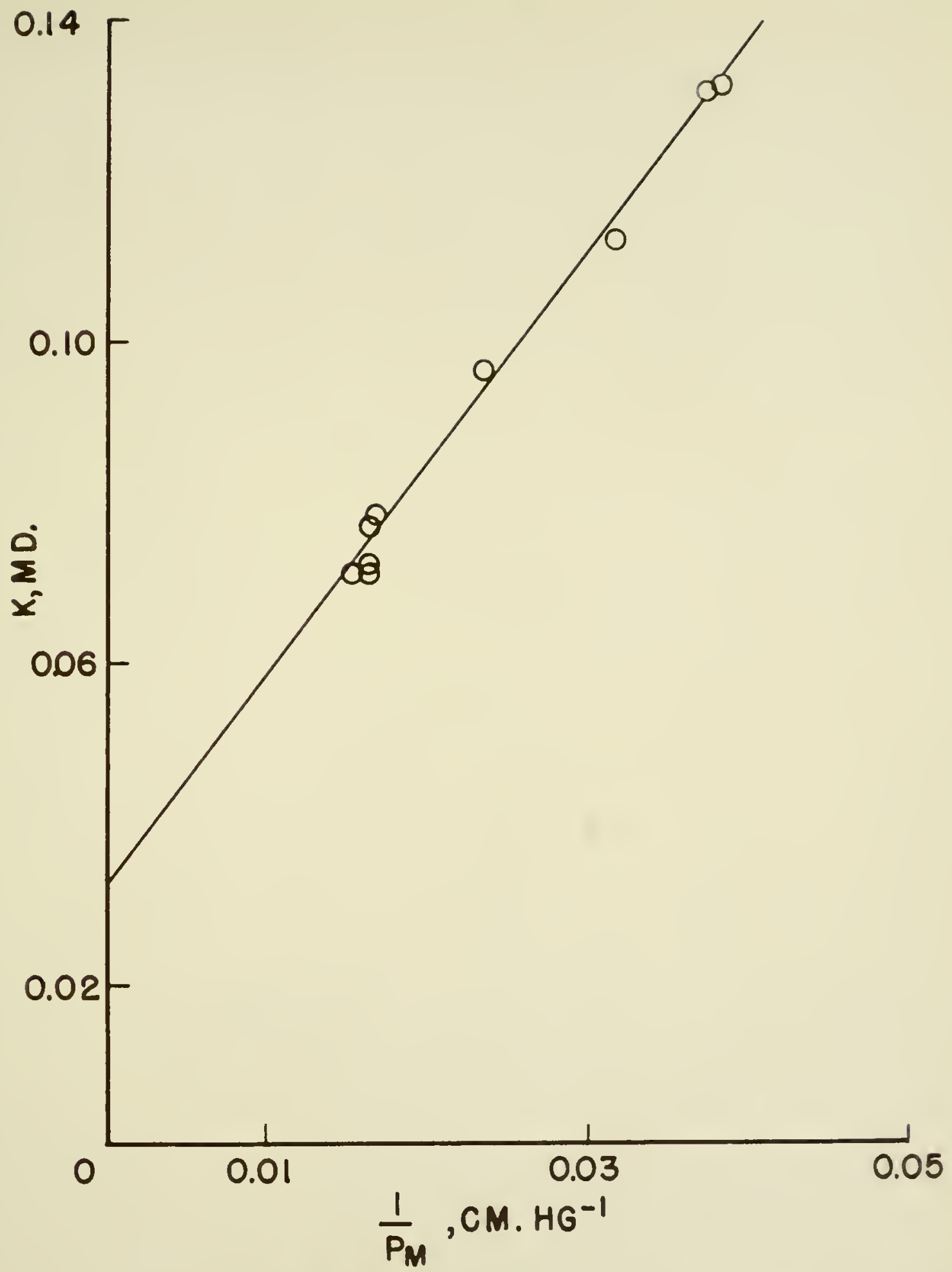

FIG. II PERMEABILITY OF 47-2S-P-98 


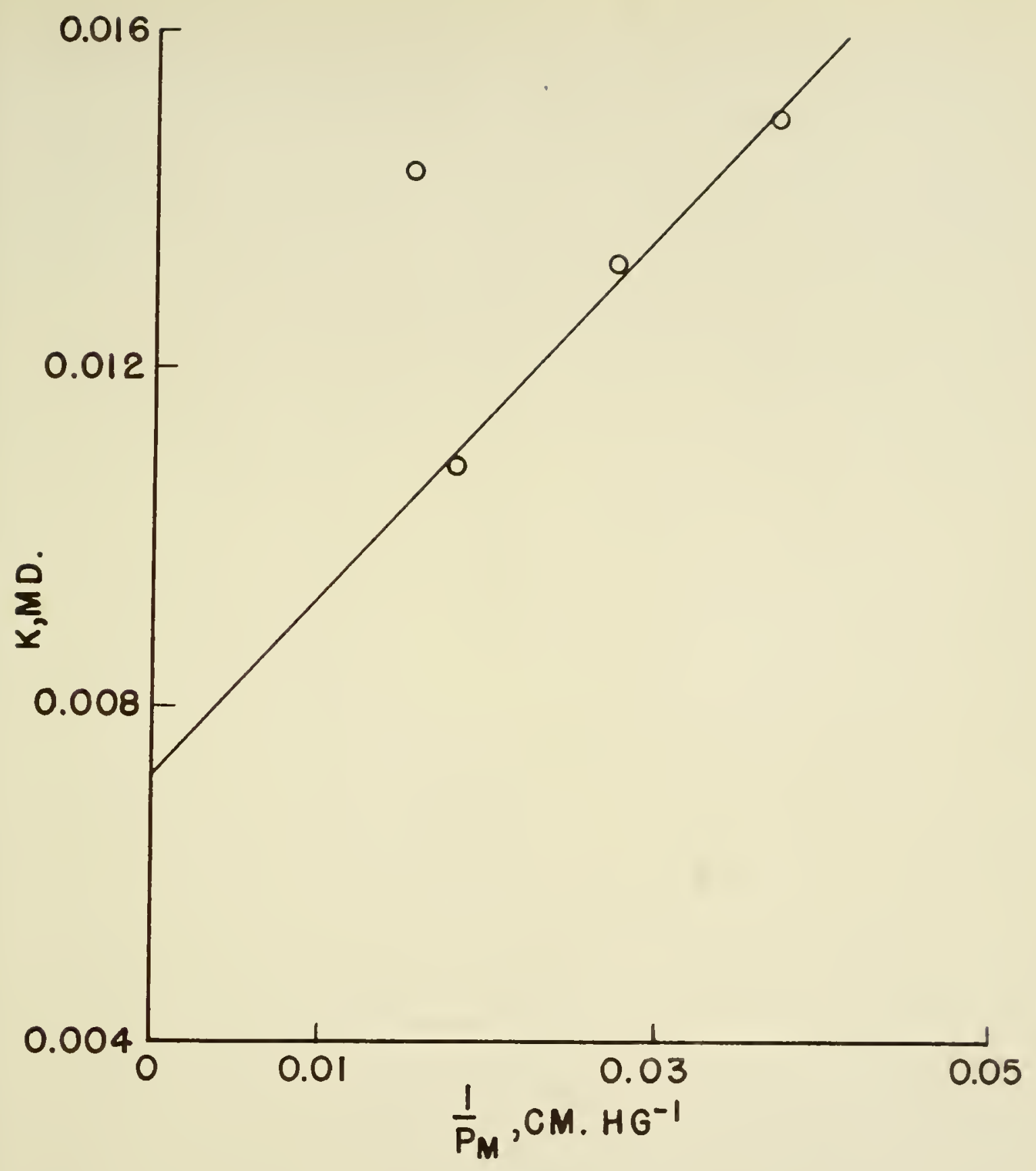

FIG. 12 PERMEABILITY OF $67 \cdot 25 \cdot P \cdot 45$ 
error. In each instance these are the first runs made on the sample and the only explanation that can be offered is that of "starting up" errors.

Table 6

Permeability and slip Factor

\begin{tabular}{cccc}
\hline Source No. & $K_{I}$, md. & $\mathrm{pK}_{I}$ & $\mathrm{~b}, \mathrm{cm.}+\mathrm{s}$ \\
\hline I-IS & 0.00205 & 13.694 & 43.2 \\
$3-1 S-\mathrm{H}-\mathrm{p}$ & 0.036 & 12.449 & 66.9 \\
$9-1 S$ & 4.30 & 10.372 & 26.9 \\
$9-1 S-\mathrm{p}$ & 8.16 & 10.094 & 18.6 \\
$47-2 S$ & 0.032 & 12.500 & 82.5 \\
$67-2 S$ & 0.0072 & 13.148 & 29.7 \\
\hline
\end{tabular}

Figure 10 shows the results of two low-pressure runs. The crosses are taken from adjacent intervals of one decay cumve and the circles from another. At higher pressures this same calculation can also be made but the resultant points are relatively close togetiner and cannot be used to define the line. It was thought that, by this means, perhaps only one run would suffice to define the entire line. The higher pressure curve shom is that of Figure 8 for the sarte sarple. The agreement is fair but a discrepancy exists, especially for the slope, and the idea was abandoned for this study. 


\section{Absorptivity}

The $\log -\log$ plots of $\mathrm{V} / \mathrm{A}$ vs. $t$ for the capillary absorption runs are given in Figures 13 - 19. The data were such that straight lines could be draw satisfactorily by eye in all cases except that of 1-2 (Figure 13). This one was done by least s,uares. The values obtalned from the curves are given in Table 7. A comparison of the curves with equation (20) shows that the square of the intercept at $t=1 \mathrm{mLn}$. is the absorptivity coefficient in $\mathrm{cm}^{2} / \mathrm{m}$ n. Division by 60 gave the value in $\mathrm{cm}^{2} / \mathrm{sec}$, which is the unit for the $k_{\mathrm{a}}$ values in Table 7 . The logaritun of the reciprocal of this value, $\mathrm{pK}_{\mathrm{a}}$, is also given.

Table 7

Absorptivity Results

\begin{tabular}{lllll}
\hline Source No. & $\mathrm{K}_{3}, \mathrm{~cm}^{2} / \mathrm{sec}$ & $\mathrm{pK}_{\mathrm{a}}$ & $\alpha$ & $\mathrm{S}_{\mathrm{wa}_{\alpha}}$ \\
\hline I-IS & $3.74 \times 10^{-9}$ & 8.427 & 0.0106 & 0.413 \\
$3-1 \mathrm{S-H-p}$ & $1.22 \times 10^{-7}$ & 6.913 & 0.0504 & 0.602 \\
$9-1 \mathrm{~S}$ & $1.82 \times 10^{-5}$ & 4.739 & 0.1770 & 0.731 \\
$9-1 S^{\prime} \mathrm{p}$ & $6.00 \times 10^{-5}$ & 4.221 & 0.1629 & 0.573 \\
$47-2 S$ & $6.62 \times 10^{-7}$ & 6.179 & 0.2650 & 0.010 \\
$67-2 S$ & $9.89 \times 10^{-9}$ & 8.004 & 0.0129 & 0.554 \\
\hline
\end{tabular}

The values marked $\alpha$ are considered to be the effective porosities applicable to the capillary process, i.e., the volune of capillary permeant per unit bulk volume of material when capillary equilibriun was reached. The values marked $S_{w \alpha}$ are the corresponding saturations. 


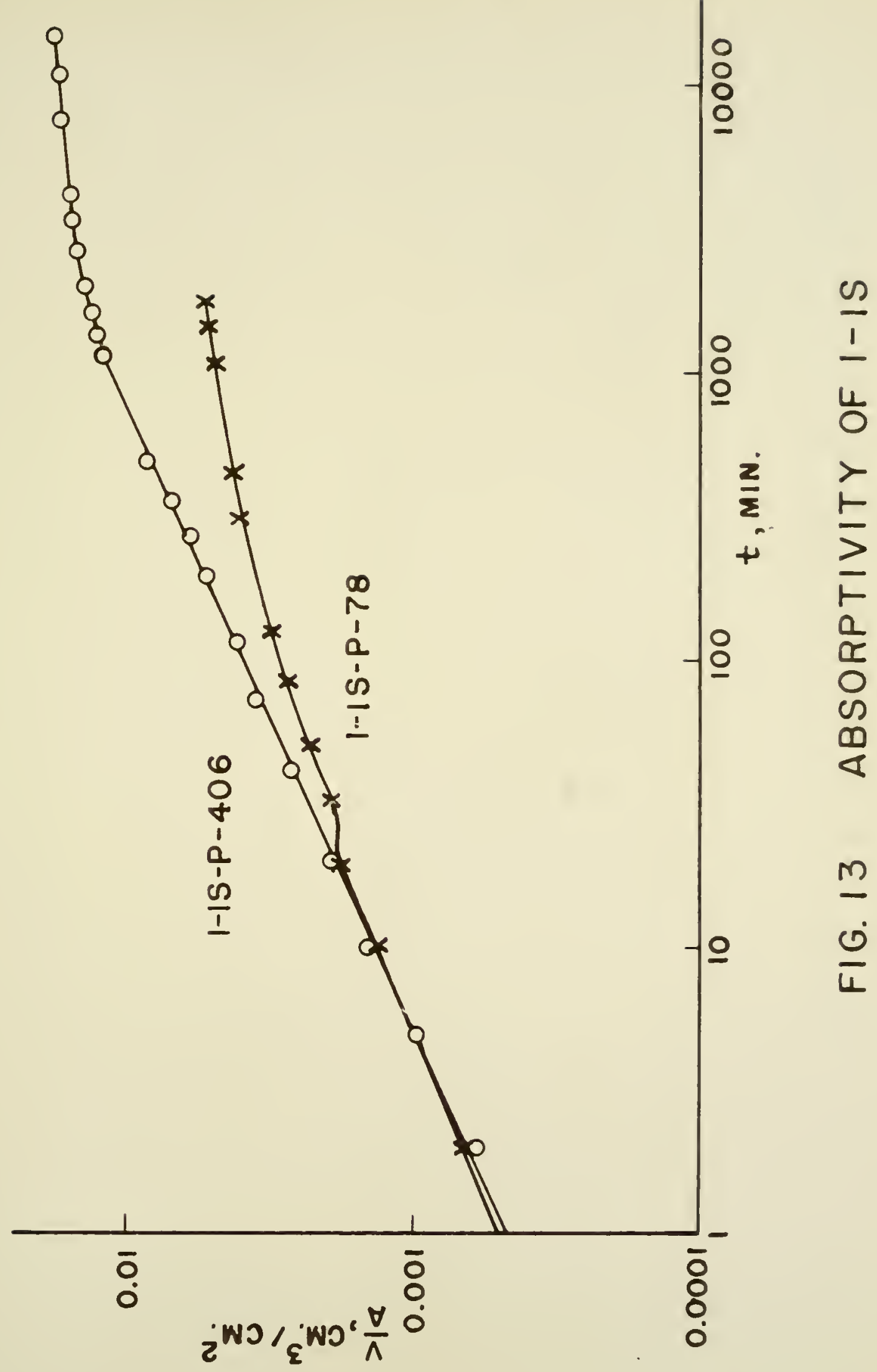




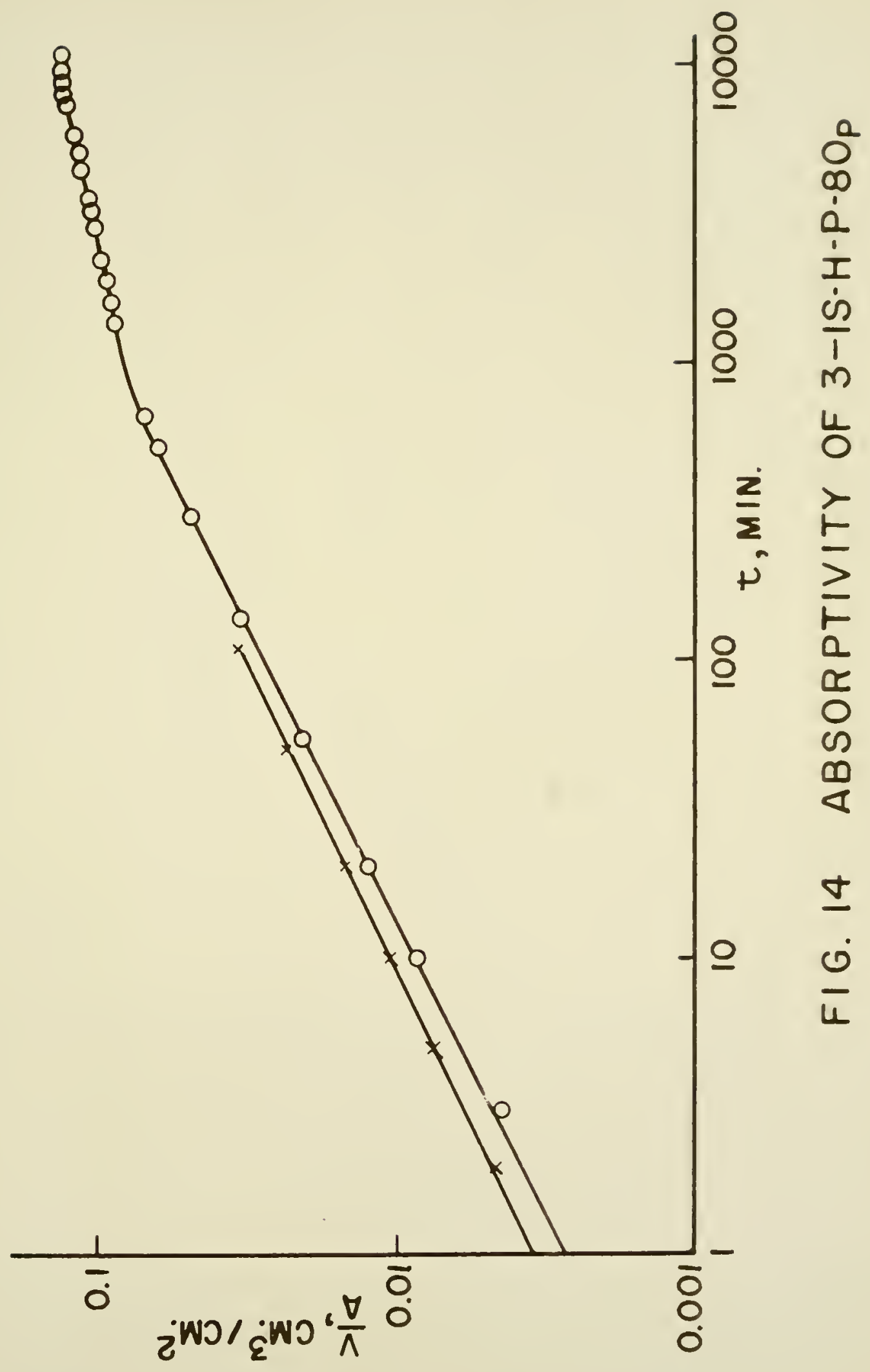




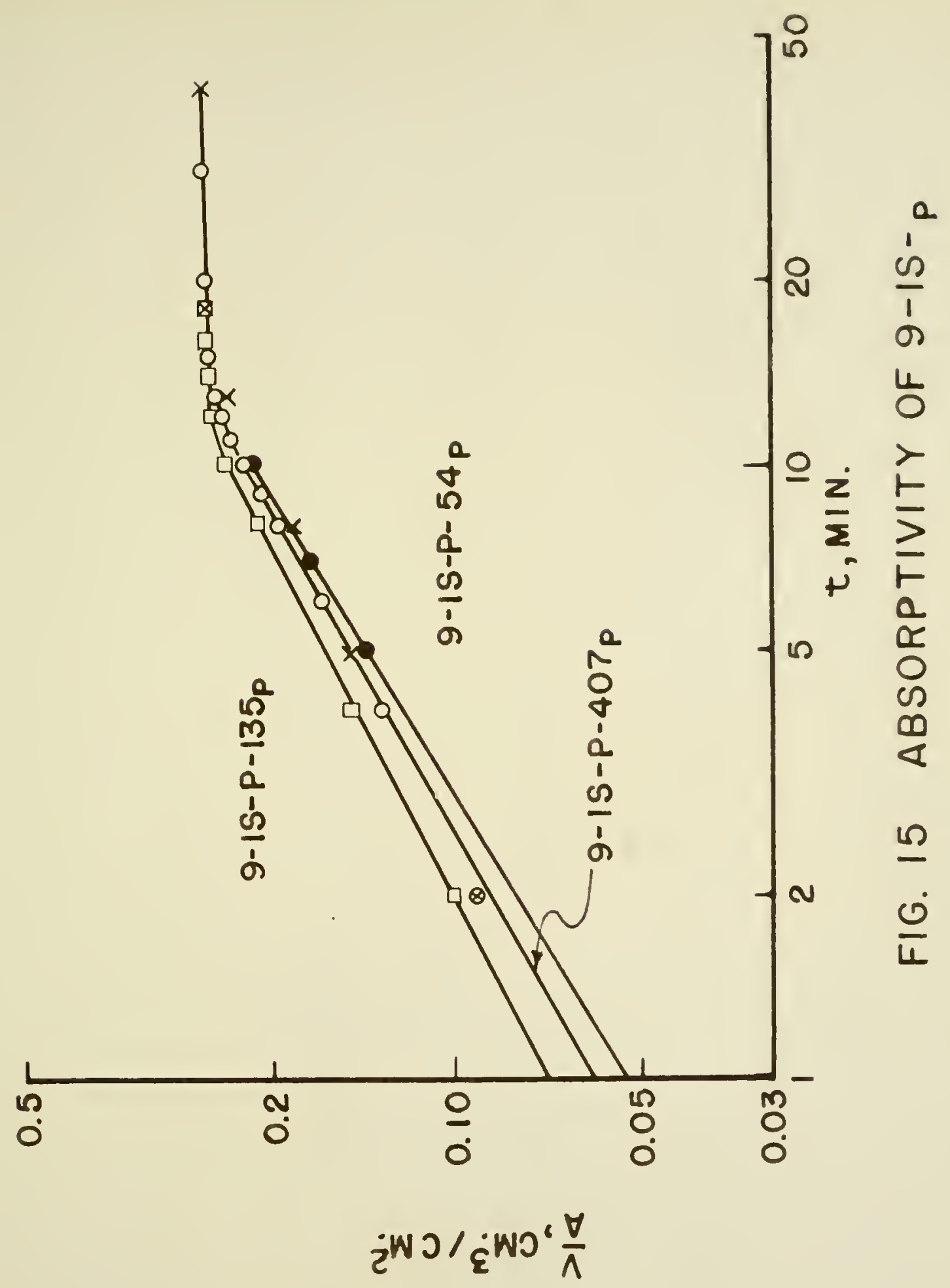




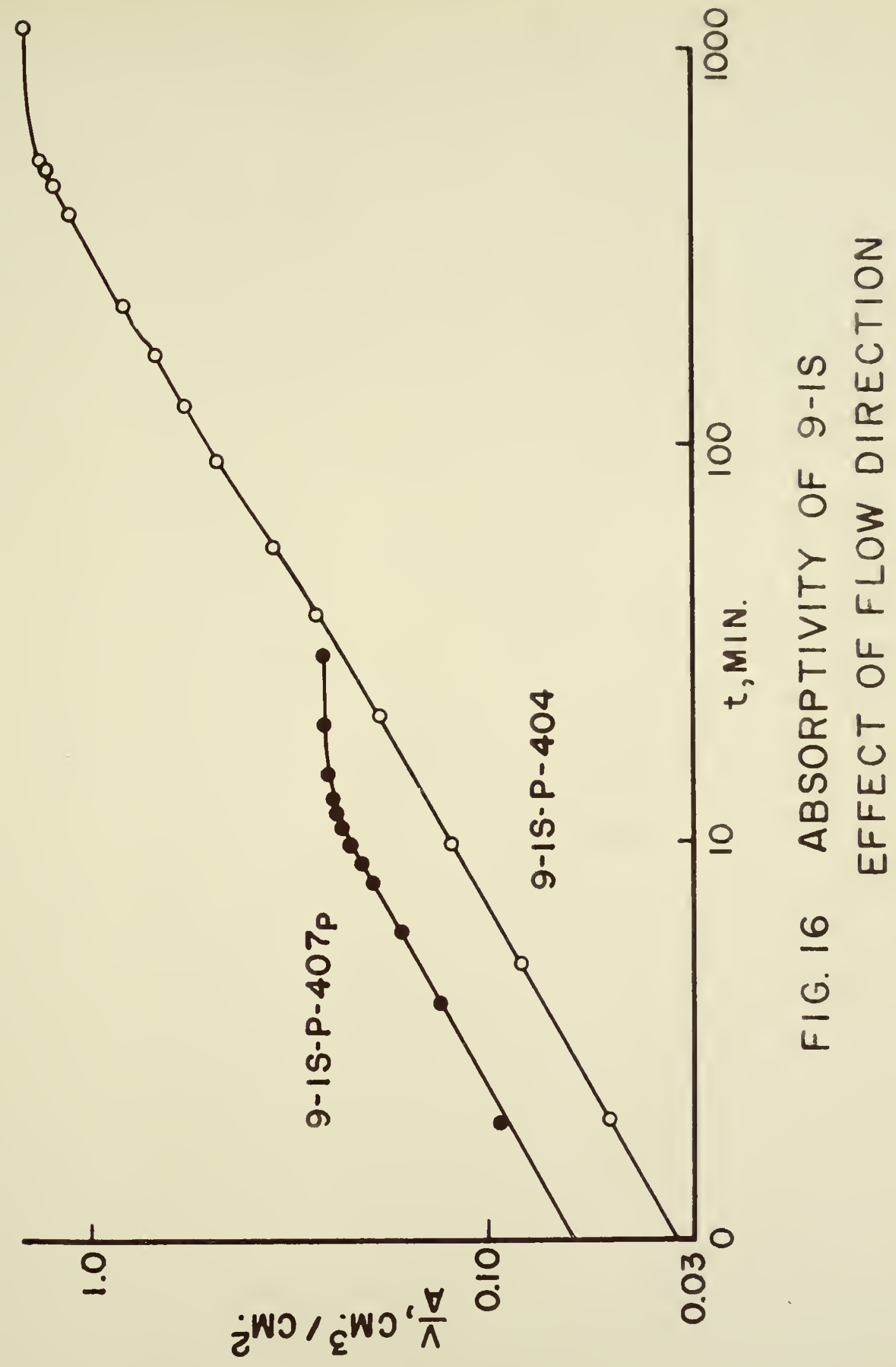




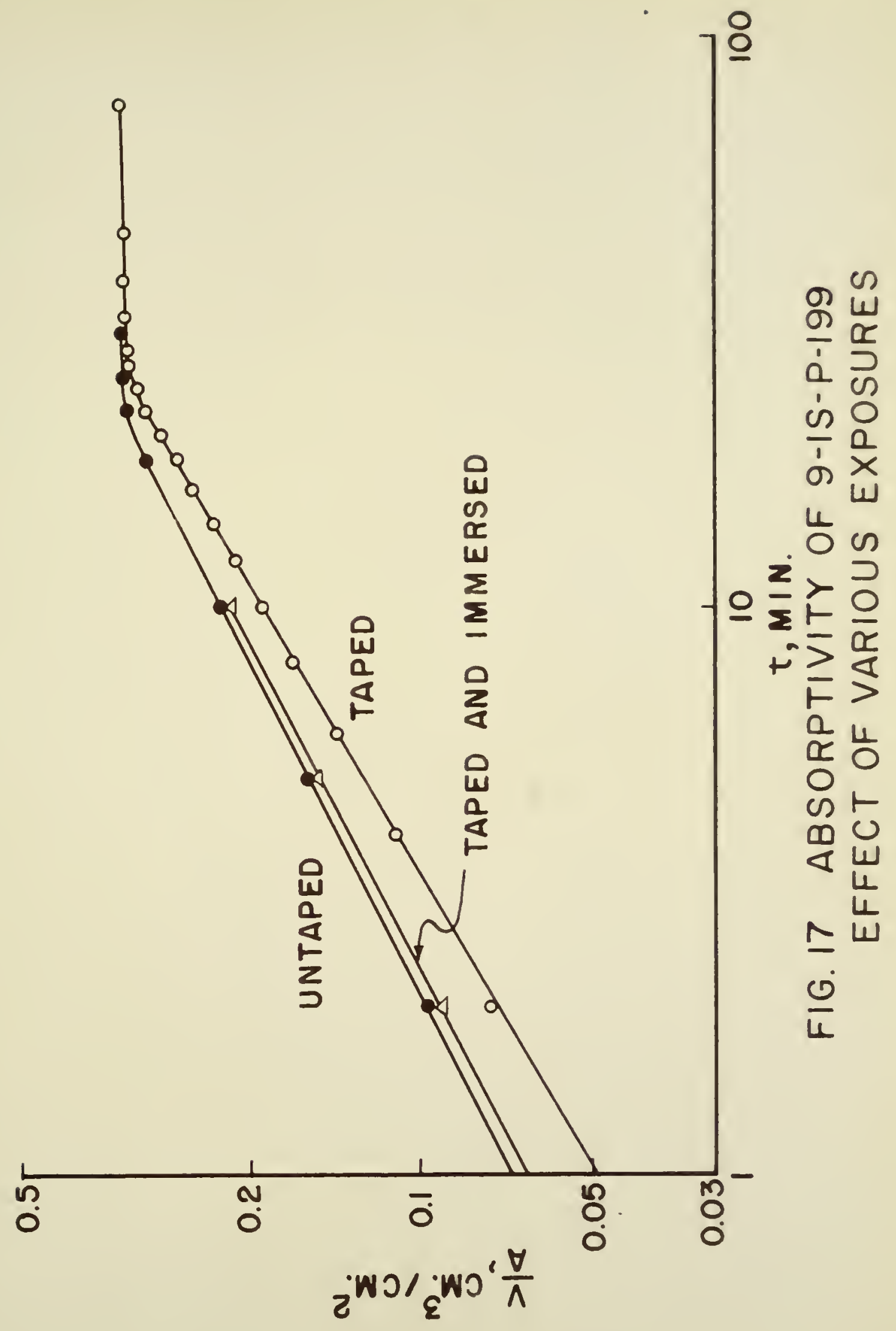




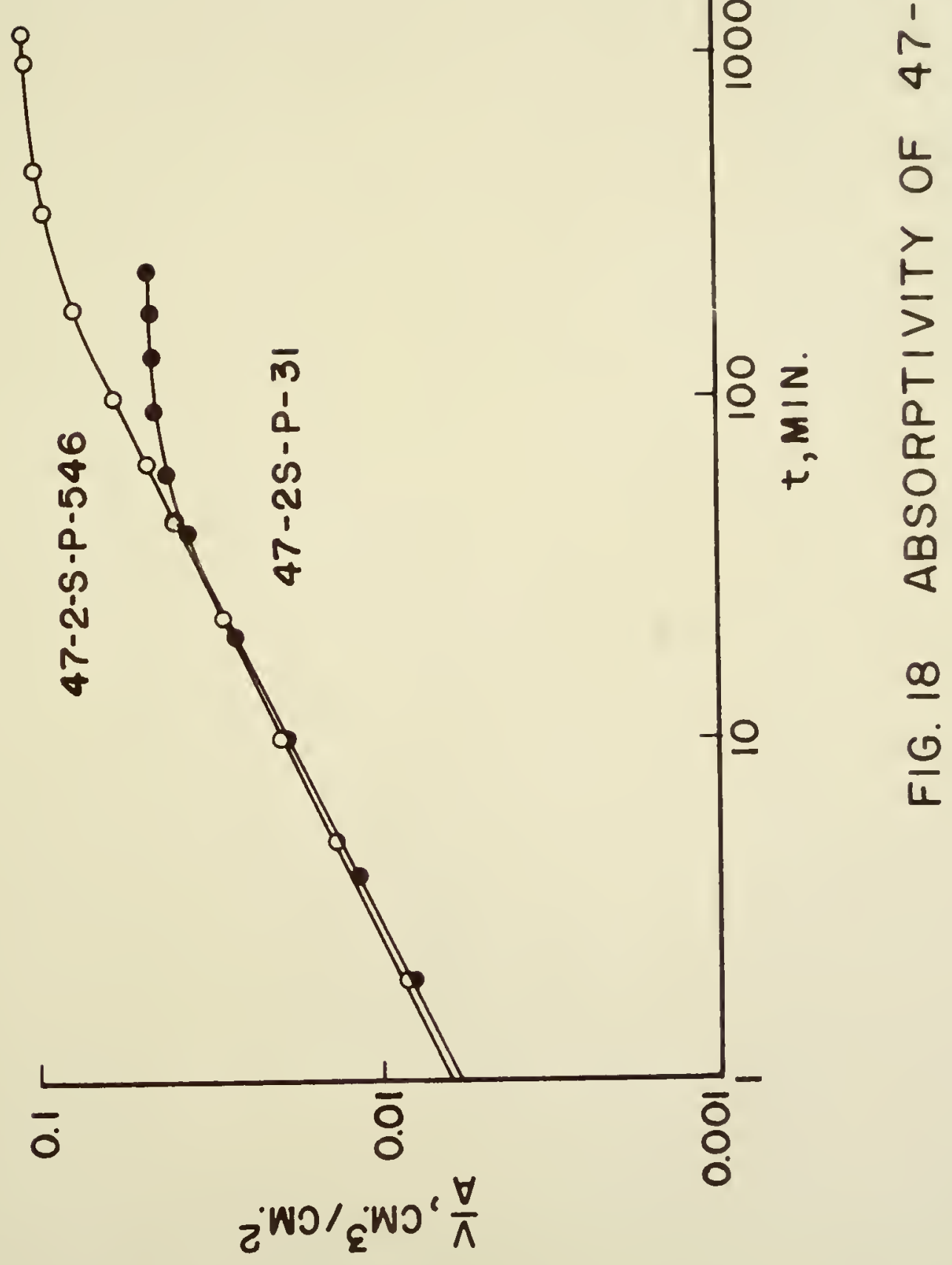




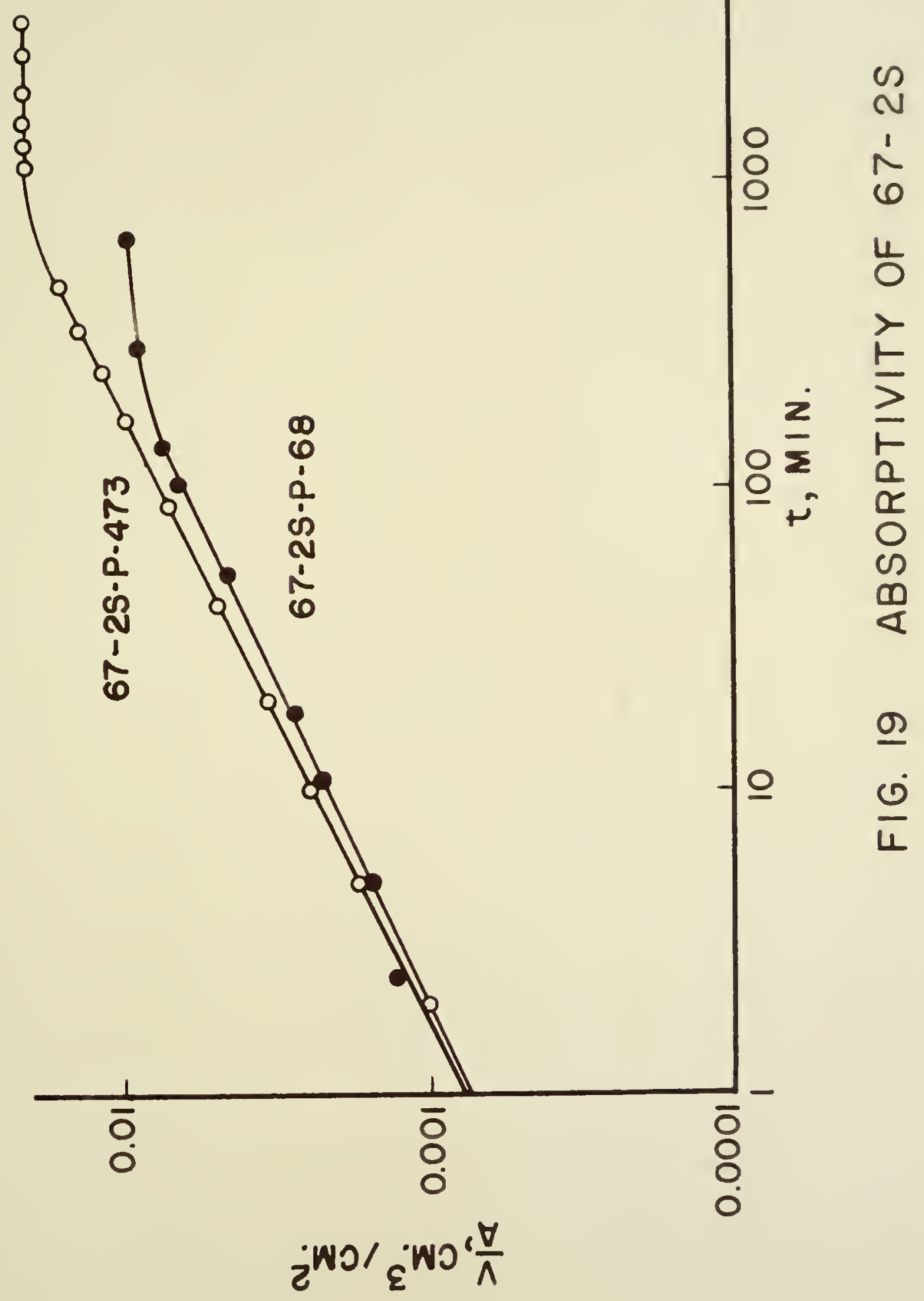


A problem vras ancountered in connection witn the evaliation of $\alpha$. It was desired to know the amount of lirulid that har entersed bo capi2lariby alone. Diffusion starts as soon dis water enters but its contribition. is probably small at any comparatively short interval of time. For those curves, therefore, that ascended and then broke reasonably sharrly into the region of littie gain in weight the problem was simple. It grew more complicated for those curves (I-IS, 3-IS-H) rhich hid a corsiderable curved portion, i.e., a section not on the theoretical cap illary absorption line but still not so flat as to indicate nezligible weight gain. It was finally decided to use as the capillary water value that corresponding to the intersection of the original straight line and the straight line drawn through the points in the substantially flat region of negligible weight gain. The matter is referred to again in the Discussion section.

Most of the curves show neasurements on two different prisns. The general agreement in intercept is trken as an indication of capillary similarity in the different prisms from the same source. Figures is and 15 show duplicate measurements on the same sample and given an indication of the reproducibility of this measurement. Figure 16 shows curves for flar both parallel and perpendicular to laminations in the same prism. Figure 17 shows the effects of varying the condition of the sample. One curve was obtained in the regular way. One is for the same prism untaped, and one is for the same prism taped and incersed to about $1 \mathrm{cn}$. deptis in the water (contained in a beaker). 


\section{ISCUSS ION}

\section{Theoretical Backsround}

\section{Permeability and Pore structure}

The basis for the use of fluid-flow measurements for the invest1gation of the intemal structure of porous solids is the fact that the viscous flow rate is controlled by the interaction between the solid surface and the fluid. The extent of the surface and, therefore, the size of the flow channels are theoretically determinable by the use of such measurenents.

The calculation of the values of these characteristics depends on a preconceived notion about the general nature of the porous structure, i.e., it involves the choice of a model. The use of a model is necessitated by the complex nature of the interior of porous materials. '!ost porous substances have a structure which is continuously variable and which cannot, by the nature of things, be described in detail. Even if the point-to-point details could be described the resuiting equations for the description of fluid flow through the medium would be so canplicated as to defy solution $(55 \mathrm{p}$. 144, 74). Th: net result is that, for practical purposes, the use of a model, the details of which can be described mathematically, is necessary. Such a model is postulated to have the same values for its experinental properties as the actual sample, i.e., the same macro dimensions, porosity, densities, permeability, and absorptivity. The model can be simple such as ane of straight, equal-sized, cylindrical pores, or it can be complicated sucil as the 
random statistical model described by Schejdegger (73), who =lso liscussed the details of some simpler models (72). The use of a model is a recognized compromise for which there seems to be no altemative.

The model used in the calculations to follow is a comnon one which recognizes and accounts for two important properties of actual porous media. These are 1) that the actual flow channels are of some irregular cross-sectional shape, and 2) that the actual flow path traversed by a "particle" of fluid is tortuous rather than straight.

The model used here is of the sort described by Carman (19). The approach area is $A$ and the macro length is $L$. The porosity is $c$. The pore space is completely interconnected and, from the point of vien of fluid flow, can be thought of as a "pipe" of very corplax but constant cross-section. The length of this "pipe" is $L_{t}$, which is greater than L. The hydraulic radius of this "plpe" is $\mathrm{m}$.

Given this model, the next step is to derive an expression describing viscous flow of a fluid through the model. Such an expression, with the flow rate given in terms of permeability, is usually called a Kozeny equation after its originator. One of the chief advocates of the use of this equation has been Carman, and a derivation of the Kozeny equation for substantially the same model used here is given in papers by him $(19,20)$. In the latter paper he also discussed the assumptions involved in the equation and the consequent restrictions on its use. The derivation of the Kozeny equation for the model used herein, which follows substantially Carman's method, is given in Appendix C. The result is

$$
k_{1}=\frac{\varepsilon m^{2}}{k_{0} k_{t}}
$$


where the symbols are as previously deflnod. The hydraulic rarlius, $m$, of the cross-section of the pore system is, by definition, the ratio of the area of fluid to the wetted perlmeter. Por the condition of a saturated pore system and complete contact of the soldd by the flowing liquid, the hydraulic radius becomes the ratio of the porosity to the specific surface (bulk volume basis),

$$
\mathrm{m}=\frac{\varepsilon}{\mathrm{S}} \cdot \frac{\varepsilon}{\mathrm{S}_{\mathrm{g}} \rho_{\mathrm{B}}}
$$

The insertion of this expression into equation (22) gives the kozeny equation in terms of the specific surface,

$$
k_{1}=\frac{\varepsilon^{3}}{k_{0} k_{t}{ }_{g}^{2} \rho_{B}^{2}}
$$

Since the Kozeny-Carman equation is based on a generalized analogy with Poiseuille's law, the condition of viscous flow is an important assumption. This condition was checked by the use of the Reynold's number formula given by Johangen et 21. (35) and was found to be fulfilled. For the conditions of this study, therefore, only viscous flow need be considered.

The Kozeny equation has been used extensively. The constants have been evaluated for unconsolidated porous media by means of an independent determination of the surface area of the materials and are fairiv well-established.

The shape factor, $k_{0}$, was given by Carman (19) as 2.5 for bead packs (1.3., spherical particles) and this figure has recently been confirmed by Wyllie and Gregory (97) for packs of vari-shaped particles. This factor is expected, on theoretical grounds, to be fairly constant. Carman (19) listed the shape factors applicable to widely differing 
cross-sectional shapes. The factor for circular cross section is 2.0 and the whole range of values is only from 1.2 to 3.0 . Rocks are, of course, consolidated porous media but the shape factors applicable should be of the same order as those discussed above. Wyllie and Spangler (99) considered this question and their conclusion was that, for the rocks they tested, the shape factors were approximately constant with the best value being about 2.7. This is the value that has been used here.

The tortuosity, $k_{t}$, of a porous medium can, on the other hand, have widely varying values. The value for spherical bead packs was found by Carman (18) to be around 2. The product of $k_{0}$ and $k_{t}$ is the parameter appearing in the Kozeny equation and, using Carman's values, this product is equal to 5 . This is the value which has been widely accepted and used with a variety of porous materials. This was the best that could be done as long as independent methods of measuring tortuosity or specific surface for consolidated medla were lacking.

These limitations have been lessened with the development of (at least) two independent methods of measuring tortuosity.

The first of these involves a combination of static and dynamic effects in an effort to relate the capillary properties of a fluid in the porous medium to its permeability. Equations have been derived by Purcell (63), Wyllie and Spangler (99), and Burdine, Gournay, and Reichertz (17). They differ in method but the idea is the same. Involved or implicit in these equations is the concept of tortuosity.

The other method, which was used here, is the electrical analog method. This method is discussed briefly and the pertinent equations 
are given in the Experimental section. Further discussion is perhapo needed concerming the different concepts of the relation betreen tortuosity, formation factor, and porosity. As noted previously, Wyllis and comathors $(98,99)$ considered tortuosity to equal $(F \in)^{2}$ while Comell and Katz (22) preferred $F \in$. The distinction between the two concepts depends upon what is considered to be the effective crosssectional area of the conductor in the resistivity experiments. None of the above authors spelled out in detall the reasons for their preferences. Wyllie and co-authors apparently think of a conductor of area $\in A$ since any plane through a homogeneous porous medium will, by definition, intersect an area of free space proportional to the porosity. On the other hand, if one considers a sort of "slanted tube" model in which the "tube" of complex shape has a cross-sectional area nomal to the longitudinal axis (and, therefore, normal to the direction of current and fluid flow) of $a$, and a length $L_{t}$ in a matrix length of $L$, then the volume of voids will be al, and the bulk volume will be AL, where $A$ is the approach area. Porosity, $\epsilon$, will, by definition, be $\mathrm{aL}_{t} / \mathrm{AL}$ and the area of conductor in a resistivity experiment, $a$, will be $\in A L / L_{t}$ or $\in A / k_{t}$. This agrees with the proposition as stated by Cornell and Katz. Wyllie and Gregory (97) compared the two concepts for unconsolidated media composed of particles of various shapes and concluded that the $(F E)^{2}$ tortuosity was preferable to the $(F \in)$ tortuosity. Slightly different relationships from either of the aforementioned have been obtained, empirically, by other investigators. Winsauer et al. (94) found a tortuosity of $(F E)^{1.2}$ and Farls et al. (27) found $0.671(F \in)^{1.95}$. 
For the low values of tortuosity associated with bead packs and other unconsolidated media the differences between the nurerical valuss of these varying formulations are comparatively small but for the higher tortuosities of consolidated media the differences are large. On the evidence of the Wyllie and Gregory peper (97) the concept of $(F \in)^{2}$ for tortuosity has been provisionally accepted as the best founded for the calculations that follow here. But the Comell and Katz formlation of $(F \in)$ has also been used to illustrate the differences. Direct measurement of tortuosities has shown that the value can be mach higher than had been assumed previously. iigllie and Spangler (99) found good agreement between surface areas of petroleum sands measured by permeability determinations and using independentlymeasured tortuosity values and those obtained by a "pin-dropping" statistical technique. Brooks and Purcell (13) used the Wyllie-spangler capillary-pressure method for the measurement of tortuosity and found good agreement between Kozeny and geometrical areas for bead packs. But when the Kozeny areas for sandstones were compared with nitrogen sorption areas a large discrepancy was found with the sorption areas always being considerably the larger. Two reasons were given for the differences. One was that sorbed molecules contact 311 of the surface while flowing fluid contacts only parts of the surface and the rest (e.E., cracks in pore walls, dead-end pores) bounds stagnant fluid and does not contribute to retardation of flow. The other was that an essential assumption of the Kozeny equation is a more or less constant pore size and this condition is not usually met in consolidated media. 
The basis of this difficulty is the fact that a large pore will contribute to the permeability entirely out of proportion to its surfece area.

The other approach to pore-size determination via permeabilitj measurements is through the dependence of permeability on pressure if the experiment is conducted with a gas. The concepts of slip-flow have been used to modify the Kozeny equation for the measurement of surface areas of powders (2). The Klinkenberg equation and its background have been described in the Experimental section. The slip corf ponent to permeability, as specified by the slip factor, b, of the Klinkenberg equation, is related to the size of the flow channel and the properties of the gas. One derivation was given by KIinkenberg (40) and a slightly different one, used here, is given in Appendix D. The derivation is for round tubes but the result probably holds fairly well for irregular shapes. For an actual porous media with a variety of sizes of channels through which the gas is flowing, tro conflicting effects are probably operative in determining the slip contribution. These are 1) that the smaller the channel the greater the degree of slip but 2) the smaller the channel, the less the flow through it. The net result is probably that the slip factor reflects the size of the larger channels. Heid et al. (32) evaluated the slip factor for oil-bearing rocks and calculated the pore size therefrom using KIinkenberg's original formula.

Absorptivity and Pore Structure The theory of the penetration of capillary tubes by liquids by 
capillary pressure has been in existence for many years. The general matter is called hore "absorptivity", which should be distinguished from "absorption."

Equations for the rate of capillary advance in a single tube were given by Washburn (86). The basic problem was the inclusion of the capillary pressure, i.e., the pressure difference across a meniscus, in the Poiseuille expression for viscous flow. Washburn's equations subsequently were refined by Rideal (68). Barrer (6) has given a similar equation in a review of fluid flow. Eley and Pepper (24) derived an equation which includes the concept of tortuosity. Razoul. (64) discussed these matters briefly.

The equations for penetration into single capillaries have been extended to the more complicated problem of absorptivity in porous media. Bangham and Razouk (5) measured the absorptivity of charcoal blocks for methanol by a weighing technique. Their method, incidentally, involved periodic interruption of the capillary process just as did the one used on the rocks in this study. Madgwick (53) measured the absorptivity of building stone for water but did not relate the "penetration constant" so obtained to the pore structure of the material. Heid et al. (32) used the method on petroleum sands. They reasured the time for the penetrant to traverse the sample from bottam to top and used the integrated form of the equation for straight tubes to calculate an average pore size. Powers and Brownyard (60 p. 865), who seem to have coined the term "absorptivity," measured this property for blocks of hardened neat-cement paste by inmersion in water and continuous weighing. 
Powers and Brownyard derived an equation which relates the absorptivity and the permeability of the sample to the specific surface of the conducting channels. This equation assumes that the two flon processes involve the same channels. The equation is, in the symbollsm used in this work,

$$
\eta K_{a}=2 K_{1} \gamma S_{g c} P_{B}
$$

where $K_{l c}=$ liquid permeability, assuming all flow takes place through the "capillary" channels

$$
\begin{aligned}
\mathrm{S}_{\mathrm{gc}}= & \text { specific surface (weight basis) of the } \\
& \text { "capillary" channels. }
\end{aligned}
$$

Appendix $E$ contains the derivation of the equations relating the absorptivity coefficient to the properties of the pore system of the model. Equation (EI) is similar to that of Barrer (6) except that the restrictions of steady-state conditions and circular cross-section are not applied here. The statement is made in the derivation that the equation can be simplified by ignoring the presence of the gas, the weight of the liquid, and the deceleration force term. This simplification has been assumed by most of the workers cited previously. A sample calculation shows that the only term which is arguable with respect to its being ignored is the one for the viscous retardation force in the gas. At the start of the run the capillaries are filled with air. The ratio of the viscous retardation force for the air to that for the water is (see equation EI).

$$
\frac{\eta_{g}}{\eta}\left(\frac{L_{t}}{x}-1\right) \text {. }
$$

Since the ratio of the viscosities is about 0.02 , the gas viscousforce term may be consequential when $L_{t} / x$ is large, i.e., at the start 
of the run. It is thought, however, that little difficulty has been encountered from this source. With all terms ignored except the capillary and viscous terms for the liquid the result of the derivation is an equation of the form

$$
\left(\frac{V}{A}\right)^{2}=c_{1} t
$$

On a log-log plot this equation is linear with a slope of $1 / 2$. If the gas viscosity term is included the result is an equation of the form

$$
\left(\frac{V}{A}\right)^{2}+C_{1}\left(-\frac{V}{A}\right)=C_{2} t
$$

The data for these rocks do plot as straight lines on log-log paper with a slope of $1 / 2$, within experimental error. It is possible that if data points had been taken very early in the run some deviations would have been observed. As matters stand, however, the conclusion is that the dropping of the gas viscosity term is justified. The net result of the derivation in Appendix $E$ is

$$
K_{a}-\frac{2 \gamma m \alpha^{2}}{k_{0} k_{t a} \eta}
$$

Results

In this section are given the results of the calculations corcerning pore structure, based on the theories of permeability and absorptivity just discussed, and using the measured values listed in the Data section.

In Table 8 are presented the calculated values for effective or average radii of the pores if the model chosen is that of equal-sized, round, tortuous tubes. 
Tablo 8

Calculated Average Pore Radil of the Rocks.

\begin{tabular}{|c|c|c|c|c|}
\hline \multirow{2}{*}{$\begin{array}{c}\text { Source } \\
\text { No. }\end{array}$} & \multicolumn{4}{|c|}{ Radius, $\mu$} \\
\hline & Slip & Pormeability & Absorptivity & Sorption \\
\hline $1-1 S$ & 0.460 & 0.493 & 0.187 & 0.110 \\
\hline $3-1 S-H-p$ & 0.296 & 0.422 & 0.0144 & 0.101 \\
\hline $9-15$ & 0.737 & 1.18 & 0.0269 & 0.131 \\
\hline $9-I S-p$ & 1.07 & 1.73 & 0.159 & 0.131 \\
\hline $47-25$ & 0.240 & 0.394 & 0.0684 & 0.0372 \\
\hline $67-25$ & 0.668 & 0.364 & 0.0261 & 0.0208 \\
\hline
\end{tabular}

The slip radii were calculated by means of equation (D8). The permeability radii were calculated using equation (C7) which is the Kozeny equation for round tubes. The shape factor, $k_{0}$, is 2.0 in this equation and the tortuosities used were the Wyllie-Rose tortuosities for complete saturation. The absorptivity radii were calculated from equation (EII) using the Wyllie-Rose tortuosities, $k_{t_{\alpha}}$ for the capillary saturation. This equation also implies a shape factor of 2 . The sorption radii were calculated from the BET specific surfaces by means of the relationship $m=\varepsilon / s_{g} P_{B}$ and assuming round pores, for which $r=2 m$.

The use of the round-tube model is an approximation which ray be acceptable for comparative purposes. The differences between the round-tube radii and the hydraulic radii are only the difference between the shape factors, 2.0 and 2.7 respectively. 
In Table 9 are presented the calculated values for the speciric surfaces of the rocks along with the measured BET sorption values.

The "slip" areas were computed usdng the "slip" radil, 1.e., tney are the areas of arrays of round tubes with radii equal to the calculated "slip" radii.

The "permeability" areas were computed from equation (24). Two expressions for the tortuosity factor appearing in this equation have been used. The column mirked $k_{t}$ contains values computed using the Wyllie-Rose tortuosity, i.e., $(F E)^{2}$. The colum marked t contains values corputed using the Comell-Katz tortuosities, i.c., FE.

The absorptivity areas were calculated according to exuations (E13) or (E14) depending upon the interpretation placed on $\mathrm{m}$. This choice is discussed in more detail in the following section. The tortuosities used for computing the values on the $=\varepsilon / s$ basis were the Hyllie-Rose values computed for the capillary saturations. Both tortuosity concepts have been used for the values computed on the $m=\alpha / s_{\alpha}$ basis. The colum marked $k_{\text {ta }}$ contains values computed using the tortuosities just described. The colum marked $\tau_{\alpha}$ contains values computed using the corresponding Cornell-Katz tortuosities.

The colum headed $S_{g c}$ contains values for the "capillay" specific surface" computed using equation (25) which was derived by Powers and Brownyard. It should be noted that the units of the values in th:s colum are $\mathrm{cm}^{2} / \mathrm{g}$ while those in the rest of the table are in $\mathrm{m.} 2 / 5$.

\section{Discussion of Data and Results}

In this section the data and results are discussed irom the point of view of the tests per se, the agreenent, or lack thereof, among 


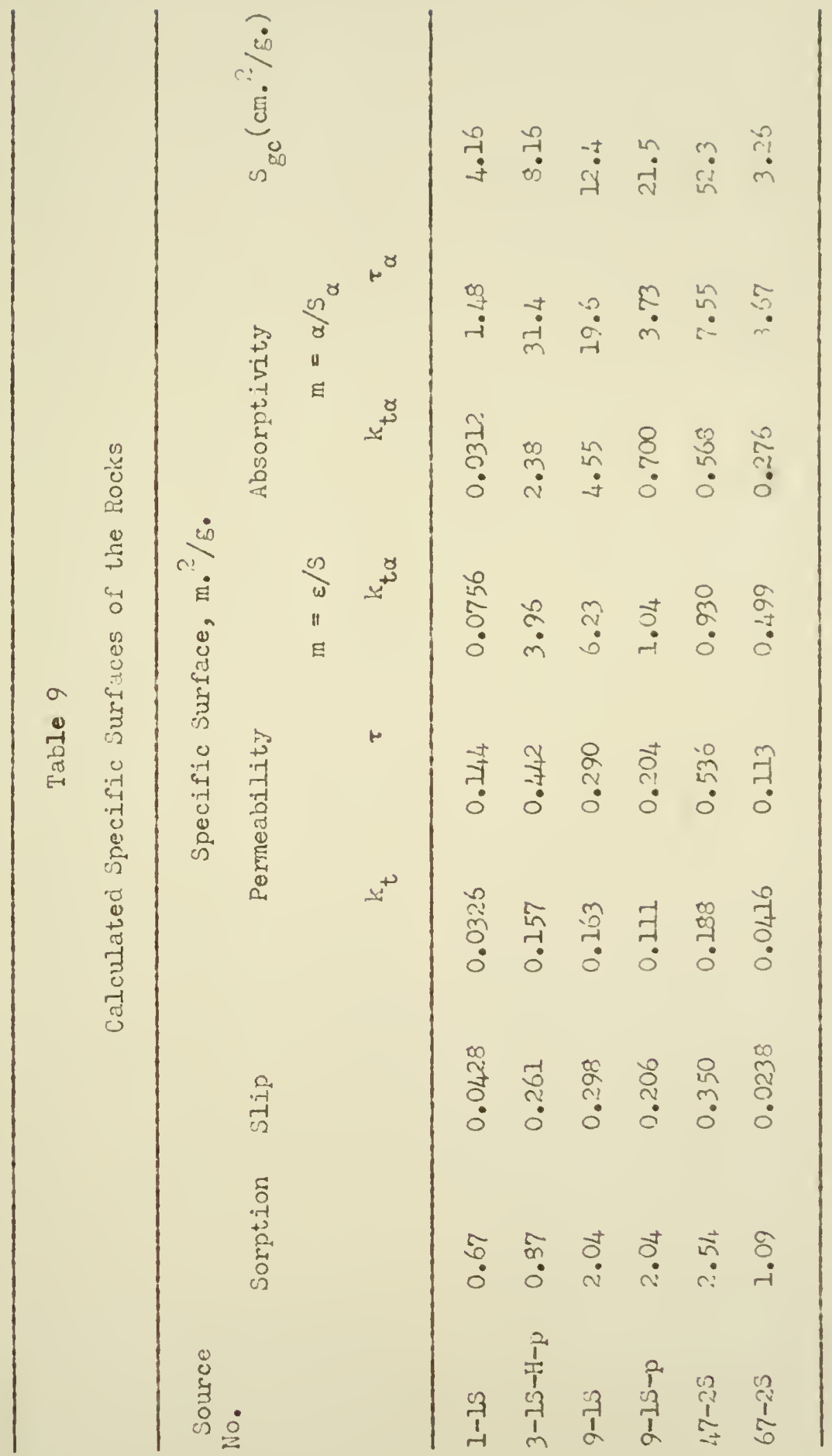


various values, and the concepts of pore stmucture which can be inferred from the results. Most of the operational guestions have previously been discussed in the Experimental section. The interpretation of the results in terms of the quality of the rocks as concrete aggregates is taken up in the next section.

\section{Densities and Porosity}

The truedensities (Table 3) are derived from the values for the volume of solids obtained with the volumenometer. The advantages of this method are that the test is non-destructive, rapid, and that questions of degree of saturation, encountered when using liquids, are not a factor. An inherent disadvantage, on the other hand, is that totally-enclosed voids will appear as a volume of solids rather than of voids. Any real porous body will have some such voids and the Lr destruction is an advantage to the techniques in which the sample is powdered. All that can be said here is that the values obtained in this study agree fairly well with those obtained by others who used the powdering method on materials from the same sources. They also agree within a few percent with values obtained by calculation from the chemical composition and the appropriate values for the pure mineral species. The bulk densities calculated from the true densities and voids ratios agree to approximately a half percent, with those, for the same samples, obtained by the direct measurement of the dinensions.

If regular shapes are obtairable, dimensional measurement is probably the best way of detemining bulk volume. Slight irregularities in the shapes of prisms could, hovever, result in considerable 
orror. The values reported here for the bulk density are, therefore, those obtained using the volumenometer and the calculation from the true density.

The "Micleod gage" porosimeter method for the detemination of porosity has the same virtues of non-destruction, speed, and simplicity which were listed for the volumenometer. A disadvantage, especially for large samples, is the difficulty in constructing a leak-free joint for closure. Even with the small apparatus used here the ball and socket joint gave trouble and it had always to be greased carefully to keep grease out of the system. Even so, frequent cleanings were necessary.

The results shown in Table 3 for the porosity and for the absorption and consequent degree of saturation are all of the correct general magnitude, with one exception, when compared with previous results on the same materials $(8,16,28,81)$. The exception is for source $3-15-4$. The values obtained for the absorption and, especially, for the saturation are considerably different from any published for this source. The matter already has been mentioned with respect to the small pieces that were available and the low degree of homogeneity of the rock. This lack of agreement may not, however, be as serious as it seems. Recent tests (54) on the same batch from which the pieces used here were obtained show approximate agreement with the values given here. The conclusion, therefore, is that the values are not erroneous for these specific pieces. The inferences with respect to the quality of the stone will be given later. 


\section{Tortuosity}

The method of measuring the tortuosities was straightfornard and simple. The measurements were precise in every case except that already noted, 1-lS. A possible reason for this has been mentionsd, i.e., differences in orientation of the conducting saturant from run to run. The final result, a tortuosity of 384 , is certainly high. It is not, to be sure, impossible but it is unusual. The values for the other rocks are all of a reasonable magnitude.

The basic validity of the electrical analog method is dependent on an assumed equality between the overall magnitude, if not the small details, of the electrical and fluid flow paths. This assumption seems justified for completely saturated conditions but it may not be for partial saturation. Wyllie and Spangler (99) discussed this point and described the electrical tortuosity at incomplete saturation as lower than the hydraulic tortuosity because an almost empty pore space will not support fluid flow but will pass an electric current by weans of a "skin effect" in the liquid wetting the pore walls.

The use of the value 2.0 for the resistivity index exponent, $n$, has already been discussed (and see Appendix A). Rather than assuming an arbitrary value, it would have been better to measure $n$ directly by making a number of resistance measurements at various saturations. Such experiments, on the same piece of rock, have been difficult because of the necessity to get different saturations without changing the composition of the saturant. Birks (7) introduced a method for this determination in which he used a saturated solution of calcium 
sulfate and evaporated some of the water for each ruccessive test. He obtained somewhat different values for the formation factors of dense limestones when using calcium sulfate than when using sodiun chloride so the choice of electrolyte may be important. For any choice, the specific conductance of the solution used should probably be measured directly rathern than dependence being placed on handbook values. If $\mathrm{n}$ is measured directly the experiment should be the last of the serles because the presence of the salt in the rock pores would alter subsequent measurements and its removal is difficult.

The tortuosity measurements, particularly for the denser rocks, are probably the least accurate of the measurements reported here.

\section{Sorption Measurements}

The experimental technique for the sorption runs was simpler than the more common volumetric or gravimetric techniques. It is faster than the humid-air-train apparatus of Powers and Brownyerd (60 p. 249). Where room temperature and run temperature are almost equal there is no objection to removing the sample from the constant-temperature bath for weighing. The successful use of the Tygon joints rather than the more cumbersome standard-taper joints is worth mentioning.

The surface area values obtained using water vapor have been found $(10,31)$ to be different from those obtained with nitrogen, a more conventional sorbate for this experiment. The matter is somewhat arbitrary and the simplicity possible for the apparatus and the precedent with concrete materials $(31,60$ p. 249) dictated the choice of water vapor at room temperature. 
The Brunauer-Emmett-Teller theory was used because of 1 t8 successful history. Its basic assumption that the net heat of adsorption In every layer after the first is zero has been questioned (29). The necessity to assume a constant area for a sorbed molecule in the first layer is also a disadvantage. But, regardless of its possible shortcomings, the theory has given reliable results for surface area determinations and has been used probably more than any other for this purpose.

The particular data obtained here could have been improved by using more experimental points to define the isotherm. The data, however, fit well when plotted according to the linear form of the BET equation. The concurrent measurements were fairly precise, as is shown by the individual values in Table 5, especially considering the comparatively low specific surfaces involved. The values of the heat constant, C, in the BET equation were so low (about 4 to 8 ) that the use of the single point appraximation method gave, as stated previously, large errors in the final area value.

No previous measurements of surface area of these Indiana aggregates have been made. These values are, in fact, the standards to which other methods for area measurement are later compared. They are, however, of the same order of magnitude as the results of the measurements on "Iimestones" made by Blaine, Hunt, and Tomes (10) and by Brooks and Purcell (13). 


\section{Permeability}

The pressure-decay permeameter is preferable to the conventional apparatus for a substance of low permeabillty (less than about one millidarcy). The conventional type of apparatus necessitates a measurement of the flow rate either by collectine the permeant or by the use of a flowmeter. For substances of high permeability either operation is feasible but the elimination of the direct measurement is better for dense material.

A disadvantage to this particular apparatus was the metinos of holding the sample. The hard asphalt cement was difficult to remove completely from the sample and the test is destructive to this extent.

Considerable differences exist between the times for a run on $a$ dense and on a fairly perneable sample. With the inpernable samples the rate of travel of the meniscus of the differential manometer was so slow that there was some question as to the tije at which the meniscus was opposite the appropriate mark on the scale. On the other hand, the overall time for the pressure to decay was proportionstely longer than for the more perweable samples and the relative accuracy was probably about the same in all cases.

The data presented in Figure 10 shom an interesting possibility which has already been mentioned-that of defining the whole curve with one run at low pressure rather than with several at higher pressures. For a low-pressure run the small absolute changes in mean pressure during the decay represent comparatively large numbers when the reciprocals are taken and so show up on the plot at a distance apart suf- 
ficient, to define the line. The large increase in pemeability at Low pressures is evident frorn the figure and may be the reason for the shortness of the time needed for the run with the licleor gage poros1meter. The low-pressure technique is reasonably preclse as is thown by the good agreement between the two runs on the same sample that are shown in the figure. The intercept that iras obtained is slightly higher than that obtained for the same sample vith the higher-pressure technique--5.8 as contrasted with 4.3 millidarcys. A more serious difference is in the slopes. The extrapolated line for the hish pressure datz is show also on the figure and the corresponding b values are about seventeen and twenty-seven.

The fairly good agreement in intercept indicates possibilities for using the low-pressure method for the determination of $\mathrm{k}_{1}$. The higher permeabilities at the lower pressures mean that the time for the run is shorter and this is an attractive feature. There were, however, enough uncertainties present so that the higher pressure method was used here.

The curves show good linearity of the data with the exception of some of the points for 1-IS (Figure 6). This agreement is taken to mean that no gross errors were made in the experiments. A further argument in favor of the data is the record of a few runs made on 9-1S and 47-2S with a conventional train apparatus and collecting the permeant over water. The values obtained by the two methods agree well. 


\section{Absorptivity}

The method used here for the moasurement of absorptivity is, as far as the writer knows, novel. The main question that can be brought against it is that of possible moisture movernent during the rolghing and this matter has already been discussed in the Exporimental section and the reasons given for thinking that such movement is slight. Assuming no trouble from this source, the method has to reconmend it Its simplicity and directness. A disadvantage to the technigue is the amount of time necessary for the reaching of capillary equilibrium with samples of the nature and thickness of those used here. If only the value of the absorptivity coefficient is desired it can be obtained in a few minutes by taking the first data points on the curve. But if the properties of the pore system are to be calculated from $K_{a}$, the capillary porosity, $\alpha$, must be known. With the present experimental technique the only way to determine $\alpha$ is to wait for equilibrium. With these samples (roughly $2 \mathrm{~cm}$. thick) the time needed was from extremes of approxinately ten minutes to a week. The obvious way to lessen such a long time is to use thinner samples. Examples of the changes that can be expected are shorm in Figures 18 and 19 in which samples of different thickesses have been used with a great reduction in the time for the thinner pieces to reach equilibrium.

The question of taping the sides is somewhat arbitrary. Figure 17 shows three runs on the same sample under different conditions. The lowest curve is a record of a run dane in the ordinsry way. The longer upper one is for the same sample untaped. The shorter upper 
one is for the sample taped and immersed to about $1 \mathrm{cn}$. In the water. The reasons that suggest themselves for the differences are that, for the untaped sample, the diaplaced air can escape to the sides instead of being trapped by the advancing menisci or forced to traverse the longer route to the top. The amount imbibed in a certain time would, therefore, be greater than for the same sample in the taped condition. The immersed sample had a hydrostatic head applied and again, the net result should be $a$ higher apparent absorptivity such as was actually observed. For adherence to the principle of the capillary tube model, however, the sides should be taped and the absorption should be by capillarity from a free-water surface.

The values of ' $K_{a}$ reported in Table 7 are those for the large prisms on which the density and porosity measurements were made. Generaily curves for another sample of the same rock are given to indicate the variation from piece to piece. For $1-15,47-25$, and 67-2s the agreement between the two is good. The agreement is poorer for the 9-1S samples. This rock is laminated with altemating bands of fine and coarse material and it is understandable that companion pieces might exhibit differences in individual behavior. Two curves from runs on the same sample are show for 3-1S-H-p and for $9-15-p$. The pracision is good for the $9-1 S-p$ and fair for the $3-15-H-p$.

Since such a comparatively large volume is absorbed in the early part of the test, care should be taken with the initial manipulation. With attention to details the method is capable of good precision.

The sample of 9-1S was tested by exposure both perpendicular and parallel to the laminations. The two curves of the data are shom in 
Figure 16. The perpendicular exposure had the lower absorptivity. This difference is in line with the expectations from the perneabllity which exhibits the same differences (Table 6). The curve for the perpendicular exposure was the only one where non-linearity was observed. Two discontinuities can be seen. It is thought that those were caused by the water front reaching a layer of material whose capillary potential was particularly high. This behavior is one reason for preferring the parallel exposure technique for those layered materials.

The theoretical slope of the log-log curves of the data should be 0.5. The slopes of all the curves except those for 9-1S are in agreement with this figure within the limits of experimental error $( \pm 0.03$ or so). The slopes of the curves for 9-1S are uniformly high. The average for the six muns (taped samples) show is 0.57 with a range of 0.52 to 0.60 . What this difference means, if indeed a valid difference is present, is unicnown.

The capillary porosity, $\alpha$, is the fraction of the bulk rolure occupied by the capillary permeant under the conditions of the absorptivity experiment. Kention has already been made in the Data section about the determination of this value from the experimental curves. For only two of tine rocks ( $1-15$ and $3-15-H)$ was a problem encountered. These two rociss have data curves which have a comparatively long intermediate section that is neither on the straight-line, slope-of-one half, capillary-absorption curve nor on the almost flat portion which indicates negligible capillary absorption. These two rocks are the least homogeneous of the group. They both have comparatively large amounts of material which appears different from the majority of the 
mass and which may be assumed to have different capillary properties from this majority. In the runs on both materials there was observol an uneven wetting of the top surface. It is a logical assumption that the first break in the curves represents the point at which the permeant first broke through to the top. This was observed to be approximately true.

From this point on, the sample size was changed, i.e., the $V / A$ ratios were calculated using a macro area larger than that applicable to the capillary process which was still active. The situation just outlined can account for the shape of the curres in question. It is not until the flat region is reached that the capillary pore space is filled. This point should, therefore, be the one at which the weight of water in the sample represents the capillary porosity. The nearly flat portion of the curve was extrapolated to the original line (to remove small deviations from ideality) and the intersection so obtained was taken to represent the capillary-held water.

\section{Saturation}

This is perhaps the place to discuss one further aspect of the degree-of-saturation. The problem is the reason for incamplete saturation--during capillary absorption and particularly when the sample has been evacuated and immersed.

A possible mechanism to account for incomplete saturation is that of entrapment of gas in the pores. The commonly-used examples are a blind-end pore or an "H" structure in which gas is trapped in the connecting passageway between two pores. If the air trapped in the pore 
is at atmospheric pressure the advancing water will not enter unless the capillary pressure across the mentocus is greater than atmospheric. If the capillary pressure is greater than atmospheric the vater $x 11 l$ enter the pore and compress the gas unt1l equilibrium is established. Any higher saturation can be accomplished only by dissolution of the trapped gas and.its diffusion from the region.

When a piece of stone is immersed in water as is done in the ordinary 24-hr. immersion test, the water starts to enter from all sides more or less at once. The situation is presumably ideal for entrapment of air. In the capillary absorptivity test the air can escape from the top surface but still there are many possibilities for entrapnent. An inspection of Tables 3 and 7 will sinow that the saturations by the two methods were roughly equal except for the case of $3-15$.

Alr-entrapment processes should, however, not apply to the method of vacuum saturation. If all the air is removed from the pores, it is difficult to see how it can block anything. Only molecules of water vapor are in the pores under these conditions. No blochage is possible and complete saturation should be achieved. But the fact is that, except perhaps for very open materials, complete saturation is not obtained and in some cases as much as a third or more of the pore space remains unfilled under these conditions.

The argument that the evacuation is not complete if it is done with an aspirator is poor in view of Sweot's (82) tests which showed that no improvement was obtained by substituting a good vacurum pump for the aspirator. 
Some mechanism other than simple blocking mat bo operative to account for the facts observed in vacuum saturation experiments. Such a mechanism would presumably also be operative for absorption under conditions of simple immersion but would then be augmented by entrap ment processes.

Another possible mechanism is that of the capillary pressure being lowered or reversed. Powers (59) refers to the reluctance of water to enter a large void from a small space. If water progressing by capillary action comes to a bulge the capillary pressure will decrease. The viscous drag retarding the flow will, however, remain almost the same. But there is a further aspect to the problem. A change in the contact angle can take place if a change in the angle of the pore walls occurs. The action has been called the "overtuming" of the meniscus and was discussed by Adam (1). Unless perfect wetting takes placeand it probably seldom does for the advancing angle--a change in the angle of the pore walls can result in the contact angle becoming large, even greater than 90\%. The capillary pressure therefore becomes saall or reverses and the driving force causing penetration is renoved or counterbalanced. Adam's (1) Figure 1 illustrates the point. The extent to which a pore space remains unfilled under vacuum saturation conditions is, according to these ideas, a measure of the extent to which these capillary pressure diminishing or reversing operations take place.

Absorptivity-Perneability Relationship

A final aspect of the absorptivity part of these experiments which remains to be discussed is the relation between the absorptivity 
and the permeability. If onc assumes that in both procssses tne flow takes place through the same pore space and is affected in the same quantitative manner by this space, the equations for the absorptivity and the permeability coefficients can be related through comron factors. This was done by Powers and Bromyard $(60 \mathrm{p} .865)$ in their derivation, the result of which was given as equation (25). Por thase rocks, the measured absorptivities and permeabilities were inserted in this equation and the resultant area was computed. The results are given in the last colum of Table 9, in $\mathrm{cm}^{2} / \mathrm{g}$. These specific surfaces are so small that they negate the equation and the assumptions it involves for these rocks. It is inconceivable that the areas of the pore walls supporting the flow are so small compared to the total area as determined by the sorption measurements.

On the other hand, if the sorption areas and the absorptivities are introduced into the equations relating $K_{a}$ and $K_{I}$ and these are solved for the permeability the results are much lower than the measured permeabilities. Even if account is taken of the principles of relative permeability and the results of the above calculations are called effective rather than total permeabilities, the results are still powers of ten away from the theoretical relative permeabilities. The reason for this great disparity may be that the widenings in the pores are spaces which, according to the previously-discussed saturation mechanisms, stop or retard the capillary flow. But these spaces are, on the other hand, just tbose which permit the marimu of the saturated flow which takes place in a permeability experitent. These spaces, in other words, tend to give a comparatively high per- 
meability and lov absorptivity.

For rocks of the same general texture (and specifically for the rocks studied here) there should be a rough correspondence betvieen the absorptivity and the permeability. Permeabil1ty measurements are difficult. They require comparatively complicated equipment. The measurement of absorptivity, on the other hand, requires (at least with the technique used here) only a few minutes and hardly any special equipment at all. For many situations, therefore, the ability to get even a rough value of the permeability from the absorptivity coefficient vould be of value. The extent to which this can be done with these rocks is shown in Figure 20. The values plotted here are the socalled "p" values, i.e., the negative logarithms of the values. A tentative line has been drawn through the points in Figure 20. "iith the exception of the value for 47-2S the points are within a reasorable distance of this line; certainly they are close enough so that permeability values obtained in this way would be acceptable for general use.

The disparity in the case of 47-2s may be due to actual structural differences from the rest of the rocks. It should be noted that, except for the 3-IS-H-p and 47-2S samples, the absorptivity and permeability determinations were not run on the same individual pieces of rock. Any differences from piece to piece would add to the uncertainty of these points.

An illustration of the extent to which structure alters the position of points on this diagram and of the danger of generalizations is given by the point plotted for a fairly-mature cerrent paste of a 


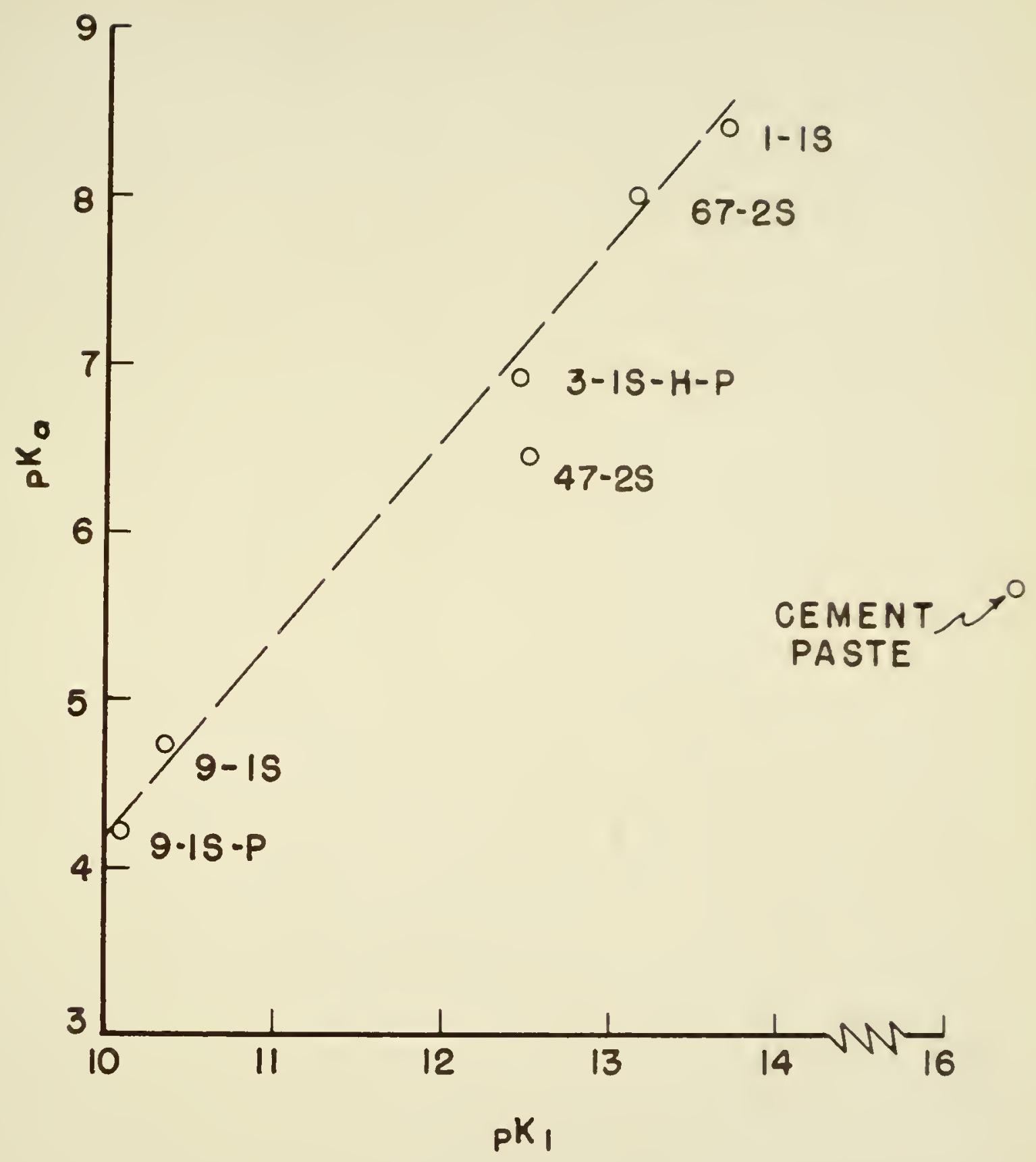

FIG. $20 \quad p K_{a}$ VS. $p K_{1}$ 
water-cement ratio of about 0.46 after bleeding. The absorptivity value was taken from Powers and Brownyard $(60 \mathrm{p} .865)$ and the permeability from Figure 6A of powers et al. (61). The large difference between the paste and the rocks is obvious. The permeability is only about $10^{-5}$ of that which a rock of this type and having the same absorptivity as the paste would have.

No advocacy for the general use of this curve is being given but It is suggested that the relation shown for these rocks is valid and perhaps a similar one exists for other types of structures. If this surmise is true, the practical advantages of the relationship are obvious.

Radii

The radii values given in Table 8 have little meaning in themselves. Their relation to durability will be taken up in the following section. They are only reflections of the porosities and specific surfaces and the comments in the following paragraphs on results of the surface area calculations apply, in a sense, to the radil also.

The fact that there are no large differences between any of these listed values should be noted. The values for 9-1s for flow parallel to the bedding planes are larger than are those for the flon perpendicllar to the planes. The situation may be though of approximately as tubes of different sizes in parallel or in series for the flow parallel and perpendicular to the laminations respectively.

The values for the slip and the permeability radii are in rough agreement as are those for the absorptivity and the sorption radii. Furthermore, the values for the slip and permeability radii are uni- 
formly and, in most instances, considerably hipher than are those calculated by the other two methods. This result is expectable from a consideration of the processes involved in the tro pairs of cares. The slip and permeability values reflect a higher pore size because the flow of air is through a saturated medium in which the larger spaces permit the major part of the flow. The absorptivity, on the other hand, may be expected to reflect a smaller pore size since the larger spaces, by the mechanism previously discussed, deny capillary absorption of the liquid. The flow, therefore, preferentially takes place in the smaller spaces.

\section{Specific Surfaces}

With respect to the results of the specific surface calculations given in Table 9, the sorption values should be the largest, i.e., no value for surface area can, theoretically, be larger than the sorption value and be valid. The sorbate presumably contacts the entire surface of the material. Inspection of the table will show that most of the values, there being several exceptions, are smaller than the sorption values for the same rocks. In comparing the values for any one source it should be remembered that the sorption, permeability, and absorptivity runs were usually done on different individual samples. They were, to be sure, taken from adjacent pieces of the same mass but they may, nevertheless, reflect inherent, short-range variations of the material.

The values calculated from slip and permeability data shom fair agreement with each other, as did the corresponding values for the radii. The essential agreement between the slip and permeability 
values is interesting in view of the sensitivity of the $b$ value (ser Figure 10, for example) to changes in experimental conditions. Probably more reliance should be placed on the permeability values than on the slip values for this reason. The use of the Cornell-katz tortuosity, $T$, rather than the Wyllie-Rose $k_{t}$ results in only a slight change in area values even for these rocks which have comparatively high tortuosities. No choice between the two concepts can be made on the basis of this comparison.

The slip and permeability area values are, in every case, considerably lower than the sorption values. This finding corroborates that of Brooks and Purcell (13) who obtained similar differences for sandstones.

The values for specific surface calculated from the absorptivity data and theory are larger than the values calculated from the permeabilities and they more nearly approximate the sorption areas. The absorptivity values are divided into two groups depending on the interpretation placed on the hydraulic radius. By definition, the hydraulic radius is the ratio of the capillary porosity to the area of the capillary walls, i.e., $m=\alpha / s_{\alpha}$. If the assumption is made that the unfilled part of the pore space has the same volume to wallarea ratio-has, that is, the same structure as the capillary-filled space--then the extrapolation can be made that $m=\varepsilon / s$. The implication of such an assumption is that the barrier to capillary flow is a meniscus overturning due to angular changes in the capillary walls and not due to the occurrence of bulges or other large spaces which the Iiquid cannot enter by capillarity. 
The data show that, saving two exceptions to be noted below, the absorptivity specific surfaces are uniformly lower than the sorption surfaces if the Wyllie-Rose tortuosities are used in the computation. No distinction as to structure can, however, be made because the data are few and there are exceptions. Other mechanisms may be operative to account for the absorptivity surfaces being smaller than the sorption surfaces. Also, since the absorptivity surfaces are inversely proportional to the absorptivity coefficients, the measurements of this property are probably not accurate enough to place great reliance on the specific surface values in the table.

They are, on the other hand, accurate enough so that it becorres necessary to account for the absorptivity surfaces being less than the sorption surfaces.

The reason probably lies in the presence of comparatively large pores which cause a higher absorptivity than is accountable to surface area. A bulge or large section in a pore will cause a retardation in the flow due to a reduction of the capillary pressure but a pore that is uniformly large will have a higher absorptivity than will a swaller one because the viscous drag is proportionsl to the square of the size while the capillary pressure is proportional only to the first porer of the size. Until now the implication has been that the pores are approrimately the same size with possible bulges here and there. Đut certainly sone pores are larger than others throughout all the in length. There are probably continuous passageways through this lite: connected pore system which are larger than other possible passzzerays, whether or not they contain bulges. The presence of such larger 
passageways negates the model to a corresponding extent and gives rise to higher absorptivities and, consequently, to lower speciflc surfaces when the calculation 13 made on the basis of the model.

The exceptions to the generalizations made conceming the various values for specific surface are the samples 3-15-H-p and 9-IS (fIJk perpendicular to the laminations). All absorptivity surface area values of these two groups of data are higher than the sorption vilues. For the case of 9-1S (perpandicular) the reason my be that the strata composed of fine pores cut down the absorptivity so much that the resultant area value is too high. In view of this result and of the other reasons mentioned earlier, it seens preferable to rn these tests with the flow parallel to any laminations.

The reasons for the results for $3-2 \mathrm{~S}-\mathrm{H}-\mathrm{p}$ are not apparent. This material may be so inhomogeneous that the pieces on which the sorptim values were run were greatly different from those on which the absorptivity was determined. An attempt was made to run the sorption test on the absorptivity piece but the weight of the sample was so lom that a reliable sorption test could not be perfornad. No otiner statements can be made concerning the matter. Further work on this rock would be necessary to determine whether or not a real difference between it and the others exists in this respect.

The general statement can be made that, except for tire case of 3-ls-H, the absorptivity method is superior to the permesbility nethod as an interpretor of specific surface. The statement applies best to the values calculated on the $m=\epsilon / S$ basis. For three cases-9-1S-p, 47-25, and 67-25--there is roughly a two to one relationship between 
the sorption and the absorptivity specific surfaces. The 1-2s emple is a poorer agreement. And the $3-1 S-H-p$ sample fills.

Absorptivity methods have received little attention for the determination of the specific surface of porous 3011 ds; permeabllity has received a great deal. If these data are vald, however, the forwer holds, for consolidated media, more promise than the latter.

It was stated in connection with the values for the permeability specific surfaces that no distinction could be made between the HyllisRose and the Comell-Katz tortuosities. A distinction can, horever, be made by means of the values for the absorptivity sreas. The arez values computed according to the Cornell-katz tortuosity concept are Iisted under the symbol $\tau_{\alpha}$ and are, in every case, higher than the sorption areas. Assuming the reasonable correctness of the model and the data, such a result tends to substantiate the Wyliie-Rose rather than the Cornell-Katz concept. The data are, of course, too fev to be firm about the point.

\section{Interpretation of Data and Results}

In this section, the information presented in the Data and the Results sections are examined from the point of view of possible correlation between laboratory data and field durability of the paverient concrete that has been made with aggrogate from the rock sources studied.

The standard for comparison is the field histories of the raterials in Indiana experience. This is a rather general yardstick and the conparisons are correspondingly qualitative. It is true that more quantitative data are available. The original blomp survey of lioods, Sreet and Shelburne (95) contains data on blowup frequency for three of the 
rocks $(1-15,9-15,67-25)$. Sweet's (81) tests included all of the sources used here and durabllity factors can be calculated from his curves. Bugg (16) and Blackburn (8) used some of these same raterials and durability factors can also be calculated from their curves. Eut the mix designs in these three studies varled, particularly nith respec to the air contents of the concrete. The durability factors show considerable variation in some cases (e.c., up to 1006 differences, even for the same aggregate, same air content, and ane type of gaturation prior to mixing).

It was decided, therefore, for the comparisons to be made here, not to attempt to use a numerical measure of durability but merely to use the field classification in a general sense. On such a basis the pavement history of these rocks is, in order of decreasing durability, 67-2S, 1-1S, 47-2S, 3-1S-H, and 9-1S. Stones 67-2S and 1-1S are about equally good. Neither has given trouble. Source 47-2S does not seen to be as bad an offender as are materials $3-15-H$ and $9-15$ and its situation may be complicated by factors other than lack of resistance to simple freezing and thawing. The field cracking pattem is not the typical D-line cracking of frost damage but seems frequently to be a more general map-crscking such as is often found in connection with chemically reactive aggregates. The ASTM "quick chemical test" for alkali reactivity does not, however, show it to be reactive. The broken concrete has, nevertheless, darkened rims inside the aggregate particles and these have been diagnosed as being due to 3lkali-3gsregate reaction (43). In spite of this, stone 47-2s has a poor rating in laboratory freezing and thawing tests when incorporated in the con- 
crete with a saturation approximating the quarrj-wet condition (31) and, therefore, has been rated here as poor in frost durability. Stones 3-IS-H and 9-IS have the poorest historles of all.

This study was chiefly exploratory in nature. The principle test methods used have rarely, if ever, been used on concrete aggregates. They have never been used in the Indians studies on these materlals. This work was done to investigate their promise as test methods in themselves, as tests for interpreting pore characteristics, and as tests for predicting aggregate durability with respect to frost action. The assumptions involved in the selection of samples is related to these purposes. These assurmtions are stated in detail in the Exper1mental section. The small pieces used in these tests cannot, obviously, be statistically representative of the sources. The essence of the point is that the samples are assumed to be representative of "good" and "bad" aggregate materials even though they may differ somewhat frow other material in the quarries.

This last assumption seems justified in all cases except that already noted, 3-1S-H. AII the tests indicate that, contrary to field performance, these samples from source $3-15-H$ ere not those of a par ticularly poor aggregate. The tests indicate a material intermediate in performance and nuch better than the field history of the source. The sampling from which these pieces were taken probably mas of a different material than that which was made into the pavenents with the poor service record. Current tests tend to confirm this conclusion (54). They show absorptions for this batch that are auch lower than those obtained on former samples from the source and that aporoxitate 
that obtained in this work. Freezing and thawing tests on concrete made with this material also show it to have superior frost resistance to that tested by former investigators. This disparity is unfortunate. The results of the tests on this rock should be interpreted in the light of the above remarks and its "bad" rating should probably be held in question here.

The various ways in which coarse aggregate can affect concrete deleteriously have been mentioned in the Review section. The pield history of the source does not discrininate between these action 3 and the confusion this may lead to may be illustrated by the case of 47-25, previously discussed. Nevertheless, since the laboratory freezing and thawing tests have reproduced reasonably the field histo ries of these materials, it will be assumed that a poor history reflects frost instability of the material in pavement concrete. Such instability often means a high blowup frequency as well, since it is thought that blown occurrence is preceded by cracking due to some other cause.

The standard test methods applied to concrete aggregates fre fuently are poor as predictors of performance with respect to freezing and thawing stability. Nany studies have show that such tests as absorption, unconfined freezing and thawing, sulfate soundness, and degree of saturation do not always give the correct prediction. Enough exceptions are encountered in their interpretation so that the results of these tests cannot be used unreservedly. Extremes, of course, can usually be recognized. A limestone with half a percent absorption, 50 percent vacuum saturation, and practically no loss in the soundness tests would probably be acceptable and, conversely, rocks having the 
other extremes in results would be rejected. But in the large middle ground, the line is difficult to draw. Highway speclfication vriter3, being unwilling to discriminate agalnst possibly good material on the basis of quasi-proven tests, frequently do not use to advantage even the tests that exist.

The necessity of the aggregate piece to acquire considerable water before it can cause frost danage has been repeatedly exphasized: "The effect of an aggregate particle upon freezing and thawing durability of concrete depends largely upon the ability of the particle to attain a high degree of saturation while it is enclosed by cement (66)." "The durability of solid materials during freezing and thawing is controlled by the freedom with which they are permeated by water (1I)." "Materials that contain no water are not likely to be harmed bj freezing (45)." The point is obvious. Agreement is universal. But how this water gets into the piece and what happens to it, with and without freezing, is not well-understood and is the question upon which research is focused.

Perhaps a brief discussion of the history of a linestone agsregaie is appropriate in order to examine the ways in which it can get, and keep, the water which is so potentially destmuctive.

At the time the rock is formed in the seimentary process, a certain amount of water, the socalled connate water, is included therein. The subsequent history of the formation in genersl and of the small part of it which later becomes the quarry in question determines what subsequent changes in the water content will take place. The position in relation to the water table is important. The rocir has, 
for geologic ages, opportunity to acquire water if it is below the water table or to lose water if it is above the table. Any changes that occur in the formation which change the perneability and porosity of the mass will be important. Dolomitization, faulting, cracking, and secondary deposition in cracks, are factors which can alter these properties and can influence the water content.

When the rock is quarried it will have a certain "quarry-wet" degree of saturation which is determined by the above-mentioned fectors. The rock is then crushed. Whether or not it is stockpiled prior to its use in the concrute is an important quegtion. If it has an opportunity to dry out at this point the frost durability of the cor.crete made with it can be materially improved. Conversely, if it is unprotected from the rain it can becone even wetter.

The aggregate is then mixed with the other components of the concrete and, restricting the discussion to pavement concrete, the slab is laid. One of these components of concrete is, of course, water. While the mixture is plastic an opportunity exists for the agsregate to pick up water. Once the initial set has taken place, the agsregate must compete with the surrounding paste for any water it gets. The matter becomes more complicated. During the period when the cement is hydrating comparatively rapidly a self-dessication of the paste occurs. Water in what are to become the capillary pores is withdram into the gel to continue the hydration process. Even effective curing methods apparently cannot prevent this self-dessication of the paste and it is reasonable to suppose that water can be withdraw from the aggregate as well at this time. 
If, at this stage of the process, the stone is saturated to a dangerous extent and freezing occurs, disruption can start at once. A rach more common situation, however, is for the pavement to give service for a number of years and for the damage to become appartni only after some time. After symptoms begin to appear the cordition of the pavement becomes progressively worse until it is unserviceable. Mechanisms for the acquisition of water must, therefore, take this time element into account.

If the surrounding paste forms a perfect seal, the agregate plece can obtain water only by capillary attraction from the reste. Various reviewers have discussed this aspect of the matter $(11,59,66)$. The basic consideration is the relative size of the pores in the paste ard in the rock. If the capillary potential in the rock is higher than that of the paste at the degree of saturation in ruestion, the rcck will extract water from the paste and vice versa. Powers (59) staied that the pores in most rocks were larger than those in the paste and that, therefore, the rock could acquire water by capillarity only if the paste vere saturated. He apparently based his statement on permeability measurements of pastes and various rocks (61). Blanks (11) reported measurements on rocks and on concrete using an apparatus which measured the capillary pressure of the smallest gection of the largest continuous pore through the sample. The capillary pressures were then converted to the equivalent radii of round pores. His results showed certain argillaceous limestones to have a "pore size" smaller than those of the concrete specimens tested. He concluded that water could, therefore, move by capillarity from the paste into 
the aggregate particles.

The situation has other aspects. Powers'(58) extensive studies on hardened cement paste have show that the capiliary pores in a paste are, for normal water-cement ratios, discrete vold spaces and that only at comparatively hich water-cement ratios do they lint. up to form a connecting network. Paving mixes are stiff enouch to fall into the category of "normal water-cement ratios." If this picture is accurate, an aggregate particle enclosed in a perfect paste rould be surrounded by a gel structure which would contain isolated "capillarj" pore spaces whose size would be a function of the water-cement ratio but which would be, very roughly, about the same as that of the pores in most dense rocks. These capillary pores would presurably be at least partly filled with water. So would the pores in the rock. But the two kinds of pores would be separated by a gel whose characteristic pores are only a few times the size of a water molecule and whose permeability is exceedingly small. The permeabllity of a paste which has no capillary pores ( $w / c$ about 0.35 ), i.e., the permeability of the gel alone, has been determined (61) to be in the neighborhood of $10^{-6} \mathrm{md}$. This is the material that water would have to traverse in moving between rock pores and paste cepillaries. If the paste capillaries were not saturated the driving force for water movement would be the difference in capillary pressure between the capillaries and the rock pores. Under these conditions, the two kinds of pores being even approximately equal in size, the flow of water would be vanishingly small. The maximum flow would take place wher the paste capillaries were saturated and could remain so by acquisition of water 
from an outside source. Even in this clrcunstance, the Ios would still be small. For a slab, however, that is situated on a poorlydrained subgrade and whose underside is continually wet, saturation of the aggregate particles by this mechanism would be possible. It would take a long time. Whether or not this mechanism is principally responsible for the long-time aspects of frost darage is a question that cannot be answered now; but it is a possibility.

The "perfect paste" that has just been discussed is hardly ever a real1ty. A number of things can and do happen which destroy its ability to seal the aggregate effectively. The webs of gel which separate the paste capillary pores from each other and, presumably, also the abregate from the capillaries, may be broken by drying shrinkage. Porers et al. (61) found large increases in the permeability of a paste upon drying it to equilibrium with about eighty percent humidity. He postulated cracking of these webs to account for his results. Such cracking would tend materially to decrease the barrier to the flow of water between the aggregate pores and the paste capillaries. During the early stages of hydration, bleeding channels are formed throughout the mass. Spaces appear under aggregate particles due to setting of the materials, particularly for the case of flat particles. Spaces may occur at the surfaces of aggregate particles due to poor adhesion, and imperfect consolidation of the concrete can leave a variety of spaces in its interior. Many of these spaces would act as macropores which would be difficult to fill by capillarity. But others, particularly the micro gel cracks and any channels leading from an outside surface into the interior of the slab might facilitate the entrance of rater 
into the mass and thereby, into the aggregatc particles.

Another process, which may be important in admitting water to the intertor of the concrete, is paste failure due either to frost action or to wetting and drying. If the paste capillaries become saturated, and particularly if properly-spaced entrained-air bubbles are absent, the paste can dilate and crack upon freezing. The mechanisms of this action have been listed in the Review section. Since the gel swells and shrinks on wetting and drying, it is reasonable to assume that cracking can result from this action as well. Either kind of damage would open the concrete and aggregate to easier invasion by water.

These mechanisms could also be augmented by failure of the aggregate pieces and the surrounding mortar due to checmical or thermal instability of the rock. Cracking due to overloading is not considered as a lack of durability but could, of course, augment the destructive processes that have been outlined.

All these actions tend to open the concrete to penetration by water and to make the acquisition of this water by the aggregate easier. Wany of these processes are long-time in their nature and may help to account for the interval that frequently takes place before overt frost damage appears.

Once the aggregate became saturated to a critical degree and began to cause freezing-and-thawing dilation and failure, the situation would become progressively worse. Damage would cause more darage until the slab could no longer perform its structural job. Entrained air helps the situation in, presumably, two wass. Cne way, probably the more important, is to protect the paste from frost 
damage and so to permit it to seal the ageregate more effectively. The other is to provide, in the form of air voida adjacent to the aggregate, a certain amount of space into which water forcod out of a saturated piece by progressive freezing could move. Whatever the mechanism, studies have show that the use of air-entresinins cerent helps the frost durability of these materials.

However the water may enter the mass, whether by any or all of the mechanisms outlined, its acquisition and retention by the aggregats is probably fundamental to any freezing-and-thawing instability of the concrete which is caused by the aggregate. Emphasis should, ani will, be given this aspect of the protlem. Powers (59) stated the proposition clearly - - ". . a principal difference amon' different rinds of rock particles is the rate at which they become satursted when given free access to vater."

Still another possible mechanism for disintegration is iatigue cracking from repeated freezing. Altinough any one stress application would not cause rupture, the fatigue effect might eventually cause a crack. This process would also take a long time but night not necessitate such high aggregate saturations.

The data reported here on porosity, absorption, and saturation can add little to previous work on these properies of these materials. Sweet (81) found the materials with good durability to be charscterized by a voids ratio for voids smaller than $5 \mu$ in diapeter of less than 0.06 . This value corresponds to a porosity of about 0.057 so by this criterion any rock whose total porosity was less than this ajount would, perforce, be a durable one. Other things being equal, the 
higher the porosity the porer the freezing and thaming prospects for the raterial, but the danger of sucla generalizations is show by the exaraple cited by Rhoxdes and líelenz (66) of a volcanfc taterial vilth an absorption of almost 25 percent which had, in concrete, a coraparitively good freezing and thawing record.

There is an absolute lower limit to the conceivably harmful porosity below which, even if saturated, the rock can elastically accomodate any volume increase on freezing. Host sedirnentary rocks probably have porosities higher than this minimum value.

The only serious departures of the data from previous values are for the case of the sample of 3-1S-H stone. The values (Table 3) of around 45 and 71 percent saturation for the inmersed and evscuated conditions respectively are much lower than, for instance, Sweet's (81) values of about 80 and 90 percent. This is a clear indication of the statement made at the beginning of this section that the material used in this work from this source does not represent a bad aggregate. Although the absolute critical saturation value for aggregate particles is about 91 percent, the practical value, for reasons ientioned in the Review section, is probably somerhat lower-around 85 percent perhaps. But this saturation is that of the particle in the concrete and the problem is to determine which, if any, of the wethods of test on the aggregate alone gives an accurate indication of this value. The tendency has been to emphasize the vacuur saturation values (47) pussibly on the pragmatic grounds that this is almost invariably the only method bj means of which saturations in the high and critical region are obtained. An inspection of the appropriate tables ( 3 and 7) 
will show that in no case was the 24-hr. immersion or the absorptivity saturation value high enough to be critical. The fuarrg-vet saturation can, however, be much higher than these capillary absorption values, since geologic tine has been available for the entrance of water.

An interesting observation, which has a bearing on the guestion of the rate at which these materials absorb water, can be made by comparing the values for the saturations obtained in the resistivity experiments, $S_{\text {we }}(\mathrm{Table} 4)$, with those for the immersed and evacuated conditions (Table 3). The resistivity saturations, as previously described, vere mu by vacuum saturating the materlal but letting it soak for only an hour or so rather than the 23-hr. period of the usual vacuum technique. $(3-15-H$ is an exception. It was allowed to go the full 24-hr. period because both values were being obtained simaltaneously.) The good materials (1-1S, 67-2S) had not attainet, in spite of the evacuation, even their 24-hr. imersion values while the poor materials (9-1S, 47-2S) had attained saturations approximately equal to those of the usual vacuum method. The marked reluctance, evacuation notwithstanding, of the good materials to pick lo the liquid is obvious.

Tortuosity apparently has nothing to do, per se, with the question of the durability of the materials. Even if the very high value for I-IS is disregarded the others show no recognizable relation to the quality of the stones.

The results of the sorption specific surface deterinations confima the findings of Blaine, Hunt and Tomes (10) that the materials 
with poor durability have hisher specific surfices than do those with good durability. This finding is, of course, partly misleading 3 ince a comparatively high porosity will give rise to a comparatively high surface area even if the pore stmucture is not different in the two cases being compared.

The low result in the case of material from source 3-15-H has already been discussed.

It should be noted that the sorption surfaces reflect durability in a qualitative sense only, e.g., the specific surface of stone 9-IS is about twice that of stone 67-2s but the durability ratio of tne two materials is enormously greater.

The results of the radii calculations (Table 8) show the inadequacy of an average value or pore size (determined, at least, by any of the four nethods used here) for the purpose of distinguishirg betrieen good and poor-performing aggregate materials. The table shows no discemible relation between the two properties. The inadequacy of the simple madel and the complex nature of the actual pore characteristics and of their relationsip to durability are particularly evident here. It seems to the writer that the capillary pressure apparatus of Blanks (11) would suffer from similar shortcomings. The value for pore size obtained with this apparatus is that of a round tube which has a capillary pressure equal to that at the smallest opening in the largest continuous passageway through the material. Such a value is rather aroitrary but Blanks nevertheless obtained pore size values which were not only reflections of durability but conformed, more or less, to the $5 \mu$ diameter dividing line which has become semiconventional. 
Probably experiments, such as those with the mercumy prosimeter, which give data showing the distribution of pore volume accor ling to size would be more valuable than averape-value tecnniques. Expense and complexity are disadvantages to the mercury porosineter but its use with concrete aggregate materials is clearly desirable.

The values for the absorptivity and pemeability coeficicnts show promise with respect to correlation vith durability. An examination of Tables 6 and 7 will show that for both these coefficients the good aggregates (1-15, 67-2S) have the smallest values, the bad-butintermediate ones $(3-1 S-H, 1+7-2 S)$ have intermediate values, and the worst material (9-IS) has the largest value. These three groups are, furthermore, distinct from each other, the values, for the most part, being separated by powers of ten. A comparatively high absorptivity means a comparatively high rate of water absorption ior the material in question and this, in turn, should mean a correspondingly low durzbility. But beyond a certain minimum absorption, the degree of saturation may be more important than the overall absorption. For instance, a material could have a high absorption but if this amount of water filled only half the pore space the material would probably be durable in freezing-and-thawing action. The rate at which the saturation changes might, therefore, give insight concerning the comparative durability of the materials. This matter was evaluated by dividing the square root of the absorptivity coeficient by the appropriate porosity $(\epsilon$ or $\alpha)$. The square root of the absorptivity is the volure (cm.3) of water that would enter a cube $1 \mathrm{~cm}$. on a side in 1 see. The bulk volume of this cube would be $1 \mathrm{~cm} .3$ and the pore volume would 
therefore be $\epsilon$ or $\alpha \mathrm{cm}^{3}$, depending on whether the total or "capillamy" porosity was being used. The ratio of $\mathrm{K}_{a} \frac{1}{3}$ to the porosity is therefore the degree of saturation at $1 \mathrm{sec}$. for this unit cube. The valuez so computed are listed in Table 10 and are called the "unit saturat10.3."

Table 10

Unit Saturations

Source No.
$K_{a}^{\frac{1}{2}} / \varepsilon$
$K_{\mathrm{a}}{ }^{\frac{1}{2}} / \alpha$

I-IS

0.00248

0.00576

$3-I S-H-p$

0.00348

0.00578

9-15

0.0176

0.0241

$9-15-p$

0.0320

0.0475

47-2s

0.00764

0.0125

$67-25$

0.00429

0.00775

The values have no meaning in themselves. On a comperative basis, they reflect the respective durability histories rather well with the high values indicating low durability and vice versa. Again the exception is 3-1S-H; it has dropped dam to a position near the good aggregates which may well be where it belongs as far as these samples are concerned. Preference between the use of $\varepsilon$ or $\alpha$ in this connection is a moot point.

A high absorptivity is, by the nature of things, associated with a high permeability. Figure 20 shows this general relationship. How ever, within the framowork of the absorptivity and capillary properties 
of the material, a high perneability is preferable. An indication of the magnitude of a relationship of this sort is given by the ratios of $\mathrm{K}_{2}$ to $\mathrm{K}_{I}$ which are tabulated in Table 11.

Table 11

Absorptivity-Perneability Ratios

Source No.

$1-15$

$3-1 S-H-p$

9-15

$9-15-p$

$47-25$

$67-29$

$$
\left(10^{-5}\right) K_{a} / K_{I}
$$

$$
\begin{aligned}
& 1.85 \\
& 3.44 \\
& 4.30 \\
& 7.45 \\
& 10.2 \\
& 1.39
\end{aligned}
$$

The values used in computing these ratios are the ones which rere plotted on Figure 20. The statement made earlier that, while a general relationship between $K_{a}$ and $K_{I}$ might exist for these materials, the small differences therein might be imoortant, begins to have meaning. With these ratios a cistinction is possibie on the basis of the durability histories with the poor materials having higher values for the ratio than do the more durable materials. (In Tatles 10 and 11 the values for 9-1S perpendicular (i.e., no "p" after the source nurber) have been included for the sake of completeness but heve been inored in the assessments because of the previously-stated preference for data from parallel flow experiments.) The value for 47-2s is too high when it is compared with that for 9-1s in the light of their relative 
durabilities. The approximate reflection by these $K_{\mathrm{a}} / \mathrm{K}_{1}$ ratios of the relative durability of the materiais is in conformity with peneral theoretical expectations. The higher the absorptivity and the lomer the permeability, i.e., the larger their ratio, the less durable vould a rock be expected to be in concrete because it would tend to gain water relatively rapidly but would present a comparatively high obstruction to its movement on freezing. The case for the more durable raterials would be the converse.

Whether these ratios have any lisefulness in describing the pore structure of these materials is an interesting possibility. If the material had bulges in the pore system and these bulges were responsible for the limitation of capillary absorption, the material would tend to have a comparatively high perneability for its absorptivity, i.e., a low value of the $K_{a} / K_{I}$ ratio. It would also have a comparatively low caplllary saturation. The data on the rocks $1-1 S$ and $67-2 \mathrm{~S}$ fit this picture. 1-1S has some voids which are large enough to be visible to the naked eye and might, therefore, tend to fit such 3 "buIge" theory. But 67-2s is a dense, fine-grained stane with no apparent macropores. The fact that they cannot be seen does not, of course, prove them to be absent.

If the material did not have bulges it would have a relatively lower permeability and, therefore, a higher ratio of $K_{2}$ to $K_{I}$. 1eIcury porosimeter hysteresis data would be necessary to prove the point. Whether or not the values in Tables 10 and 11 have any real relation to durability or structure, the measured values that were used in their calculation are felt to be accurate enough so that the differ- 
ences between the values for the various rocks (with respect to the durability interpretation) are real rather than epparent. 
SUMMARY OF FESULTS

The following is a recapitulation of the major findings of this study:

1. The use of the volumenometer and KcLcod gage porosimeter techniques gave values for the true and bulk densities which rere precise and were consistent. In the case of the bulk densities, the computed values compared favorably with those obtained by measurement of the sample dimensions.

2. The electrical analog values for the tortuosity of the racks ranged from 10 to 384 . This latter value is unusually high and its measurement was difficult. The next highest value was 65 . No apparent relation was found between the durability histories of the materials and their tortuosities.

3. The specific surfaces of the rocks, as deternined by the sorption method and the BET theory, ranged approximately from 0.7 to $2.5 \mathrm{~m} .2 / \mathrm{g}$. The poor materials had the higher specific surfaces but the differences were only qualitative. The sorption data followed the BET theory at the low humidities used. The $C$ values of the BET equation were too low to permit the use of one-point approximation nethods. 4. The values for the permeability of the rocks ranged approximately from 0.002 to $8 \mathrm{md}$. A fair distinction could be made between the rocks with good, poor, and bad durability reconds on the basis of their permeability values. The permeability data corresponded to the Klinkenberg slip theory in all cases but the slip (b) factors bore no relation to the durability histories. A few tests at low mean pressures 
advanced the possibility of simplifying the test procedure considerably with relatively little sacrifice in precision. In the case of one of the laminated rocks the permeability parallel to the laminations was roughly twice that perpendicular to them.

5. The absorptivity test method was found to be simple and reliable. An equation was developed which relates the absorptivity coefficient to the pore characteristics of a model. The data show agreement with theoretical expectations. The absorptivity values for the rocks ranged from $4 \times 10^{-9}$ to $6 \times 10^{-5} \mathrm{~cm}^{2} / \mathrm{sec}$. The values for the good, poor, and bad materials were separated by order of magnitude differences, the good materials having the lorer absorptivities. The saturations obtained in the absorptivity runs vere in rough agreement with the 24-hr. immersion values.

6. The pore radii of the rocks calculated from the slip and permeability theories were in rough agreement with each other and were larger than those calculated from the absorptivity theory. The latter values approximated those calculated from the sorption specific surfaces and the porosities. The values from the saturated flow experiments ranged from 0.2 to $1.7 \mu$ and those from the absorptivity experiments from 0.01 to $0.2 \mu$. There was no relationship betweer the durability histories of the rocks and their average pore radii calculated by any of the four methods.

7. The specific surfaces calculated from the slip and the permeability theories were much lower than the sorption surfaces. The absorptivity surfaces were lower than the sorption surfaces alsc but the agreement was considerably better than was that for the saturated 
flov methods. For the cases of materlals 3-13-H and 9-25 (nerpendicular flow) the absorptivity surfaces were hlgher than the sorption surfaces. The absorptivity surfaces, calculated for just the capillarypenetrated portion of the stmucture, vere higher than the sorption surfaces in every case when the Cornell-Katz tortuosity was used rather than the Hyllie-Rose tortuosity. The specific surfices calculated from the Powers and Brownyard equation relating absorptivity and perneability were extremely low, about a thousandth of the sorption surface values. 8. A fairly-good empirical relationship was found between tre absorptivity and permeability of the rocks when plotted as tre nezative logarithms of the values and to a linear scale. The values for the rocks on this basis were many onders of magnitude different from a value for hardened cement paste which was obtained from the literature.

9. The ratios of the absorptivity to the permeability ranged from about $10^{5}$ to $10^{6}$ and permitted a good distinction between the materials with good and bad service records. The ratio was higher for the poor materials if allowance is made for the probable differences between this 3-IS-H sample and the durability history of the source.

10. The unit saturations by absorptivity, i.e., the saturations a $1 \mathrm{~cm}$. cube would have after $1 \mathrm{sec}$. of exposure, ranged from about 0.002 to 0.03 and showed a clear relation to the durability histories, being higher for the poor materials (with the same qualification concerning 3-1S-H).

11. When the absorptivity test was performed an a reef rock with a very open structure, the results failed to follar the theoretical expectations. 


\section{CONCLUSIONS}

Based on the results of this study, the following conclusions seem reasonable. The parts of them which apply to the materials treted can logically be expected to apply only to other materials of the sare type. The results on the reef rock (Append ix F) illustrate this restriction.

1. The rate of saturation of the material, as mezsured by the "unit saturation," is a comparative index of the frost durability of pavenent concrete made with the aggregate. The lass durable materials have comparatively high "unit saturations."

2. Although more porous materials naturally have inigher absorptivities and permeabilities tian do less porous materials, the ratio of the absorptivity to the permeability is an intex of the frost liurability of pavement concrete made nith the aggregate. The lass durihla materials have a comparatively high ratio.

3. Specific surface is a falr indication of frost durability. The less durable materials have a comparatively high specific surface.

4. The method used to deternine the absorptivity coefficient is simple and reliable. For rociss of this tyoe a general relationship exists between the absorptivity and the permeability coefficients. This relationship is sufficiently exact to justify the process of the roush determination of permeability by making absorptivity masurements, especially considering the experinental ease of the latter method compared with the difficulty of the former. 
5. Absorptivity methols are considerably better thin rer restility methods for the deternination of the specific surface of selimentary rocks. Nevertheless, the use of the absorptivity methol may be expected to give values which are lovrer than the total internal surface.

6. The use of the gas-compression volumenometer and of the Mcleod gage porosimeter have attractive features which recomend their further applications to aggregate materials for the purpose of determining densities and porosity.

7. The use of one-point approximation methods in the sorption deternination (with water vapor) of speclfic surface is inacurate for this kind of substance.

8. The tortuosity of a rock has no direct relation to the durability of the rock as a concrete aggregate.

9. No distinction can be made betreen stones rith good and poor durability characteristics on the basis of average pore radii, when a comparatively simple capillary model is used to interpret the results of fluid flow exporiments. 


\section{RECOIN. LWDATIOHS}

The following are general proposals which seern desirsble to amplify and extend this study.

An obvious extension, which is the result of a defect in this study, is the procurement and testing of better samples of $3-25-4$. Samples should be obtained from the more absorptive led:ez to see $\dot{L}^{\circ}$ their properties it the proper place in the general correlations with durability.

The stone from source 47-23 should be further investizated with respect to its chemical reactivity. This subject was mentioned in the Discussion. Particularly, the aciu-insoluble residue of this rock should be examined for the presence of expansive clay minerais. The nature of the darkened rims inside the aggregate pieces should be investigated to determine what possible harmful reactions are tuking place.

The feasibility of detemining the permeability-slip curve by $a$ single low-pressure run should be determined. The present realits are inconclusive and such a arocedure would represent a considerable saving in tine.

Hore naterials should be studied to amplify the results obtained here. Sampling should be more representative and concurrentlygathered material should be mado into concrete whose durability shouli be deteruined by standard procenures. The comperison of results could then be made in terins of durability factor or some other quantitative measure of performance. 
Rates of absorption and saturation shouli be sisdicl by afes. of the standard tests for these propertics. These wetnods !ay: ine z:y tage of using a large sample which does not re guire shapin, Valuzida information might be easily obtained from such a projram.

The question of the degree of saturation and tine failure to obtain complete saturation should be studied. Tro possible apprsaches are 1) using large pressures to overcone any capillar; pressure reversals (some work along these lines has already been done) ant 2) evacuating the sample on a pump, saturiting it vith amonia, and admitting water to see what degree of saturation would result.

Nercury porasimeter data should be obtained for sgriegates in orler to relate pore-size distribution and other stmctural facturs to frost susceptibility. Such an investigation offers great promise. Work should be done, if possible, to devise a simpler methal for tne determination of pore-size distribution. All current mathods have disadvantages. 
1. Adam, N. K., "Principles of Penetration of Li ruids Into Solirs," Discussions Faraday Soc. No. 3, 5 (1948).

2. Arnell, J. C., "Permeability Studie.3. I. Suriace Area Veasurements Using a Modified Kozeny Equation," Cän. J. Kesearch A 24, 103 (1946).

3. Arnell, J. C., "Perneability Studies. II. Surface Area Leasurements of Inorganic Pigment Powders," Can. J. Research 425 , 191 (1947).

4. A.S.T.M., "Standard Method of Test for Specific Gravity of Soila, D854-52," Am. Soc. Testing Materials, Standards 1952, F. III, 1447.

5. Bangham, D. H. and Razouk, R. I., "The wetting of Charcosl and the Nature of the Adsorbed Phase Formed from Saturated Vapors," Trans. Faraday Soc. 33, 1463 (1937).

6. Barrer, R. M., "FIuid Flow in Porous Media," Discussions Faraday Soc. No. $3,62(1948)$.

7. Birks, J., "An Evaporation Kethod for Measuring the ReslstivityWater Saturation Characteristics of Cores," J. Ingt. Petroleum 40, 14 (1954).

8. Blackburn, J. B., "Freeze and Thaw Durability of Air-Entrained Concrete Using Indiana Aggregates," Highway Research Boam, Proc. 28, 171 (1940).

9. Blackbum, J. B., "A Study of Varlability in Concrete Freeze-Thaw Test Data," Thesis, Purdue University, 1955.

10. Blaine, R. L., Hunt, C. k., and Tomes, L. A., "Use of Intermal Surface Area Heasurements in Research on Freezing and Thawing of Materials," Highway Rosearch Board, Proc. 32, 293 (1953).

11. Blaniss, R. F., "Modern Concepts Applied to Concrete Aggregates," Proc. Am. Soc. Civil èngrs. 75, 441 (1949).

12. Bonillas, W. K., "Evaluating Lw-Permeability Cores," Petroleus Engr. 26, No. 7, B65 (1954).

13. Brooks, C. S., and Purcell, in. R., "Surface Area Heasurements on Sedimentary Rocks," J. Petroleum Technol. 4, 289 (1952).

14. Brunsuer, S., "The Adsorption of Gases and Vapors. Vol. I. Pnysical Adsorption," Princeton University Press, Princeton, N.3., 1943. 
15. Brunauer, S., Ernatt, P. H., and Teller, E., "Adsorption of Gases in Miltimolecular Layers," J. Am. Chem. Soc. 60, 309 (1938).

16. Bugg, S. L., "Effect of Air Entrainment on the Durability Characteristics of Concrete Aggregates," Highway Research Board, Proc. 27, 156 (1947).

17. Burdine, N. T., Gournay, L. S., and Reichertz, P. P., "Pore Size Distribution of Petroleum Reservoir Rocks," J. Petroleum Technol. 2, $195(1950)$.

18. Carman, P. C., Trans. Inst. Chem. Engrs. (London) 15, 150 (1937).

19. Carman, P. C., "Perreability of Saturated Sands, Solls, and Clays," J. Agr. Sci. 29, 262 (1939).

20. Carman, P. C., "Some Physical Aspects of nater Flow in Porous Media," Discussions Faraday Sac. No. 3, 72 (1948).

21. Cook, H. K., "Permeability Tests of Lean Mass Concrete," Am. Soc. Testing Materials, Proc. 51, 1156 (1951).

22. Cornell, D. and Katz, D. L., "Flow of Gases Through Consolidated Porous Media," Ind. Eng. Chem. 45, 2145 (1953).

23. Dolch, W. L., "Solubility Studies of Indiana Limestone," Thesis, Purdue University, 1949.

24. Eley, D. D. and Pepper, D. C., "A Dynamical Determination of Adhesion Tension," Trans. Faraday Soc. 42, 697 (1946).

25. Ergun, S., "Determination of Geometric Surface Arez of Crushed Porous Solids," Anal. Chem. 24, 388 (1952).

26. Fancher, G. H., Lowis, J. A., and Barnes, K. B., "Some Physical Characteristics of Oil Sands," Penn. State Coll. Mineral Ind. Exp. Sta., Bull. No. 12, 65 (1933).

27. Faris, S. R., Goumay, L. S., Lipsom, L. B., and ivebb, T. S., "Verification of Tortuosity Equations," Bull. Am. Assoc. Petroleum Geol. 38, 2226 (1954).

28. Fears, F. K., "Determination of the Pore Size of Four Indiana Limestones," Thesis, Purdue University, 1950.

29. Foster, A. G., "Pore Size and Pore Distribution," Discussions Faraday Soc. No. 3, 41 (1948).

30. Fox, R. G. Jr. and Dolch, i. L., "A Technique for the Determination of a Thermal Characteristic of stone," Highway Research Board, Proc. 30,180 (1950). 
31. Gleysteen, L. F. and Kalousok, G. L., "Simplified Methed for the Determination of Apparent Surface Area of Concrete Products," Proc. Am. Concrote Inst. 51, 437 (1955).

32. Heid, J. G., Mckahon, J. J., Nielsen, R. F., and Yuster, J. T., "Study of the Permeability of Rocks to Homogeneous FIuids," A. Petroleum Inst., Drilling and Production Practice, (1950).

33. Hodgman, C. D., ed., "Handbook of Chemistry and Physics," 30th. ed., Chemical Rubber Publishing Co., Cleveland, Oh10, 1947.

34. Howe, J. A., "The Geology of Bullding Stones," Edward Amold, Londor, 1910.

35. Johansen, R. T., Lorenz, P. B., Dodd, C. G., Pidgeon, F. D., and Davis, J.W., "The Permeation of liater and Isooctane Through Plugs of Microscopic Particles of Crushed Quartz," J. Phys. Chem. 57, 40 (1953).

36. Jones, F. E., "The Phygical Structure of Cement Products and Its Effect on Durability," Proc. 3rd. Intern. Symposium on the Chem. of Cement (London), 368 (1952).

37. Jones, J. C., "The Relation of Hardness of Brick to Their Resistance to Frost," Trans. Am. Ceram. Soc. 9, 528 (1907).

38. Kamack, H. J., "Slmple Air-Permeability Nethod for Heasuring Surface Areas of Fine Porders," Anal. Chem. 26, 1623 (1954).

39. Katz, M. J., "An Explicit Function for Specific Surface Area," Anal. Chem. 26, 734 (1954).

40. Klinkenberg, L. J., "The Permeability of Porous Media to Liquids and Gases," Ars. Petroleum Inst., Drilling and Production Practice, 200 (1941).

41. Kreuger, H., "Investigations of Climatic Action on the Exteriors of Buildings," Trans. Roy. Swedish Inst. Sci. Ind. Research, No. 24 (1923).

42. Lambe, T. W., "Soil Testing for Engineers," John Wiley and Sons, New York, 1951.

43. Lewis, D. W., personal communication.

44. Lewis, D. W. and Dolch, W. L., "Porosity and Absorption, Am. Soc. Testing Materials, Special Tech. Pub. No. 169, 1955.

45. Lewis, D. W., Dolch, W. L., and Woods, K. B., "Porosity Deteminations and the Significance of Pore Characteristics of Aggregates," Am. Soc. Testirig laterials, Proc. 53, 949 (1953). 
46. Lewis, D. W. and Venters, E., "Deleterious Constituents of Indiana Gravels," Highway Research Board, Bull. 94, 1954.

47. Lewis, D.W. and Woods, K. B., "Research as Related to the Development of Aggregate Specifications," Purdue University, Engrng. Expt. Sta., Reprint No. 51 (1950).

48. Loeb, L. B., "The Kinetic Theory of Gases," 2nd. ed., Chap VII, McGraw-Hill Book Co., New York, 1934.

49. Lu, N. Y., "Comparison of the Thermal and Moisture Expansion of Concrete and Stone," Thesis, Purdue University, 1947.

50. Madgwick, E., "Some Properties of Porous Bullding laterials. I. The Absolute Porosity and Saturation Coefficient," Phll. Uag. I2, 1155 (1931).

51. Madgwick, E., "II. The Flow of Air Through Porous Bodies," Ph1l. Nag. 12, 1160 (1931).

52. Madgwick, E., "III. A Theory of the Absorption and Transmittion of Water by Porous Bodies," Phil. 162. 13, 632 (1932).

53. Madgwick, E., "IV. The Determination of the Absorption Constants of a Homogeneous Specimen," Phil. Mag. 13, 641 (1932).

54. McLaughlin, J.F., personal communication.

55. Muskat, K., "The Flow of Homogeneous Fluids Thraigh Porous Ledia," J. i. Edwards, Inc., Ann Arbor, Mich., 1946.

56. Perry, J. H., ed., "Chemical Engineers' Handbook," 2nd. ed., H'crrawHill Book Co., New York, 1941.

57. Powers, T. C., "A Working Hypothesis for Further Studies of Frost Resistance of Concrete," Proc. Am. Concrete Inst. 41, 249 (1945).

58. Powers, T. C., Discussion, Proc. 3rd. Interm. Symrosium on the Chem. of Cement (Lond on), 425 (1952).

59. Powers, T. C., "Basic Considerations Pertaining to Freezing-andThawing Tests," To be published by Am. Soc. Testing 'iaterials.

60. Powers, T. C. and Bramyard, T. L., "Studies of the Fhysical Properties of Hardened Portland Cement Paste," Proc. Am. Concrete Inst. $43,101,249,469,549,66 \%, 845,865,933,971(1947)$.

61. Powers, T. C., Copeland, L. E., Hayes, J. C., and Mann, H. U.., "The Permeability of Portland Cement Paste," J. Am. Concrete Inst. 26, 285 (1954). 
62. Powers, T. C. and Helmuth, R. A., "Theory of Volume Changes in Hardened Portland Cement Paste During Freezlne," Hiftway Research Board, Proc. 32, 285 (1953).

63. Purcell, W. R., "Capillary Pressures--Their beasurement Using Kercury and the Calculation of Permeability Therefrom," J. Petro leum Technol. 1, 39 (1949).

64. Razouk, R. I., General Discussion, Discussions Paraday Soc., Ho. 2, $119(1948)$.

65. Reilly, J. and Rae, N. Ro, "Physico-Chemical Methods," Vol. I., 5th. ed., Chap. XII (Section 2), D. Van. Nostrand Co., Ner York, 1953.

66. Rhoades, R. and Mielenz, R. C. "Petrography of Concrete Aggregate," Proc. Am. Concrete Inst. 42, 581 (1946).

67. Rhoades, R. and Kielenz, R. C., "Petrographic and Lineralogic Characteristics of Aggregates," Am. Soc. Testing Materials, Special Techn. Pub. No. 83, 20 (1948).

68. Rideal, E. K., "On the Flow of Liquids Under Capillary Pressure," Phil. Mag. 44, 1152 (1922).

69. Rigden, P. J., "The Rheology of Non-Aqueous Suspensions," Dept. Sci. Ind. Research, Road Research Paper No. 28, H.H.S.O., London, 1954.

70. Ruettgers, A., Vidal, E. N., and iing, J. P., "An Investigation of the Permeability of Mass Concrete with Particular Reference to Boulder Dam," Proc. Am. Concrete Inst. 31, 382 (1935).

71. Schaffer, R. J., "The Weathering of Natural Building Stones," Dept. Sci. Ind. Research, Building Research Special Dept. No. 18, H.K.S.O., 1932 .

72. Scheidegger, A. E., "Theoretical Models of Porous Hatter," Pro ducers Monthly 17, No. 10, 17 (1953).

73. Scheidegger, A. E., "Statistical Hydrodynamics in Forolis Hedia," J. Appl. Phys. 25, 994 (1954).

74. Scheidegger, A. E., "General Statistical Hydrodynamics in Forous Ledia," Geofis. pur. e appl. 30, 17 (1955).

75. Scholer, C. H., "Significant Factors Affecting Concrete Durability," Am. Soc. Testing Materials, Proc. 52, 1145 (1952).

76. Seipp, H., "On the Theory of the Action of Frost on Natural Building Stones," Proc. 5th. Intern. Congr. Pestlng Haterials, 1909. 
77. Slate, F. O., "Chemical Reactions of Indiana Ageregate in Diaintegration of Concrete," Am. Soc. Testing Materials, Proc. 49, 954 (1949).

78. Slate, F. O., "Comprehensive Bibliography of Cement and Concrete. 1925-1947," Joint Highway Research Project, Engrng. ixpt. Sta., Purdue Univ., Lafayette, Indiana, 1949.

79. Sweet, H. S., "Chert as a Deleterious Constituent in Indian? Aggregates," Highway Research Board, Proc. 20, 599 (1940).

80. Sweet, H. S., "Physical and chemical Tests of Hineral iggregates and Their Significance," Arn. Soc. Testing Laterials, Special Tech. Pub. No. 83, 49 (1948).

81. Sweet, H. S., "Research on Concrete Durability as Affected by Coarse Aggregates," Am. Soc. l'esting Haterials, Proc. 4E, 988 (1948).

82. Sweet, H. S., "Concrete Durability as Affected by Coarse iggregates," Thesis, Purdue University, 1948.

83. Sweet, H. S, and woods, K. B., "lapcracking in Concrete Paveronts as Influenced by Soil Textures," Highway Research toam, Froc. 26, 286 (1946).

84. Thomas, w. N., "Experiments on the Freezing of Certain Building Materials, "Dept. Sci. Ind. Res., Buildin Research Rech. Paper No. 17, H.K.S.O., Lond.2n, 7938.

85. Walker, S. and BIoem, D. L., "Perfonmance of Autontic Freezing and Thawing Apparatus for Testing Concrete," Am. Soc. Testing bisterials, Proc. 51, 1120 (1951).

86. Washbum, E. W., "The Dynamics of Capillary Flow," Phis. Rev. 17, 273 (1921).

87. Washburn, E. W., "Porosity. I. Purpose of the Investigation. II. Porosity and the Nechsmisn of Absorption," J. Ar.. Cerza. Soc. in, 916 (1921).

85. Washburz, E. W., ed., "Internationzl Critical Tables," Vol. I, MoGraw-Hill Book: Co., New York, 1926.

89. Washburn, E. W. and Bunting, E. N., "Porosity. TV. The Use of Petroleum Products as Absorption Liquids," J.A.t. Ceram. Soc. $t$, 983 (1921).

90. Washburn, E. W. and Eunting, E. N., "Porssity. VI. Detemination of Porosity by the Method of Gas Expansion," J.An. Ceran. Soc. 2. 112 (1922). 
91. Washbum, E. W. and Bunting, E. N., "Porosity. VII. The Determin=tion of the Porosity of Highly Vitrified Bodles," J.h.c. Seram. Soc. 5, 527 (1922).

92. Nashbum, E. W. and Footitt, F. F., "Pornzity. III. Natar 29 an Absorption Liquid," J.An. Ceram. Soc. 4, 961 (1921).

93. Weissberger, A., "Physical Methods of Organic Chemistry," 2nd. ad., Part I, Vol. I, Chap. VI, Interscience Publishers, New Yori, 194?.

94. Winsauer, W. O., Shearin, H. M., Masson, P. H., ant "illima, L., "Resistivity of Brino-Saturated Sands in Relation to Pore Geonetry," Bull. Am. Assoc. Petroleun jeol. 36, 253 (1952).

95. Woods, K. B., Sweet, H. S., and Shelbume, T. E., "Parenent BIonups Correlated with Source of Coarse Aggregate," Highway Resenrch Bozrd, Proc. 25, 247 (1946).

96. Wray, F. H. and Lichtsfeld, H. J., "The Influsnce of Test L'ethods on Moisture Absorption and Resistance of Caarse Aggrezate to Freezing and Thawing," Ari. Soc. Testing Matarials, Proc. 40, $1007(1940)$.

97. Wyllie, K. R. J. and Gragory, A. R., "Fluid Flo" Through Unconsolidated Porous Aggregates. Effect of Porosity and Particle Shape on Kozeny-Caman Constants," Ind. Eng. Chem. 47, 1379 (1955).

98. Wyllie, 4. R. J. and Rosc, W. D., "Some Theoretical Considerations Related to the Quantitative Evaluation of the Physical Characteristics of Reservoir Rock from Electrical Log Data," J. Petroleum Technol. 2, 105 (1950).

99. Wyllie, M. R. J. and Spangler, M. B., "Application of Electrical Resiativity leasurements to Problens of Fluid Flow in Porous Media," Bull. Am. Assoc. Petroleum Geol. 36, 359 (1952). 


\section{APP::ULI! A}

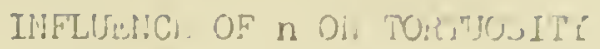

"Whe purpose of this section is to shor the varistion in the conputed value of the tortuosity due to viriation in the choire of the exponent $n$ in equation (15).

Rewriting the pertinent equatiors and assunin"; the? correatnes: of the Wyllie-lose expression for tortuosity,

$$
F=\frac{k_{t}^{l / ?}}{\varepsilon}
$$

$$
\begin{aligned}
& \text { where } F=\begin{array}{ll}
F & \text { formation factor for the couletely siaturatec } \\
& \text { state } \\
k_{t}= & \text { tortuosity } \\
\varepsilon \quad=\text { porosity }
\end{array}
\end{aligned}
$$

and

$$
I=\frac{F_{e}}{F}=S_{H}^{-\pi}
$$

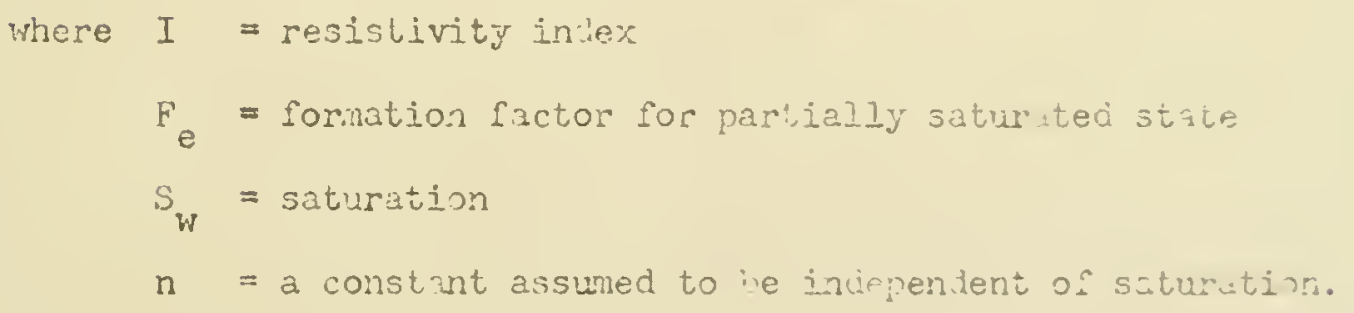

Eliminating $I$ and $F$ from these equations an solvin for $k_{t}$, the result, is

$$
k_{t}=F_{e}^{2} \varepsilon^{2} S_{w}^{2 n}
$$

Taking the total differential of $k_{t}$ witiv respect to $n$ and diricirs by the value for $k_{t}$, the result is

$$
\frac{d k_{t}}{k_{t}}=2\left(\ln s_{i}\right) d n
$$


which for small values of the increnent vecones

$$
\frac{\Delta k_{t}}{k_{t}}=2\left(\ln S_{w}\right) \Delta n
$$

This is the expression for the relat1ve varlation of $k_{t}$ in terms of change in $n$.

As an illustration, if $n$ is assuned equel to 2 an. tris value is 5 percent in error, $\Delta n=0.1$. Lt a saturction of 0.5 the error in $k_{t}$ would then, by equation ( 15 ), be about 1 , percent. At larger saturations the error is ruch less, e.?., for the above conditions but $S_{W}=0.9$, the error in $k_{t}$ is about 4 percent. A comparatively high saturation in the resistance runs is, therefore, desirable. Reference to Table 4 shows that in two cases, 1-1s and 67-25, the saturation was rather low. The tortuosit: values for these two rocks may, therefore, be less accurate than are those for the others. 


\section{A.PPT AiLIX B}

\section{DIRIVATION OF PEZLWWTER E UATION}

The purpose of this section is tie derivation of equation (13) bj means of which the perreability of the samples vas calculated from the measured quantities.

Keeping in mind the nature of the apparatus as shown in Finure 4 , the mass of gas $m$ on the high-pressure side of the sample at any tine during the decay process is

$$
m=P_{h}\left(V_{h}+\frac{h A_{t}}{2}\right) \rho_{I}
$$

where $P_{h}=$ pressure on the hich-pressure side of the sumple

$V_{h}=$ volune of the apparatus on the high-pressure side of the sample when the differential manoneter is at equilibrium

$\mathrm{h}=$ heizht difference on the differential nanometer

$A_{t}=$ internal cross-sectional area of the differential manoneter tube

$\rho_{1}=$ density of the gas at unit pressure, i.e., $\rho_{1}=1 / \mathrm{RT}$ where $M=$ mol=cular weight

$$
\begin{aligned}
& R=\text { Eas constant } \\
& T=\text { absolute temperature. }
\end{aligned}
$$

The time rate of chane of $m$ is the mass flow rate assuming steady state conditions. These are not, of course, stendy-state conititions. Kamack (35), however, stated for a similar set of circunstances "...a negligible error is involved in assuming that the air instantly adjusts itself to the equilibrium flow rate corresponding to the pressure drop. This situation is usually refered to as a quasistationary state." If, then, steady -state concitions are assuned 
and equation (BI) is differentiated with respeci to $t$ the resilt is

$$
\frac{d m}{d t}=V_{h} P_{I}\left(\frac{d P_{h}}{d t}\right)+\frac{A_{t} P_{I}}{2}\left(\frac{h d P_{h}}{d t}+\frac{P_{h} d h}{d t}\right) \text { (52). }
$$

The approach velocity at mean pressure, $u_{a}$, is given by

$$
u_{a}=\frac{1}{A P_{I} P_{m}}\left(\frac{d m}{d t}\right)
$$

where $A$ = approach area of the sample

$$
\mathrm{P}_{\mathrm{m}}=\text { mean pressure across the sample. }
$$

Substituting the value for $\mathrm{dr} / \mathrm{dt}$ from equation (B3) in equation (B2) and solving for $u_{a}$, the result is

$$
u_{a}=\frac{1}{A P_{m}}\left(V_{h}+\frac{h A_{t}}{2}\right)\left(\frac{d P}{d t}\right)+\frac{A_{t} P_{h}}{2 A P_{m}}\left(\frac{d h}{d t}\right)\left(B_{4}\right) .
$$

Specific perreability, $K$, for the case of gaseous flor, is defined by Wuskat (55), via Darcy's law, as

$$
u_{a}=\frac{K \Delta P}{\eta L}
$$

where $\Delta P=$ head loss across sample, in pressure units

$\eta=$ viscosity of the gas

$L=$ macro length of sample.

Eliminating $u_{a}$ from equations (B4) and (B5) an. solving for $k$, the result is

$$
K=\frac{\eta L}{\Delta P A P_{m}}\left[\left(v_{h}+\frac{A_{t} h}{2}\right) \frac{d P h}{d t}+\left(\frac{A_{t} P_{h}}{2}\right) \frac{d h}{d t}\right](35) .
$$

Practically speaking, the manonetric filuid is mercury so, if pressures are in $\mathrm{cm}$. $\mathrm{Hg}$ and $\mathrm{h}$ is in $\mathrm{cm}$. , then

$$
\frac{d P_{h}}{d t}=\frac{d h}{d t}
$$


if the low pressure, $P_{1}$, is kept constant by neans of the surce flask. Introducing equation (B7) and using the conversions $60 \mathrm{sec}$. 1 min., $1 \mathrm{~cm}^{2}=(1.013)\left(10^{11}\right) \mathrm{ma}$, and $(1.333)\left(10^{1}\right)$ dimes/ $\mathrm{cn}^{2}=$

$1 \mathrm{cr} . \mathrm{Hg}$, the final result is the rorking formula

$$
K=\frac{\eta I(1.013)\left(10^{21}\right)}{\Delta P A P_{m}(1.333)\left(10^{4}\right)(60)}\left(\frac{d h}{d t}\right)\left(V_{h}+\frac{A_{t} h}{2}+\frac{A_{t} P_{h}}{2}\right)
$$

where $\mathrm{K}$ is in md. and $\mathrm{dh} / \mathrm{dt}$ is in $\mathrm{cm}$. / inin.

To use this e uation $A_{t}$ and $V_{h}$ must be detergined. $A_{t}$ was found by measurement with divider and scale and appropriate cilculation. The deterrination of $V_{h}$ was made by expanding the gas in the volume $V_{h}$ by a knom amount and measuring its pressure before anc after the expansion. Asswing the gas law holds, $V_{h}$ can be calcilated from such data. The measurement was performed in two different, wajs. In the first method the sample was replaced by a muber stopper of the same approximate dimensions. The differential manometer was renoved and replaced by plurs of sealed tubing, the one for the hizh-pressure side boing cut to the proper length so that $V_{h}$ would be unchanged. The volume of the low-pressure side was tinen detemined by ineasuring the linear dimensions of the various tubes involved, culculating the corresponding volunes, and adding the sum of these to that of the surge flask. Adnittedy, this is an inaccurate method of obtaining this volune but the relative erros in the result was probably saall due to the large surge volume. Air at atmospheric pressure (neasured with a rooin barometer) was then acinitted to $V_{h}$ and the bjpass stopcock was closed. The lompressure side ras punved conpletel: out and the stopcock to pump at the surge flask was closed. The 
bypass stopcock was then opcned and the air in $V_{h}$ expended lnto the total volune. The final pressure was measured on the larce ninoineter and the value for $V_{h}$ was calculated.

The second method for deternining $V_{h}$ was as follows. The sample was replaced with a stopper as before. The differential manometer was left attached. With air at atmospheric pressure in $V_{h}$, and with the bypass stopcock closed, the lor-pressure side of the apparatus was purped dom until a comparatively large differential was on the bypass manometer. The purping was then stopped. The air in $v_{h} h_{3} d$ expanded by the small, but accurately measurable, volume hif $t / 2$. The new pressure in $V_{h}$ was mensured by combining the readings of the lar-e and the differential manometers. The value of $\nabla_{h}$ was then calculated from these data. The values obtained by the two methods vere $64 \mathrm{~cm}^{3}$ and $66 \mathrm{~cm}^{3}$ and their average was used as $\mathrm{v}_{\mathrm{h}}$. 


\section{DERIVATION OF PEREABILITK RLATTOISHIP3}

The purpose of this section is the derivation of the equations which relate the properties of the chosen model to the liquid nermeability of the samples, $K_{I}$. The result is a Kozeny-Carman equation. The method of derivation here is similar to tiat of Caman $(19,20)$. The model is that previously descriined.

The generalized Poiseuille law for viscous flow of a fluid through a pore of complex cross section is

$$
u_{t}=\frac{v}{t a}=\frac{m^{2} \Delta P}{k_{0} \eta I_{t}}
$$

where $u_{t}=$ true velocity in the pipe

$V / t=$ volume flow rate in the pipe

a $=$ area of the pipe nonal to the tortuous flow direction

$\mathrm{m}$ = hyòraulic radius of the pipe

$\Delta \mathrm{P}=$ total head loss, in pressure units

$k_{0}=a$ cross-sectional shape factor

$\eta=$ viscosity of the fluid

$L_{t}=$ tortuous length of the tube.

This true velocity will have a direction at some ankle o to the macro flow direction because the flow is tortuous. The conponent of the true velocity in the macro flow direction is called the streaning velocity, $u_{s}$, and is given by

$$
u_{s}=u_{t} \cos \emptyset
$$


but $\cos \phi=L / L_{t}=I / k_{t}{ }^{1 / 2}$ so

$$
u_{3}=\frac{u_{t}}{k_{t}^{2} / 2}
$$

$$
\text { where } \begin{aligned}
L & =\text { macro flow path length } \\
k_{t} & =\text { tortuosity. }
\end{aligned}
$$

The flow actually takes place only through the pore space of the medium so the relation between the streaning velocity and the approach velocity, $u_{a}$, is

$$
u_{a}=u_{s} \varepsilon
$$

where $\varepsilon=$ porosity.

Darcy's law, by ineans of which the perneability is defined, is

$$
u_{a}=\frac{K_{1} \Delta P}{\eta I}
$$

A combination of equations (C2), ( $\left.\mathrm{C}_{3}\right),\left(\mathrm{C}_{4}\right)$, and (C5) to eliminate the velocity terms gives

$$
\mathrm{K}_{1}=\frac{\varepsilon \mathrm{m}^{2} \mathrm{~L}}{k_{0} \mathrm{k}_{t} \mathrm{I}^{2} \mathrm{~L}_{t}}=\frac{\varepsilon \mathrm{m}^{2}}{k_{0} k_{t}}
$$

This is the kozeny equation with the product $k_{0} k_{t}$ being tine conventional Kozeny constant.

By a strictly analosous procedure a model of tubes with circular cross section of radius $r c_{a} n$ be analyzed. The result for such a case is

$$
K_{1}=\frac{\varepsilon r^{2}}{8 k_{t}}
$$

By the use of the relationship 


$$
m=\frac{\varepsilon}{S}=\frac{\varepsilon}{S_{G} P_{B}}
$$

equation (C6) can be transformed into

$$
K_{1}=\frac{\varepsilon^{3}}{k_{0} k_{t}{ }_{g}^{2} P_{B}^{2}}
$$


APPINIJIC D

\section{LERIVh'TIOIV OF SLIP FACTOR RGĹRTIURSHIP}

This purpose of this section is the derivation of the relationship between the Klinkenberg slip factor, $b$, and the pors size of a round-tube model.

Klinkenberg ( 40 ) showed that the b factor could be expressed as

$$
b=\frac{4 c \ell P_{\mathrm{rm}}}{r}
$$

$$
\text { where } \begin{aligned}
l & =\text { mean free path of gas at } P_{m} \\
P_{m} & =\text { mean pressure } \\
r & =\text { pore radius } \\
c & =\text { a constant. }
\end{aligned}
$$

The only difficulty with the use of this formula is the interpretation of the value of $c$. Analysis shows it to be approxinate? the exact value depends on an aroitrary choice of several factors. In Klinkenberg's paper $c$ is defined by

$$
u_{0}=c \ell\left(\frac{d u}{d r}\right)
$$

where $u_{0}=$ slip velocity at the tube wall

$d u / d r=$ velocity gradient in the vicinity of the wall.

In Loeb's book on the kinetic theory (48) an analozous expression is given which is

$$
u_{0}=\frac{\eta}{\phi}\left(\frac{d u}{d r}\right)
$$

where $\eta=$ viscosity of the gas

$$
\phi=\text { friction coefficient of the tube sides. }
$$


Obviously then,

$$
\frac{\eta}{\emptyset}=c \varepsilon
$$

and comparison with equation (LI) sho:rs that

$$
b=\frac{4 \eta P_{m}}{\phi r}
$$

Loeb stated further that

$$
\phi=\frac{P_{m} \rho_{1}^{1 / 2}}{\left(\frac{\pi}{2}\right)^{1 / 2}\left(\frac{2}{1}-1\right)}
$$

where $\rho_{1}=$ gas density at unit pressure

$$
\begin{aligned}
f= & \text { fraction of the molecules randomly emitted rather } \\
& \text { than specularly reflected after striking wall. }
\end{aligned}
$$

The proper value for $f$ is a moot question. Values from about 0.7 to 1.0 have been reported $(38,48 \mathrm{p} .289,69)$. Here the question is settled by assuzing $f=1, i . e .$, all molecules that strike the pore wall are assumed to be re-enitted randonly.

If then $f$ is taken as unity and the corresponding value for $p$ from equation (D6) is inserted in epuation (D5) the result is

$$
b=\frac{4\left(\frac{\pi}{2}\right)^{1 / 2} \eta}{\rho_{1}^{1 / ?} r}
$$

The values for $\rho_{1}$ and $\eta$ are temperature-denendent and $25 \mathrm{C}$ is assumed (nearly correctly). The viscosity valie for air at $25 \mathrm{C}$ is 180 micropoise $(56 \mathrm{p} .790)$ and the equivalent nolecula: weight for air was taken as $2 \hat{3} .9$.

Substitution of all appropriate values in equation (IF) gives as the fina] result 


$$
\text { b } r=\left(1.93 \%,(1 .)^{-3}\right)
$$

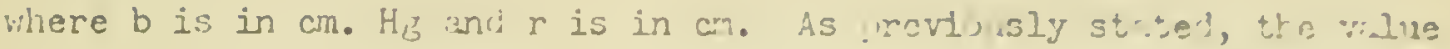
of the pronct is ternerature- dependent but not reatly so, 1.e.,

$$
\frac{c(b r L}{d T}=(0.02)\left(1 u^{-3}\right) \mathrm{cm} \cdot \mathrm{He}-\mathrm{c} . / \mathrm{dec} \cdot \mathrm{C} \text {. }
$$




\section{LLEIVATION OF AB.3ORPTIVITY RULATIMUEIIE:}

The purpose of this section is the derivation of the equations which describe capillary absorption and wich relate the aib..or.tivity coefficient to the properties of the chosen 'oodel.

The model is that previously described with the excsption tazt not all the pore space is postulated to be capable of bein; filled with water by capillarity. The "capillary porosity", i.e., the fraction of the bulk volune capable of filling by cavillarit.; is $\alpha$. The tortuosity appropriate to this space is $k_{t x}$ end its specific surface on a bulk volurae basis is $S_{\alpha}$, and on a weight busis 3. when water enters this "cupillary" pore space of co zplex shane a dynamic equilibriura is set up amont the forces involved. For the case of upward capillary absorption from a frec-inter surface the driving force is the capillary force present at the meniscus. The retarding forces are the viscous dras and the veight of both the entering liquid and the gas being displaced. The vector sits of these forces will be equil to a residual acceleration force. This force balance is e:pressed mathematically by

$$
\begin{aligned}
& \left.\frac{a \gamma \cos \theta}{m}-\frac{k_{0} \eta a x}{m^{2}}\left(\frac{d x}{d t}\right)-\frac{k_{0} \eta_{g} \frac{\left(L_{t}-x\right) a}{m^{2}}\left(\frac{d x}{d t}\right)-a x \rho \delta \cos \beta}{d L_{t}}\right) \\
& -a\left(L_{t}-x\right) \rho_{g} g \cos \beta=a x p\left(\frac{d^{2} x}{d t^{2}}\right)
\end{aligned}
$$

where $\mathrm{a}=$ area of capiliary poves perpendicular to toruivis flon direction

$\mathrm{m}=$ hydraulic radius 


$$
\begin{aligned}
k_{0}= & \text { shipe factor } \\
x= & \text { tortuous distance the liquid } h=s \text { triversed in } \\
& \text { time } t \\
L_{t}= & \text { tortuous length of complete flow path } \\
\eta= & \text { viscosity (subscript g refers to the gas) } \\
\rho= & \text { density (subscript g refer:j to the gas) } \\
\gamma= & \text { surface tension of the linuid } \\
\theta= & \text { wetting angle } \\
\beta= & \text { average angle of inclination of the pore fron } \\
& \text { the vertical } \\
g= & \text { gravitational acceleration. }
\end{aligned}
$$

Practicaly speaking, for porous systems of the sort considered rere, al force tems are comparatively small except the first trio in the foregoing equation - the capillary and viscous forces in the Iiruid. This arounts to saying that the presence of the gas, the rieight of the liquid, and the force term due to acceleration can be ignoped. The result is a force balance between the capillary and viscous effects for the liquid. Witl the further assumption that the true advancing wetting angle is zero the sinplified result is

$$
r m=k_{0} \eta x\left(\frac{d x}{d t}\right)
$$

The rolume, $V$, of ligauid in the capillary pore space at tine $t$ is

$$
V=a x
$$

so

$$
\frac{d V}{d t}=a\left(\frac{d x}{a t}\right)
$$

Introducing the appropriate expressions for $x$ and $\mathrm{dr} / \mathrm{dt}$ iran e $u$ itions 
(53) and $\left(E L_{4}\right)$ in equation ( 52 ) gives

$$
r m=\frac{k_{0} \eta v}{a^{2}}\left(\frac{d V}{d t}\right)
$$

The rolume of the capillary pores is $a J_{t}$. The bult volune of the sample is AL. The ratio of the former to the latter is, by definition, the capillary porosity, i.e.,

$$
x=\frac{a L_{t}}{A L}=\frac{a k_{t a}^{I / 2}}{A}
$$

Substituting the value for a derived from this expression in exuation (E5) Eives

$$
v d v=\frac{\gamma m \alpha^{2} A^{2} d t}{k_{0} \eta k_{t \alpha}}
$$

Then this equation is solved and the initial condition of $\mathrm{V}=0$ for $t=0$ is inserted the result is

$$
\frac{v^{2}}{A^{2}}=\frac{2 \gamma m \alpha^{2} t}{k_{0} \eta k_{t \alpha}}
$$

The absorptivity coefficient, $K_{a}$, is defined ( 50 . 0.306 ) by

$$
\frac{V^{2}}{A^{2}}=K_{3} t
$$

so therefore

$$
k_{a}=\frac{2 \gamma m x^{2}}{k_{0} k_{t \alpha} \eta}
$$

For a system of round tubes e.juation (E10) becones

$$
\mathrm{K}_{\mathrm{a}}=\frac{\mathrm{r} r \alpha^{2}}{2 \eta k_{t \alpha}}
$$

The only further question with regard to e zuition (s10) is 
the rolution of the hydraulic radius a to the specific surface of the porous material. Since $m$ is the ratio of the capillary poroaity to the corresponding wetted area, i.e.,

$$
m=\frac{\alpha}{s_{\alpha}}
$$

then

$$
S_{g \alpha}=\frac{2 \gamma \alpha^{3}}{k_{0} k_{t x} k_{a} \eta \rho_{B}}
$$

If, however, the non-capillary porosity is the sane stmucturally as the capillary porosity then $\alpha / S_{\alpha}=\varepsilon / S$ and

$$
S_{g}=\frac{2 \gamma \varepsilon \alpha^{2}}{k_{\rho} k_{t \alpha} k_{a} \eta \rho_{B}}
$$

where $S_{g}=$ total specific surface, weight basis.

This distinction is refered to further in the Discussion section. 


\section{AIIE!IIK F}

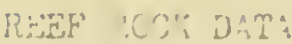

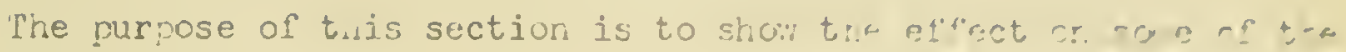
test results of varying the rock type drasticilly. Tres st to on wa irequently rade in the text that the wodel ind conclusiono arrliog only to the general type of rocks used in this stury. These reve the fine-grained, intergr nular type wibn have no 1.reg pos only I-IS has some that are visible to the eye and trese are atill small in comparison with the large pores referred to in this section. In order to be able to indicate the effect of the presence of large pores, a small. sample of a very open reep rocli was obtained in central Olizo. The pores at a plane surface range from a fraction cf a millimeter to several millimeters in size. The contrast with the rocks used in the body of this work is obvious and striking. Ore tult: density by dimensional measurement and woighing was 2.409. 1 tr.e density of 2.85 mas assumed. The correspondine porosity was calculated by means of eluation (7) to be C.133. The rock visu thus intermediate with respect to the others. The porcsity was about th.e sar.e as that of 3-15-H and 47-2s. A portion of the sample was crusined and the sorption test was run on it but the resuits were ursatisfactory due to the snall specific surface. A value of approximately $0,2 \mathrm{~m} \cdot 2 / \mathrm{g}$. is probably close.

The results of the absorptivity tests are s:10m in Figre 2.. The two upper curves are for a sarple sligitly iryersed in the sase manner as was the 9-1S sample (Figure 17). The lowest curve is ion the usual test method. The salient feature of the curres is that 


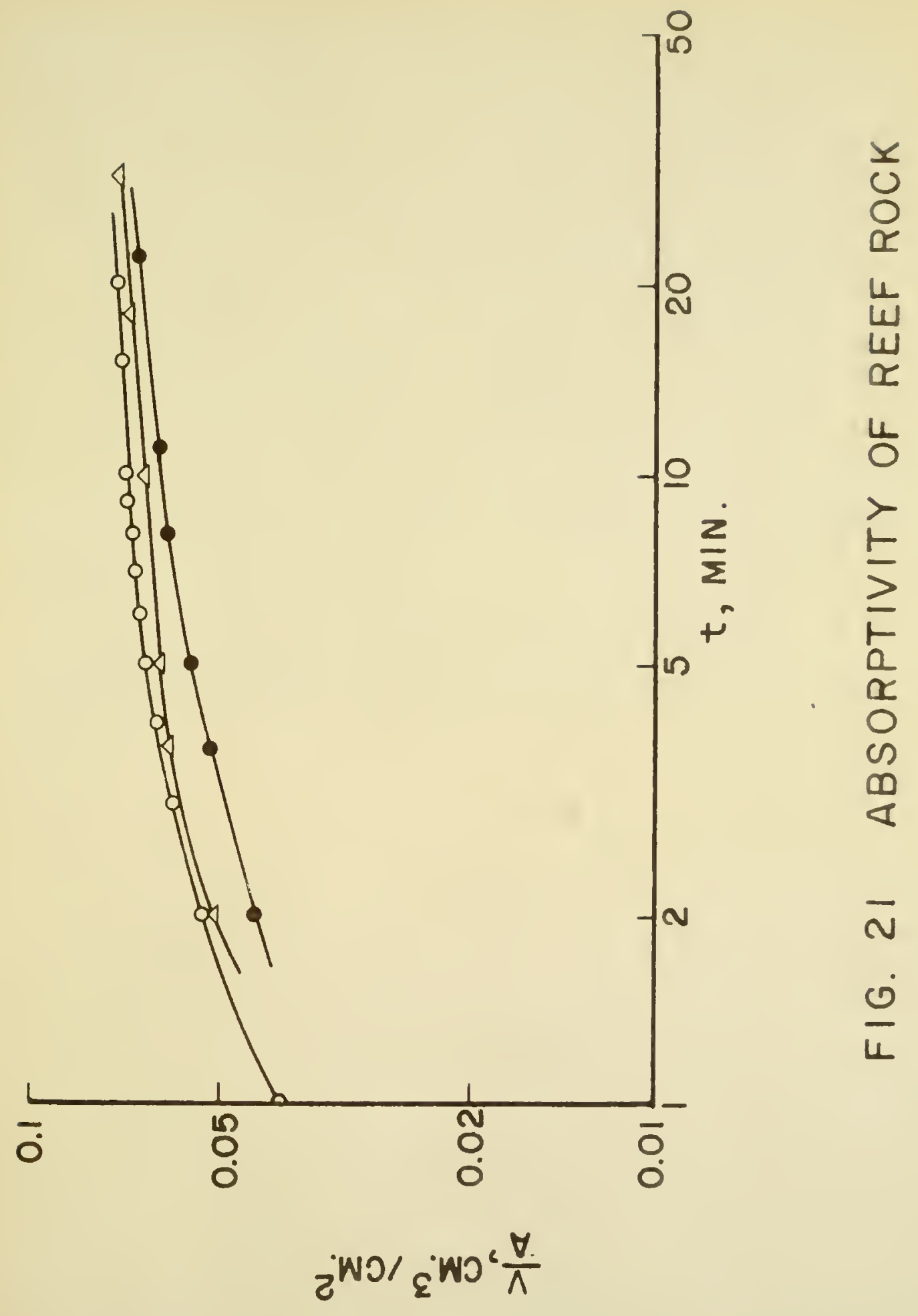


even at 1-2 min. the sample was not obeying the rodel but was or, the tapering portion of the curve. This is no doubt due to the nonuniform area of material that was being traversed by the water due to the uneven distribution of the very large pores which the water could not enter. An attempt was made to get values of the absorptivity coefficient and the capillary saturation from the curves by assur.ing, that at 1 min. the data were still on the lin-ar curves. The result for $\mathrm{K}_{\mathrm{a}}$ was $1.81 \times 10^{-5} \mathrm{~cm}^{2} / \mathrm{sec}$. (near that for $9-1 \mathrm{~S}$ ) and for $\alpha$ was 0.0236 . This value corresponds to a saturation of orly 0.17 , a result which is readily understandable in view of the high proportion of the pore space which was composed of large pores that the water could not enter by capillarity.

The main point to be gained from these results isthe inapplicability of this method of absorptivity determination for a rock of this type. 

